Cochrane Database of Systematic Reviews

\title{
Factors influencing the uptake and use of nicotine replacement therapy and e-cigarettes in pregnant women who smoke: a qualitative evidence synthesis (Review)
}

Campbell K, Coleman-Haynes T, Bowker K, Cooper SE, Connelly S, Coleman T

Campbell K, Coleman-Haynes T, Bowker K, Cooper SE, Connelly S, Coleman T.

Factors influencing the uptake and use of nicotine replacement therapy and e-cigarettes in pregnant women who smoke: a qualitative evidence synthesis.

Cochrane Database of Systematic Reviews 2020, Issue 5. Art. No.: CD013629.

DOI: 10.1002/14651858.CD013629.

www.cochranelibrary.com

Factors influencing the uptake and use of nicotine replacement therapy and e-cigarettes in pregnant women who smoke: a qualitative evidence synthesis (Review) 
TABLE OF CONTENTS

HEADER 1

ABSTRACT

PLAIN LANGUAGE SUMMARY

BACKGROUND

OBJECTIVES

METHODS

RESULTS

Figure 1.

DISCUSSION

AUTHORS' CONCLUSIONS

ACKNOWLEDGEMENTS

REFERENCES

CHARACTERISTICS OF STUDIES

ADDITIONAL TABLES

APPENDICES

HISTORY 
[Qualitative Review]

\section{Factors influencing the uptake and use of nicotine replacement therapy and e-cigarettes in pregnant women who smoke: a qualitative evidence synthesis}

Katarzyna Campbell ${ }^{1}$, Thomas Coleman-Haynes ${ }^{1}$, Katharine Bowker ${ }^{1}$, Sue E Cooper ${ }^{1}$, Sarah Connelly ${ }^{1}$, Tim Coleman ${ }^{1}$

1Division of Primary Care, University of Nottingham, Nottingham, UK

Contact address: Katarzyna Campbell, kasia.campbell@nottingham.ac.uk.

Editorial group: Cochrane Tobacco Addiction Group.

Publication status and date: New, published in Issue 5, 2020.

Citation: Campbell K, Coleman-Haynes T, Bowker K, Cooper SE, Connelly S, Coleman T. Factors influencing the uptake and use of nicotine replacement therapy and e-cigarettes in pregnant women who smoke: a qualitative evidence synthesis. Cochrane Database of Systematic Reviews 2020, Issue 5. Art. No.: CD013629. DOI: 10.1002/14651858.CD013629.

Copyright $\odot 2020$ The Cochrane Collaboration. Published by John Wiley \& Sons, Ltd.

\section{A B S T R A C T}

\section{Background}

Nicotine replacement therapy (NRT) delivers nicotine without the toxic chemicals present in tobacco smoke. It is an effective smoking cessation aid in non-pregnant smokers, but there is less evidence of effectiveness in pregnancy. Systematic review evidence suggests that pregnant women do not adhere to NRT as prescribed, which might undermine effectiveness. Electronic cigarettes (e-cigarettes) have grown in popularity, but effectiveness and safety in pregnancy are not yet established. The determinants of uptake and use of NRT and e-cigarettes in pregnancy are unknown.

\section{Objectives}

To explore factors affecting uptake and use of NRT and e-cigarettes in pregnancy.

\section{Search methods}

We searched MEDLINE(R), CINAHL and PsycINFO on 1 February 2019. We manually searched OpenGrey database and screened references of included studies and relevant reviews. We also conducted forward citation searches of included studies.

\section{Selection criteria}

We selected studies that used qualitative methods of data collection and analysis, included women who had smoked in pregnancy, and elicited participants' views about using NRT/e-cigarettes for smoking cessation or harm reduction (i.e. to smoke fewer cigarettes) during pregnancy.

\section{Data collection and analysis}

We identified determinants of uptake and use of NRT/e-cigarettes in pregnancy using a thematic synthesis approach. Two review authors assessed the quality of included studies with the Wallace tool. Two review authors used the CERQual approach to assess confidence in review findings. The contexts of studies from this review and the relevant Cochrane effectiveness review were not similar enough to fully integrate findings; however, we created a matrix to juxtapose findings from this review with the descriptions of behavioural support from trials in the effectiveness review. 


\section{Main results}

We included 21 studies: 15 focused on NRT, 3 on e-cigarettes, and 3 on both. Studies took place in five high-income countries. Most studies contributed few relevant data; substantially fewer data were available on determinants of e-cigarettes. Many studies focused predominantly on issues relating to smoking cessation, and determinants of NRT/e-cigarette use was often presented as one of the themes.

We identified six descriptive themes and 18 findings within those themes; from these we developed three overarching analytical themes representing key determinants of uptake and adherence to NRT and/or e-cigarettes in pregnancy. The analytical themes show that women's desire to protect their unborn babies from harm is one of the main reasons they use these products. Furthermore, women consider advice from health professionals when deciding whether to use NRT or e-cigarettes; when health professionals tell women that NRT or ecigarettes are safer than smoking and that it is okay for them to use these in pregnancy, women report feeling more confident about using them. Conversely, women who are told that NRT or e-cigarettes are as dangerous or more dangerous than smoking and that they should not use them during pregnancy feel less confident about using them. Women's past experiences with NRT can also affect their willingness to use NRT in pregnancy; women who feel that NRT had worked for them (or someone they know) in the past were more confident about using it again. However, women who had negative experiences were more reluctant to use NRT.

No trials on e-cigarette use in pregnancy were included in the Cochrane effectiveness review, so we considered only NRT findings when integrating results from this review and the effectiveness review. No qualitative studies were conducted alongside trials, making full integration of the findings challenging. Women enrolled in trials would have agreed to being allocated to NRT or control group and would have received standardised information on NRT at the start of the trial. Overall, the findings of this synthesis are less relevant to women's decisions about starting NRT in trials and more likely to help explain trial participants' adherence to NRT after starting it.

We considered most findings to be of moderate certainty; we assessed findings on NRT use as being of higher certainty than those on ecigarette use. This was mainly due to the limited data from fewer studies (only in the UK and USA) that contributed to e-cigarette findings. Overall, we judged studies to be of acceptable quality with only minor methodological issues.

\section{Authors' conclusions}

Consistent messages from health professionals, based on high-quality evidence and clearly explaining the safety of NRT and e-cigarettes compared to smoking in pregnancy, could help women use NRT and e-cigarettes more consistently/as recommended. This may improve their attitudes towards NRT or e-cigarettes, increase their willingness to use these in their attempt to quit, and subsequently encourage them to stay smoke-free.

\section{PLAIN LANGUAGE SUMMARY}

\section{Factors affecting use of nicotine replacement therapy and e-cigarettes in pregnancy}

What was studied in this review? Nicotine replacement therapy (NRT) delivers nicotine without the harmful chemicals found in tobacco smoke. NRT helps some non-pregnant adults to stop smoking, but it does not seem to work so well in pregnancy. This may be because pregnant women generally do not use NRT as prescribed. Studies show that some pregnant women use e-cigarettes to help them cut down or quit, although their safety and effectiveness in pregnancy is not known. Little is known about the issues that influence pregnant women's use of NRT/e-cigarettes.

What is the aim of this review? To explore factors that affect whether women take up and use NRT or e-cigarettes to reduce or quit smoking in pregnancy.

What are the key messages of this review? Three main factors influence whether women take up and use NRT and e-cigarettes in pregnancy: advice women receive from health professionals on using NRT or e-cigarette in pregnancy, women's desire to protect their unborn baby from harm, and past personal experience with NRT. Each of these factors can either encourage or discourage women from using these products.

What are the key findings? We included 21 studies; 15 of these focused on NRT, 3 on e-cigarettes and 3 on both. Our findings suggest that women's desire to protect their unborn babies from harm is one of the main reasons they use these products. They also consider the advice from their health professionals; when professionals tell women that NRT or e-cigarettes are safer than smoking and that it is okay to use them in pregnancy, their confidence about using them increases. When women are told that NRT or e-cigarettes are as dangerous or more dangerous than smoking and that they should not use them when they are pregnant, they feel less confident about using them. Women's past experiences with NRT will also affect how willing they are to use NRT in pregnancy. For example, women who feel that NRT had worked for them (or someone they know) in the past were more confident about using it again. However, women who had negative experiences were more reluctant to use NRT. We conclude that consistent messages that are based on high-quality research and clearly explain how safe NRT and e-cigarettes are compared to smoking in pregnancy, could help women use NRT and e-cigarettes more consistently/as recommended. This may improve their attitudes towards NRT or e-cigarettes, increase their willingness to use these in their attempt to quit, and encourage them to stay smoke-free.

How up-to-date is this review? We searched for studies that had been published before 1 February 2019. 


\section{B A C K G R O U N D}

Smoking in pregnancy remains an important public health issue. Europe and regions of the Americas have the highest prevalence in the world (Lange 2018), and in the UK around 1 in 10 women are smoking at the time of childbirth (NHS Digital 2019). Smoking is potentially preventable and associated with negative outcomes for both the woman and the unborn child. Compared with pregnant women who do not smoke, smokers face heightened risks of placental abruption, miscarriage, still birth, ectopic pregnancy, preterm labour, and low birthweight (Cnattingius 2004). Furthermore, a systematic review of randomised clinical trials (RCTs) shows that stopping smoking in pregnancy improves birth outcomes (Chamberlain 2017). There are also strong intergenerational associations, with children of smokers more likely to become smokers (Leonardi-Bee 2011). Tobacco smoking is also a major risk factor for six of the eight leading causes of death globally (WHO 2008).

\section{Description of the topic}

Nicotine replacement therapy (NRT) delivers nicotine without the tar, carbon monoxide and other poisonous chemicals present in tobacco smoke (IARC 2004). Numerous countries have smoking cessation guidelines that recommend offering pregnant smokers NRT if behavioural support alone has not helped them to stop smoking, including the UK (NICE 2010), Australia (Bar-Zeev 2018), New Zealand (NZ Ministry of Health 2014), Canada (CAN-ADAPTT 2011), and the USA (ACOG 2017). In the UK, NRT is available on prescription and cost-free to pregnant women (Smoking in Pregnancy Challenge Group 2019). Between 2001 and 2012, 11\% of pregnant smokers in the UK received NRT prescriptions (Dhalwani 2014), and in 2015 all UK stop smoking services offered NRT in pregnancy (Cooper 2019). It is well established that NRT is effective outside of pregnancy (Hartmann-Boyce 2018), but it appears less so in pregnancy (Coleman 2015). This is probably because pregnant women generally do not use NRT for long enough or in sufficient doses compared to non-pregnant smokers (Coleman 2015; Hollands 2013).

Encouraging greater use of NRT in pregnancy is logical and ethical provided this promotes smoking cessation without causing additional harm to the developing fetus. There is no biological rationale for suspecting that NRT used in pregnancy could be more harmful than smoking; it is more likely that NRT will be better for pregnant women and their babies than smoking. NRT produces none of the harmful products of combustion from tobacco smoke, and nicotine and cotinine levels are lower when women use NRT compared to smoking (Hickson 2018). There is no evidence that NRT has any impact on birth outcomes (Chamberlain 2017). Evidence from the largest trial of NRT used for smoking cessation in pregnancy found that infants born to women in the NRT group were more likely to have impairment-free development at two years of age than those born to women in the placebo group (Cooper 2014).

In recent years, smokers wanting to reduce or stop smoking have increasingly used electronic cigarettes (e-cigarettes); like NRT, ecigarettes deliver nicotine without the tobacco smoke. They work by heating a solution that contains nicotine, propylene glycol or glycerine, and flavourings to produce a vapour, without the release of combustion products (McNeill 2015). Internationally, non-pregnant smokers' use of e-cigarettes is increasing (Filippidis 2016; Gravely 2014; Mirbolouk 2018); in the European Union use has risen from about $7.2 \%(95 \% \mathrm{Cl} 6.7 \%$ to $7.7 \%)$ in 2012 to $11.6 \%$ (95\% $\mathrm{Cl} 10.9 \%$ to $12.3 \%$ ) in 2014 (Filippidis 2016). In England, e-cigarettes are the most popular aid to smoking cessation and are used in $37 \%$ of quit attempts (West 2019).

Comparisons of toxic chemicals in the urine and saliva of nonpregnant e-cigarette users versus smokers show significantly lower levels of harmful chemicals among e-cigarette users (Shahab 2017). In 2018, Public Health England issued a report concluding that e-cigarettes are considerably safer than continuing to smoke (McNeill 2018). Furthermore, a systematic review of RCT data shows that e-cigarettes were twice as effective as placebo in helping non-pregnant smokers stop smoking for at least six months (risk ratio (RR) 2.29, 95\% confidence interval $(\mathrm{Cl}) 1.05$ to 4.96 , placebo $4 \%$ vs e-cigarettes 9\%) (Hartmann-Boyce 2016). Since the above systematic review was published, another trial assessing behavioural support plus either e-cigarettes or NRT for smoking cessation in non-pregnant smokers found that nearly double the people using e-cigarettes were able to quit (RR 1.83, 95\% Cl 1.30 to 2.58 , NRT $9.9 \%$ vs e-cigarettes $18 \%$ ) (Hajek 2019a). Unlike NRT, in the UK e-cigarettes are a consumer product and not available on prescription; users purchase them from designated vendors, including specialist vaping shops, supermarkets, and newsagents. However, some countries such as Canada and Australia have more restrictive policies on their use (Yong 2017).

There are no published trials of e-cigarette use in pregnancy. Cross-sectional studies from the USA indicate that prevalence of e-cigarette use in all pregnant women ranges from $0.6 \%$ to $4.9 \%$ (Kapaya 2019; Kurti 2017; Liu 2019; Mark 2015), but it is considerably higher amongst pregnant women who smoke. For example, in a nationally representative sample of women in the USA who smoke, $38.9 \%$ of pregnant women reported using e-cigarettes (Liu 2019). To our knowledge, there is currently no published data on prevalence of e-cigarette use in pregnancy available from other countries. A narrative review of literature suggests that pregnant women perceive e-cigarettes as less harmful than smoking and believe these can aid smoking cessation (Breland 2019). These were also the key reasons given by pregnant women for initiating the use of e-cigarettes around the time of pregnancy (Kapaya 2019); however, the determinants of sustained e-cigarette use are not known.

\section{Why it is important to do this qualitative evidence synthesis}

It is important to understand why pregnant women choose to use or not use NRT or e-cigarettes, the nature of any concerns they might have about NRT or e-cigarette use, and how to address these concerns. For NRT, such knowledge could help improve pregnant women's adherence to NRT and could likely also improve their chances of successfully quitting smoking (Raupach 2014). Ecigarettes appear to have potential as a cessation aid (HartmannBoyce 2016), and in some countries, such as the UK, expert health professionals recommend supporting pregnant women who use e-cigarettes in this way, especially if behavioural support and/ or NRT are ineffective or inappropriate (Smoking in Pregnancy Challenge Group 2019). It is therefore also important to understand the factors that influence pregnant women's use of e-cigarettes. This qualitative evidence synthesis aims to provide an enhanced understanding of pregnant women's perceptions around using NRT or e-cigarettes.

Factors influencing the uptake and use of nicotine replacement therapy and e-cigarettes in pregnant women who smoke: a qualitative 


\section{O B JECTIVES}

To describe factors that influence pregnant women's uptake and use of NRT or e-cigarettes for smoking cessation or harm reduction, including barriers and facilitators; and to describe women's views on and experiences of using NRT or e-cigarettes during pregnancy.

\section{METHODS}

\section{Inclusion criteria}

\section{Types of studies}

We included empirical, non-review, qualitative studies, either conducted alongside efficacy trials or as 'stand-alone' studies, using any qualitative design and appropriate methods of data collection and data analysis. Mixed-methods studies were eligible if they had a distinct section dedicated to qualitative data collection and analysis and reported qualitative data.

Included studies explored views, opinions, and experiences of pregnant women who smoke(d) in pregnancy on the use of any type of NRT or e-cigarettes in pregnancy for smoking cessation or harm reduction (i.e. using NRT or e-cigarettes to smoke fewer cigarettes).

\section{Types of participants}

Participants were either pregnant women who smoked at any point during their pregnancy or women in the postpartum period who had smoked in pregnancy. As we were interested in determinants of use rather than just women's views after using NRT or e-cigarettes, participants were not required to have previous experience using NRT or e-cigarettes.

\section{Settings}

We included studies from any setting.

\section{Phenomenon of interest}

Factors influencing the uptake and subsequent use of NRT and e-cigarettes during pregnancy, from the perspectives of pregnant women.

\section{Search strategy}

We adopted a broad search strategy to include all relevant qualitative studies. As a scoping exercise, we tried different search strategies in varied bibliographic databases to test the ability of these to identify a selection of known research papers, which would be appropriate for inclusion in the review. This exercise informed the final selection of databases and of search terms, including $\mathrm{MeSH}$ terms and key words used. Using database-appropriate strategies based on the MEDLINE one, we searched MEDLINE Ovid (1946 to 1 February 2019), CINAHL EBSCO (Cumulative Index to Nursing and Allied Health Literature; 1937 to 1 February 2019) and PsycINFO Ovid (1967 to 1 February 2019). All database strategies presented in Appendix 1. Additionally, we manually searched the OpenGrey database (http://www.opengrey.eu/ searched 1 February 2019) using terms 'pregnancy' AND 'smoking cessation' and 'pregnancy' AND 'nicotine replacement' and screened references of included studies and literature reviews identified by searching. Finally, we conducted forward citation searches of included studies.

\section{Data collection and analysis}

\section{Selection of studies}

We entered the identified studies into one Endnote database and removed duplicates (EndNote X8), then we exported them to Covidence, a screening and data extraction tool. Each title and abstract was screened by two of the review authors (KB, KAC, TCH, SLC, and SC), using a priori inclusion criteria (see Appendix 2). We resolved conflicts through discussion where possible, involving a third review author if necessary. For all potentially relevant studies, two review authors independently assessed the full text, again involving a third review author to resolve conflicts.

We recorded the following study characteristics on a specially designed form.

- First study author.

- Date of publication.

- Language.

- Country and context of study (urban/rural).

- Sample size.

- Key participant characteristics (pregnancy status, smoking status, NRT/e-cigarette user status, age, gestation, ethnicity, socioeconomic data).

- Theoretical/conceptual perspective of the study.

- Data collection methods.

- Data analysis methods.

- Key themes reported by the authors.

We also screened the full text of manuscripts to identify and extract any other data that might be of relevance to this review.

\section{Appraisal of study quality}

We used the Wallace quality appraisal criteria (Croucher 2003; Wallace 2004; Appendix 3). Previous Cochrane qualitative evidence syntheses, like Husk 2016, have used this tool. With it, the review author assesses 13 criteria as being met ('yes'), not met ('no') or uncertain ('cannot tell') (Husk 2016). For this study, eight criteria relating to the research question were considered essential: clarity of research question, appropriateness of study design, adequacy of sample, adequacy of the population from which sample was drawn, description of data collection, rigour of data collection, rigour of analysis, and extent to which the data substantiated the findings. The remaining five criteria were considered desirable: clarity of theoretical perspective, adequacy of study context description, reflexivity, claims regarding generalisability, and adequately addressed ethical issues. Two review authors (KAC and SLC) independently undertook the quality assessment and met to discuss their ratings. Any disagreements were resolved through discussion. Following recent guidance, which suggests that overall ratings should not be assigned to qualitative studies (Munthe-Kaas 2018), we present specific methodological issues identified in each study in Table 1.

In addition, we assessed studies for data richness (i.e. the amount and depth of qualitative data that are relevant to the current review), using a tool devised by Ames 2019. This tool uses a scale of 1 to 5 , where 1 indicates 'very few qualitative data which are relevant to the review, and those presented are fairly descriptive' and 5 indicates 'a large amount and depth of qualitative data 
relevant to the review'. See Appendix 4 for more details. We assessed only the richness of data relevant to the review. For example, a study focusing broadly on smoking cessation and presenting large amounts of data on that topic might only present one theme or part of a theme relating to NRT or e-cigarettes; we would rate such a study 1 or 2 , as there would be few qualitative data relevant to this review. Richness of the data relevant to the review did not affect the quality assessment, as it did not reflect the quality of the primary study, only how much it contributed to the review.

\section{Data extraction and analysis/synthesis}

One review author (KAC) extracted data from included studies, and another (SLC) checked them. This process acknowledged that identifying the data or findings in qualitative studies can be challenging (Noyes 2018). We followed the guidance from Thomas 2008 and extracted study data reported as quotes from participants, as well as key concepts, that is, summaries of findings or any other relevant data presented in primary studies. We assessed the whole text of each paper when searching for relevant data. These data were extracted verbatim into NVivo software.

We used thematic synthesis described by Thomas 2008; this allows inductive data coding and flexible data exploration to identify concepts and constructs from within the data, which may not have been predefined. We were also sensitive to the fact that derived themes should relate to factors influencing uptake and use of NRT and e-cigarettes and their acceptability as cessation aids. Synthesis was conducted in three steps.

\section{Steps one and two: line-by-line data coding and development of descriptive themes}

Initially KAC read all included studies to ascertain which ones provided the potentially richest or most substantial data relevant to the study questions. At this point it was clear that very few studies of either NRT or e-cigarettes specifically investigated either the barriers or facilitators for women using these (i.e. the determinants of NRT or e-cigarette use). We decided therefore, that in order to develop descriptive themes, we should carefully consider all data for inferences about potential determinants of product use, including data describing women's general views on or attitudes to e-cigarettes and NRT.

After the initial read-through, 6/21 studies were considered likely to provide the richest and most relevant data; we selected these for initial detailed reading and sought to extract key concepts and assign codes to the data (Ashwin 2010; Bowker 2016; Bowker 2018; Fallin 2016b; Hotham 2002; Taylor 2010). Next, two review authors (KAC and KB) independently read these six primary studies and inductively coded concepts arising from the data on a line-by-line basis. Researchers first derived codes from Taylor 2010 and subsequently applied them to other studies whilst simultaneously seeking new concepts and coding these, where appropriate. However, once the initial 6 studies had been coded no new concepts were identified from the remaining 15 studies. After independently coding all studies, the two researchers met, discussed each other's emerging findings, refined coding and agreed on new definitions and descriptions for each.

The researchers then looked for similarities and differences between codes, grouped these into broader, descriptive themes, and organised them hierarchically (Table 2). KAC recoded the entire data set with the final, agreed codes. A third review author (TC) then reviewed a document comprising all code definitions and descriptive themes with definitions and discussed it with $\mathrm{KAC}$ and $\mathrm{KB}$ in order to agree on a final version.

This process showed that data from the 15 primary studies were limited, as all original concepts arising from the data had already been identified from the six studies with richer data.

\section{Step three: developing analytical themes}

In the third step of the synthesis, we organised descriptive themes into more abstract, analytical ones to help findings, as far as possible, answer review questions. Two review authors (KAC and $\mathrm{KB}$ ) discussed descriptive themes and considered their relevance to study questions. Through discussion, we identified further analytical, overarching themes that encompassed the descriptive ones and suggested barriers, facilitators, and other implications. We then synthesised descriptive codes and themes to generate analytical themes that directly answered review questions posed. A third review author (TC) considered descriptions and definitions of the derived analytical themes and discussed them with KAC and KB prior to finalisation. We considered implications for future research and practice in the context of the analytical themes.

The authors' perspective during the synthesis process, as described in the reflexive note, is that we believe it is better for pregnant women to use NRT or e-cigarettes than it is for them to smoke. This belief is based on current evidence and guidance, which suggests that:

- NRT is effective for smoking cessation in the general population (Hartmann-Boyce 2018);

- NRT used in pregnancy has no effects on the birth outcomes (Coleman 2015);

- NRT is recommended as a smoking cessation aid during pregnancy (NICE 2010);

- New evidence suggests that e-cigarettes might be effective for smoking cessation in the general population (Hajek 2019a);

- E-cigarettes are likely to be significantly less harmful than tobacco cigarettes, but are not without risk (McNeill 2018);

- Public Health England recommends e-cigarettes as a smoking cessation aid for pregnant women who struggle to quit by other means (McNeill 2018; Smoking in Pregnancy Challenge Group 2019).

\section{Assessment of confidence in the review findings}

To assess the confidence in the findings of this review, we applied the Confidence in Evidence from Reviews of Qualitative research method (CERQual) (Lewin 2015). This approach, developed by GRADE-CERQual Project Group 2004, uses four components to evaluate confidence in the review findings. These include the methodological limitations of included studies, the relevance of the included studies to review questions, the coherence of the review findings, and the adequacy of the data that contributes to each review finding. In the first instance, KAC evaluated each finding using the four components of CERQual and a four-point scoring system ranging from 'no or very minor concerns' to 'substantial concerns'; TCH then checked the evaluation. The review authors met and discussed the scores and assigned each finding an overall CERQual assessment score. Each finding started with a 'high confidence' score which could be downgraded to

Factors influencing the uptake and use of nicotine replacement therapy and e-cigarettes in pregnant women who smoke: a qualitative 
'moderate confidence', 'low confidence' or 'very low confidence' if the CERQual process revealed concerns.

\section{Reflexive note}

The review has been conducted from the epistemological stance of critical realism, which assumes that our understanding of reality is mediated by our beliefs and perceptions (Barnett-Page 2009). It is therefore important to consider the characteristics of the review authors, their beliefs and experiences, and how these might have affected the interpretation of the data throughout the synthesis process. All review authors are researchers with backgrounds in either primary health care, public health, psychology, sociology and/or midwifery and have extensive experience conducting research in the field of smoking cessation in pregnancy; none are smokers or NRT or e-cigarette users. The review team is UKbased, and this review was partially funded by National Institute for Health and Care Excellence (NICE), a funder with a particular interest in the UK context. In the UK, health authorities and/or expert health professionals recommend use of NRT in pregnancy (NICE 2010,Smoking in Pregnancy Challenge Group 2019), and they support use of e-cigarettes as smoking cessation aids in pregnancy (Smoking in Pregnancy Challenge Group 2019), which may have had impact on the authors' views. To ensure rigour, the authors considered the funder's interest as well as their own views and beliefs about NRT and e-cigarettes and how these views could affect study conduct. At the outset, all authors viewed NRT and ecigarettes in pregnancy to be potentially valuable tools for smoking cessation but were also aware of some of the issues pregnant women experience in relation to using these and in particular women's safety concerns. The review authors remained aware of their views throughout the process of screening, data extraction, and synthesis and attempted to treat all data equally and ensure that contradictory findings were given equal place in the review.

\section{RES U L T S}

\section{Description of studies}

The details of included studies appear in the Characteristics of included studies tables. The Characteristics of excluded studies tables show excluded studies and reasons for exclusion.

\section{Results of the searches}

Database searches were completed in February 2019. After removing duplicates, there were 2449 unique titles and abstracts. After initial screening, we considered 74 records to be potentially relevant and retrieved 72 full texts ( 2 were unavailable), finally including 21 studies. These consisted of a doctoral thesis (Taylor 2010), a health technology assessment with two chapters reporting results relevant to this review (Bauld 2017), and 19 studies published in scientific journals (Ashwin 2010, Borland 2013, Bovill 2018, Bowker 2016, Bowker 2018, Butterworth 2014, England 2016, Fallin 2016b, Fallin 2016a, Gamble 2015, Glover 2012, Grant 2020, Hauck 2013, Herbec 2014, Hotham 2002, Mantzari 2012, Naughton 2013, Pledger 2015, Radley 2013). Figure 1 presents the study PRISMA diagram. 


\section{Figure 1. Study flow diagram}

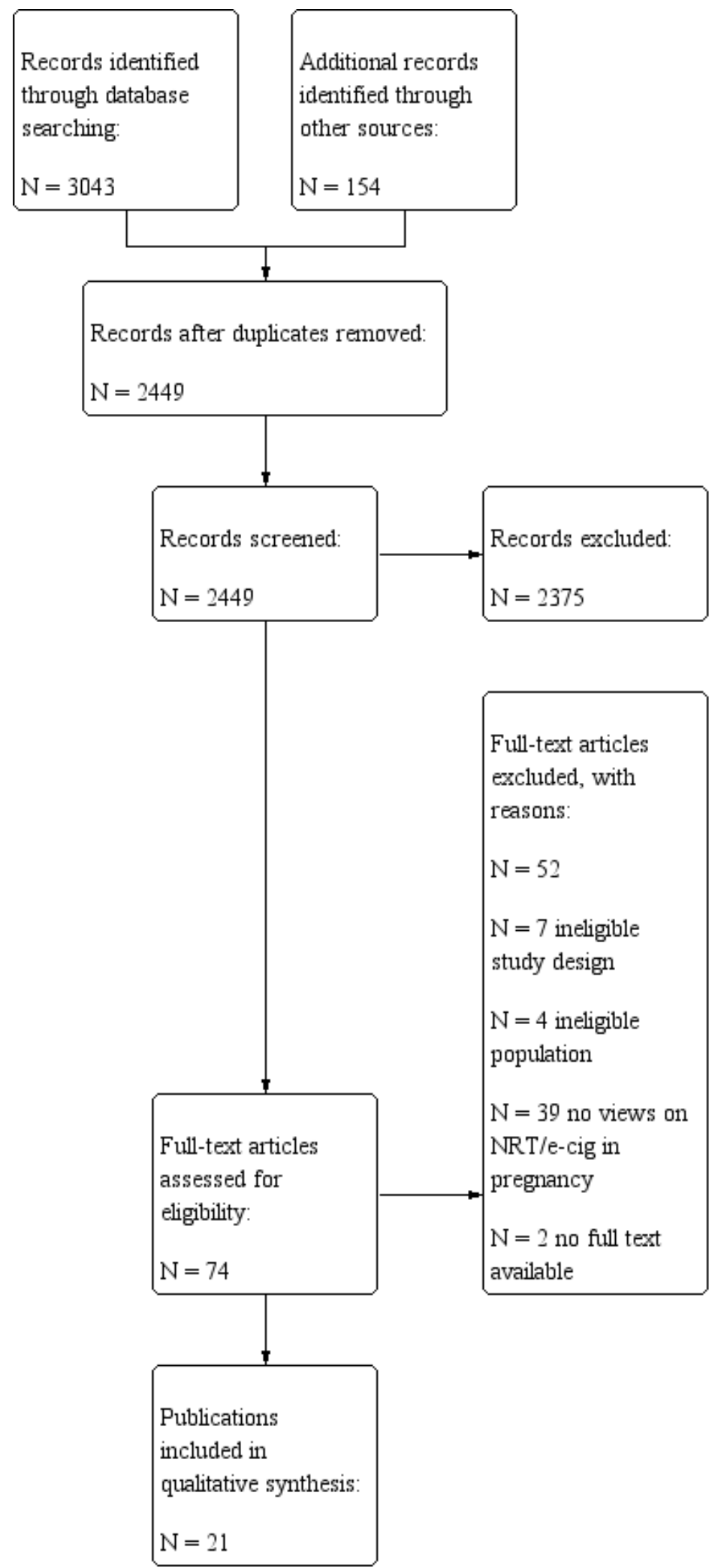

\section{Study design}

Fifteen studies used individual face-to-face or telephone interviews to elicit data (Ashwin 2010; Bauld 2017; Borland 2013; Bowker 2016;
Bowker 2018; Gamble 2015; Glover 2012; Grant 2020; Hauck 2013; Herbec 2014; Mantzari 2012; Naughton 2013; Pledger 2015; Radley 2013; Taylor 2010), five conducted focus groups (Butterworth 2014;

Factors influencing the uptake and use of nicotine replacement therapy and e-cigarettes in pregnant women who smoke: a qualitative

Copyright (c) 2020 The Cochrane Collaboration. Published by John Wiley \& Sons, Ltd. 
England 2016; Fallin 2016b; Fallin 2016a; Hotham 2002), and one used the yarning method of interviewing, which is an Indigenous cultural form of establishing rapport and qualitative data collection through conversation (Bovill 2018).

\section{Study focus}

Fifteen studies presented data relating to women's views on NRT (Ashwin 2010; Borland 2013; Bovill 2018; Butterworth 2014; Fallin 2016a; Gamble 2015; Glover 2012; Hauck 2013; Herbec 2014; Hotham 2002; Mantzari 2012; Naughton 2013; Pledger 2015; Radley 2013; Taylor 2010), three focused on e-cigarettes (Bowker 2018; Fallin 2016b; Grant 2020), two on both (Bauld 2017; England 2016), and one predominantly on NRT but with some views on e-cigarettes (Bowker 2016). Participants' level of familiarity and engagement with NRT and e-cigarettes varied across studies. Three studies purposefully recruited all participants with experience of use of NRT or e-cigarettes (Ashwin 2010; Bowker 2016; Fallin 2016b), while in the other studies only some participants had experience of using NRT, e-cigarette, or both.

\section{Study context}

All included studies were conducted in high-income countries: 12 in the UK (Ashwin 2010; Bauld 2017; Bowker 2016; Bowker 2018; Butterworth 2014; Grant 2020; Herbec 2014; Mantzari 2012; Naughton 2013; Pledger 2015; Radley 2013; Taylor 2010), 4 in Australia (Bovill 2018; Gamble 2015; Hauck 2013; Hotham 2002), 3 in the USA (England 2016; Fallin 2016a; Fallin 2016b), 1 in New Zealand (Glover 2012), and 1 in Canada (Borland 2013). Recruitment took place in a variety of settings, and some studies recruited from more than one setting. Eight studies recruited via maternity services or children's centres (Bauld 2017; Bowker 2016; Butterworth 2014; Fallin 2016a; Hauck 2013; Herbec 2014; Naughton 2013; Taylor 2010), nine via smoking cessation services or hotlines (Ashwin 2010; Bauld 2017; Borland 2013; Bowker 2016; Bowker 2018; Butterworth 2014; Gamble 2015; Mantzari 2012; Pledger 2015), three from local communities (Borland 2013; Bovill 2018; Grant 2020), two via indigenous health services (Bovill 2018; Glover 2012), two via local or online advertising (Bowker 2018; Glover 2012), one via a market research company (England 2016), and one from an opioid dependence clinic (Fallin 2016a). Three studies interviewed women who took part in trials or schemes including smoking cessation interventions, although none of these interventions focused primarily on NRT or e-cigarette provision/use in pregnancy. Instead, the interventions were an online smoking cessation intervention (Herbec 2014), financial incentives (Mantzari 2012), and financial incentives with free NRT provided at first support session by a pharmacist (Radley 2013).

\section{Participants}

A total of 497 women participated in the included studies, ranging from 6 in Gamble 2015 and Pledger 2015 to 60 in Glover 2012. Nineteen studies reported participants' ages, which ranged from 15 to 49 years, with most participants being in their twenties. All studies recruited pregnant women, and nine also included women in the postpartum period. Six studies reported mean gestational age, which ranged from 13 weeks to 24 weeks (Ashwin 2010; Bauld 2017; Bowker 2016; Bowker 2018; Butterworth 2014; Gamble 2015), while in three studies the authors reported that women in all trimesters were recruited (Bauld 2017; Bovill 2018; Glover 2012). Eleven studies provided information on ethnicity; in nine, participants were predominantly white (Bowker 2016;
Bowker 2018; Butterworth 2014; England 2016; Fallin 2016a; Hauck 2013; Herbec 2014; Mantzari 2012; Taylor 2010), whilst two studies recruited only participants of Aboriginal, Torres Strait Island or Maori origin (Bovill 2018; Glover 2012).

Studies were inconsistent in their collection and reporting of socioeconomic status indicators; overall, the presented data suggested that participants were from lower socioeconomic groups. However, 10 studies did not report any data on this variable (Ashwin 2010; Bauld 2017; Bovill 2018; Bowker 2016; Fallin 2016a; Fallin 2016b; Hauck 2013; Herbec 2014; Hotham 2002; Pledger 2015). Five studies reported level of educational achievement, which suggested that most women were not educated beyond compulsory education or high school (Borland 2013; Bowker 2018; Butterworth 2014; England 2016; Glover 2012). Five studies reported employment characteristics (Butterworth 2014; Glover 2012; Mantzari 2012; Naughton 2013; Taylor 2010), four of which suggested that most participants were unemployed. Naughton 2013 indicated that all women were employed, with occupations varying from technical occupations to higher managerial/professional occupations. One study reported that $80 \%$ of women had low income (Glover 2012), while three studies indicated that participants lived in areas of the highest quintile of deprivation and/or claimed means tested benefits (Gamble 2015; Grant 2020; Radley 2013).

\section{Support and funding for studies}

None of the studies received funding from commercial sources, and just one study declared conflicts of interest (Herbec 2014), with the last author stating "RW undertakes consultancy and research for and receives travel funds and hospitality from manufacturers of medications for smoking cessation. He also undertakes training for smoking cessation advisors and has a share of a patent for a novel nicotine delivery device."

\section{Quality assessment}

Table 1 presents the outcomes of the quality appraisal (Wallace 2004). In all studies, the research question was clearly presented, and the design was appropriate to the research question. All studies except England 2016 drew the sample from an appropriate population of pregnant women with some history of smoking in pregnancy. In England 2016, the sample was drawn from a marketing company database, and the characteristics of the wider population were unclear. Several studies had some methodological issues relating to insufficient descriptions of the study sample (Fallin 2016a; Fallin 2016b; Herbec 2014; Hotham 2002; Pledger 2015), data collection (Ashwin 2010; Bovill 2018; Fallin 2016a; Glover 2012; Mantzari 2012; Pledger 2015; Radley 2013), or data analysis (Ashwin 2010; England 2016; Fallin 2016a; Fallin 2016b; Glover 2012; Hotham 2002; Pledger 2015). Fifteen studies did not state the theoretical or ideological perspective (Borland 2013; Bovill 2018; Bowker 2016; Bowker 2018; Butterworth 2014; England 2016; Fallin 2016a; Fallin 2016b; Glover 2012; Hauck 2013; Herbec 2014; Hotham 2002; Mantzari 2012; Pledger 2015; Radley 2013), and another 15 did not sufficiently consider reflexivity (Ashwin 2010; Bauld 2017; Borland 2013; Bovill 2018; Butterworth 2014; England 2016; Fallin 2016b; Glover 2012; Hauck 2013; Hotham 2002; Mantzari 2012; Naughton 2013; Pledger 2015; Radley 2013; Taylor 2010). 


\section{Confidence in the findings}

We identified six descriptive themes that related to factors influencing women's decisions about using or continuing to use NRT and/or e-cigarettes. These were: safety concerns about nicotine, concerns about the addictiveness of nicotine, beliefs about the effectiveness of nicotine-containing products, perceived side effects, influence of others, and characteristics of nicotine products. Within these themes, we identified 18 unique findings relating to the review questions. Table 2 presents a short overview of these themes and the 18 related findings; Table 3 , a summary of qualitative findings with overall CERQual assessments for each finding; and Table 4, the matrix of qualitative findings. In Table 2 , where there is no key finding within a theme, this is because there were insufficient data reported on the issue in empirical studies. Hence, for findings 7 and 11 , there were enough data reported on concerns about addictiveness of nicotine and on side effects in the NRT studies to formulate key findings relating to NRT, but insufficient data for similar findings to arise in relation to ecigarettes.

Table 3 presents the assessment of confidence in review findings, and Appendix 5 shows individual CERQual evidence profiles. We also present an overall CERQual rating for each finding. Confidence in findings ranged from 'high' to 'low', with most being ranked as 'moderate' confidence. Findings were most often downgraded where studies contributed thin/very thin data or data from few participants, or because most studies contributing data to a finding were from only one country, similar contexts, or the context of data report was difficult to establish. Findings were also downgraded due to methodological issues with the primary studies, relating to sample, data collection and analysis.

\section{Factors influencing use of NRT and e-cigarettes in pregnancy}

Eighteen studies presented data on pregnant women's views about NRT (Ashwin 2010; Bauld 2017; Borland 2013; Bovill 2018; Bowker 2016; Butterworth 2014; England 2016; Fallin 2016a; Gamble 2015; Glover 2012; Hauck 2013; Herbec 2014; Hotham 2002; Mantzari 2012; Naughton 2013; Pledger 2015; Radley 2013; Taylor 2010). Most presented data only on NRT, while three presented data on both NRT and e-cigarettes (Bauld 2017; Bowker 2016; England 2016). Three studies presented data only on e-cigarettes (Bowker 2016; Fallin 2016b; Grant 2020). Six studies contributed rich or moderately rich data relevant to the review questions set out in Table 1 (Ashwin 2010; Bowker 2016; Bowker 2018; England 2016; Hotham 2002; Taylor 2010). Four contributed thin data, for example one substantial theme within a broader analysis (Bauld 2017; Bovill 2018; England 2016; Mantzari 2012), and eleven studies contributed very thin data, for example, less than one theme or very short theme with limited quotes (Borland 2013; Butterworth 2014; Fallin 2016a; Fallin 2016b; Gamble 2015; Glover 2012; Grant 2020; Hauck 2013; Herbec 2014; Naughton 2013; Pledger 2015; Radley 2013).

\section{Theme 1: safety concerns about nicotine - women's beliefs about safety of nicotine-containing products influence their use in pregnancy}

This theme related to barriers and facilitators relating to women's concerns regarding safety of nicotine-containing products, a concept women discussed in 15 studies (Ashwin 2010; Bauld 2017; Borland 2013; Bovill 2018; Bowker 2016; Bowker 2018; Butterworth
2014; England 2016; Fallin 2016b; Glover 2012; Grant 2020; Hotham 2002; Naughton 2013; Radley 2013; Taylor 2010).

\section{Finding 1: women believe that NRT is safer than smoking}

Six studies found that women perceived NRT as safer than smoking, as it only delivers nicotine and not the many harmful chemicals present in cigarette smoke (Ashwin 2010; Bauld 2017; Bowker 2016; Hotham 2002; Naughton 2013; Taylor 2010).

"With nicotine patches, you don't get the chemicals like you do with cigarettes - the things that keep the paper burning and the this and the that they chuck in. They [the patches] are actually better for you - you're just getting the nicotine." G1 (Hotham 2002)

In two studies, some women felt that NRT was as harmful as smoking (England 2016; Naughton 2013).

\section{Finding 2: women are concerned that NRT can deliver an unsafe amount of nicotine}

Seven studies reported that women were worried about the amount of nicotine delivered via NRT compared to smoking (Borland 2013; Bowker 2016; Butterworth 2014; England 2016; Hotham 2002; Naughton 2013; Taylor 2010). There was a common concern that women would receive more nicotine from NRT than they would from a cigarette, especially from higher dose patches or when using NRT and smoking at the same time.

"The patch can give you a nicotine overdose, so it's scary, smoking and wearing it." Pregnant smoker (England 2016)

The constant delivery of nicotine from the patch was also problematic for some women; they believed that the increased amount of nicotine supplied via NRT could be dangerous to their health.

"But with the patch you would wear it all day and there's going to be a constant kind of supply of nicotine going to the body, and I just don't like the thought of that." Pregnant woman 14, smoker (Taylor 2010)

\section{Finding 3: women are concerned that using NRT during pregnancy can harm their baby}

Participants most commonly expressed concerns about the potential harms NRT could cause to their unborn baby; in 12 studies participants expressed uncertainty regarding the safety of NRT while pregnant, which in many cases was a barrier to NRT use (Ashwin 2010; Bauld 2017; Borland 2013; Bovill 2018; Bowker 2016; Butterworth 2014; England 2016; Glover 2012; Hotham 2002; Naughton 2013; Radley 2013; Taylor 2010).

"All I was concerned about was um, was the nicotine being released into your blood stream. I was worried about it affecting the baby." W5 (Ashwin 2010)

In four studies, some women thought there was insufficient evidence about the effects of NRT on the baby for them to make a fully informed decision (Ashwin 2010; Glover 2012; Hotham 2002; Taylor 2010).

"I don't think there is a lot of information about NRT in pregnancy and I don't think I had a lot of information about that, but that was probably because it doesn't exist yet. Um, but NRT in general I think I had plenty of information on." W8 (Ashwin 2010) 
"It seems that patches might have a more direct route to your baby ... I don't know how they really work. It has to go through your bloodstream somehow... I don't know enough about them. . . they [patches] are not really tested and the baby is used to me having a cigarette and she's made it this far. I'll leave it at that." G2 (Hotham 2002)

Some women felt they would be more confident making their decision to use NRT if more specific information on nicotine effects on the fetus was offered to them (Bowker 2016; Glover 2012; Hotham 2002; Taylor 2010).

"My main concern was obviously 'smoking passes on horrible chemicals to the child, does this [NRT] still do that?' and [the smoking cessation advisor] was like 'no, it's just one main one, it's just the nicotine' so l'd have liked to have known a bit more on how that affects the baby." Respondent 11; patches (Bowker 2016)

Lack of understanding about the relative safety of NRT in pregnancy compared to smoking led to some women choosing to try quitting 'cold turkey' or continue to smoke rather than use NRT (Bovill 2018; Bowker 2016; England 2016; Naughton 2013; Taylor 2010).

"I would rather a cigarette than wear a patch because you still pumping the stuff into your blood wearing a patch. . at the end of the day if you are going to smoke cigarettes that's not going to be any more harmful than having a patch." 1501, smoker (Naughton 2013)

"I don't know enough about them. . . they [patches] are not really tested and the baby is used to me having a cigarette and she's made it this far. I'll leave it at that." G2 (Hotham 2002)

"They say the nicotine is what stunts the baby's growth and things like that, so I think, well if I can stop smoking [without NRT], then what's the point in me putting a patch on?" Pregnant woman 14; smoker (Taylor 2010)

\section{Finding 4: women believe that e-cigarettes are safer than smoking}

Women's views on the safety of e-cigarettes varied depending on whether they concerned general use or in pregnancy. Women in five studies indicated that they thought e-cigarettes to be less harmful than smoking traditional cigarettes, for both the vapour and in terms of second-hand smoke (Bauld 2017; Bowker 2018; England 2016; Fallin 2016b; Grant 2020). Study participants referred to ecigarettes as being 'cleaner' and 'safer' because they believed these contained fewer chemicals than traditional cigarettes and no tar. In some cases, e-cigarettes were perceived as a harm reduction strategy.

"It [e-cigarette] doesn't pass on second-hand smoke, because even if the baby was close by, which I wouldn't have a baby close by, it wouldn't be dangerous." 19 antenatal ex-smoker and current ecigarette user (Bowker 2018)

"I think the idea behind it-is that because it's water vapour you're not getting some of the tar and some of the other things you get out of a regular cigarette." Pregnant smoker (England 2016)

"It's just vapour, like you have nothing to lose by using their product." (Fallin 2016b)
Three of these studies also mentioned that some women feel uncertain about e-cigarette safety due to lack of evidence on this (Bauld 2017; Bowker 2018; Fallin 2016b).

\section{Finding 5: women are concerned that e-cigarettes can deliver an unsafe amount of nicotine}

In two studies some women were concerned about the amount of nicotine and the potentially harmful properties of other chemicals delivered via the e-cigarette (Bowker 2018; England 2016). Women were also concerned that an e-cigarette could be used for as long as they wanted.

"Obviously with a cigarette you can only smoke it for so long till it's finished, but with an e-cigarette you can smoke for as long as you want to. So sometimes, I guess, I was taking in more than the usual nicotine intake that I would have done with a cigarette." 01 antenatal ex-smoker and ex-e-cigarette user (Bowker 2018)

On the other hand, one study suggested that women found the opportunity to choose the concentration of nicotine in their e-liquid beneficial (Fallin 2016b).

"Lower milligrams of nicotine is better and if you can get the ones without nicotine in it, that's even better." (Fallin 2016b)

\section{Finding 6: women are concerned that using e-cigarettes during pregnancy can harm their baby}

Women in three studies reported some uncertainty about the safety of using e-cigarettes during pregnancy and believed there was insufficient available information about the effects of vaping on the baby to make an informed decision about using these in pregnancy (Bauld 2017; Bowker 2016; Fallin 2016b). Women viewed e-cigarettes as a new and untested product.

"I wasn't allowed anything like that during pregnancy because they have not tested things like that properly yet." Area A, pregnant woman 18, non-smoker (Bauld 2017)

Theme 2: concerns about addictiveness of nicotine - women's beliefs about addictiveness of nicotine influence their use of NRT in pregnancy

\section{Finding 7: women report concerns that NRT is as addictive as smoking}

Four studies briefly reported women's concern about the addictive potential of NRT (Ashwin 2010; Bowker 2016; England 2016; Taylor 2010). Data were relatively thin, however, with few participant quotes.

Some women felt that using nicotine products of any kind constituted 'not actually quitting' or replacing one addiction with another (Ashwin 2010; Bowker 2016; Taylor 2010).

"Well, all they keep saying is you know it gets rid of the toxins, you still get the nicotine but it gets rid of the toxins, this, that and the other and it's just in that the nicotine you take it in. The nicotine itself is what makes it addictive, so to me the more nicotine that you're taking in anyway, the more you're going to want to smoke or you know you're going to need that nicotine." Respondent 6; inhalator (Bowker 2016)

There was also a belief that becoming addicted to NRT would prolong the quitting process and would give women 'something else they would have to quit after quitting smoking', and therefore

Factors influencing the uptake and use of nicotine replacement therapy and e-cigarettes in pregnant women who smoke: a qualitative 
they were unwilling to start using it or tried to use it for short periods only (Ashwin 2010; Taylor 2010).

"I didn't want to be on it too long because I was worried about getting addicted to that. And replacing one addiction with another." W4 (Ashwin 2010)

"That's why I decided not to do it [use NRT] personally because you're going to give it [smoking] up, you're prolonging the process by having the nicotine still being put into your body ... you have to believe you can cope without." Pregnant woman 6; recent quitter (Taylor 2010)

In one study women noted that NRT might be better than ecigarettes with regards to weaning off nicotine (Bowker 2018).

Theme 3: effectiveness of nicotine-containing products women's beliefs about the effectiveness of nicotine-containing products influence their use in pregnancy

Eleven studies contributed data on women's views on effectiveness of NRT for aiding quit attempts or managing tobacco cravings or withdrawal symptoms (Ashwin 2010; Bauld 2017; Bowker 2016; Butterworth 2014; England 2016; Fallin 2016a; Hotham 2002; Mantzari 2012; Pledger 2015; Radley 2013; Taylor 2010). Most studies reported that effectiveness beliefs were based on women's current or past experience with NRT, but some studies also reported effectiveness beliefs of women whose beliefs were based on other peoples' reports of their experiences (England 2016; Hotham 2002; Taylor 2010). Opinions were mixed both between and within studies.

\section{Finding 8: past positive experiences of NRT can facilitate NRT use in pregnancy}

Women frequently expressed their opinion on effectiveness of NRT in terms of its ability to help them quit smoking or in terms of helping cope with withdrawal symptoms. Women in five studies reported that the NRT they used helped support their quit attempt (Bauld 2017; Bowker 2016; Butterworth 2014; Pledger 2015; Taylor 2010), and one of these studies indicated that knowing someone who found NRT effective also improved beliefs about NRT effectiveness in never-users (Taylor 2010).

"I swore by those, they were really good. . . you don't even think about a fag when you are on a patch." Area A, pregnant woman 17, nonsmoker (Bauld 2017)

"I mean if I'm stressed or anything, if I get a squirt, once I take my squirt [description of inhalator] it's like a relief, I feel calm, I feel relaxed and that's all it is pretty much. .....But that's how you basically feel, you feel calmer, more relaxed." Respondent 6; inhalator (Bowker 2016)

\section{Finding 9: past negative experiences with NRT can be a barrier to use of NRT in pregnancy}

In seven studies, women reported a belief that NRT had not helped them to stop or had failed to control their cigarette cravings (Bauld 2017; Bowker 2016; England 2016; Fallin 2016a; Mantzari 2012; Pledger 2015; Taylor 2010). A number reported that consequently they smoked occasional cigarettes to help with cravings, usually without seeking advice from a health professional (Bowker 2016).

"I was really struggling. It [the patch] was stuck but it felt like I was getting no nicotine. And it didn't matter how much I puffed on the inhalator I was just suffering like really bad. So I started smoking over that weekend." Respondent 7; patches, inhalator and mouth spray (Bowker 2016)

Additionally, one study reported that some women who struggled with cravings independently decided to wear NRT patches for longer than recommended to help cope with these (Bowker 2016). In other studies, some women who had used lower dose patches found these ineffective (Bauld 2017; Mantzari 2012).

"She did say to put them on and take them off before bedtime to give you and baby a rest. I was finding I was waking up and wanting a cigarette so I took it upon myself to leave them on for 24 hours." Respondent 9; patches (Bowker 2016)

Women treated for opioid dependency found NRT to be less effective in treating their smoking addiction than medication for opioid dependency (Fallin 2016a).

"I keep thinking to myself, I'll be able to quit if I quit the drugs [heroin] and I had medicine to help me get off of drugs [MAT]. The same thing, nicotine patch....and I still can't quit. I still have the desire to smoke." (Fallin 2016a)

Three studies found women believed that willpower was the key factor in any quit attempt and therefore felt that NRT was not going to help unless they were ready to quit (Ashwin 2010; Hotham 2002; Taylor 2010). In one, women who managed to quit attributed their success to willpower or health professionals' support, rather than the NRT (Ashwin 2010).

"I don't think that (gum) had anything to do with it. I think it was just willpower and the fact that that, um, my advisor was coming to see me as well." W9 (Ashwin 2010)

Never-users who knew of people that failed to quit on NRT had negative beliefs about NRT effectiveness (England 2016; Hotham 2002; Taylor 2010).

\section{Finding 10: women present mixed views on effectiveness of e- cigarettes}

Four studies contributed data on women's views on effectiveness of e-cigarettes, although these were very sparse, with mixed opinions reported and minimal insight into how these might affect readiness to use e-cigarettes (Bauld 2017; Bowker 2016; Bowker 2018; Grant 2020). One study concluded that women did not find e-cigarettes helpful in a quit attempt (Bowker 2016), but in two others, women perceived e-cigarettes could potentially help them to quit (Bauld 2017; Bowker 2018). An interviewee in one study reported that while she successfully used an e-cigarette to quit before pregnancy, she started craving regular cigarettes when pregnant and had to supplement her e-cigarette use with smoking to manage cravings (Grant 2020).

"I smoked and then I quit and then I, when I found out I did quit but then I started smoking again when I was pregnant and then I went onto those e-cig fags and then I stopped on that but now I am pregnant again I've started having a few fags again it's like I've got a craving for smoke or something, it's really weird, I'm not a heavy smoker but if I am in the house I'll fancy like a little cig or something, you know." Cat (Grant 2020)

Factors influencing the uptake and use of nicotine replacement therapy and e-cigarettes in pregnant women who smoke: a qualitative 
Theme 4: side effects - women's beliefs about and experiences with side effects of NRT influence their use of NRT in pregnancy

Finding 11: women who report experiencing and feeling unable to deal with side effects of NRT perceive these as a barrier to NRT use in pregnancy

Nine studies contributed data on women's experiences of side effects when using NRT (Ashwin 2010; Bauld 2017; Bovill 2018; Bowker 2016; Butterworth 2014; England 2016; Mantzari 2012; Pledger 2015; Taylor 2010).

The side effects of NRT are well documented (Mills 2010); here we focus on how experiencing these side effects had affected women's continued use of NRT once these had been encountered. Some studies noted that women were delaying the next dose or discontinuing use of their oral NRT when experiencing unpleasant effects, especially when they felt it exacerbated their morning sickness (Bowker 2016; Butterworth 2014; Mantzari 2012; Taylor 2010). Overall, women tended to discontinue or use NRT in nonstandard ways without seeking advice or support from health professionals. One respondent noted, "It would have been nice to have a heads up [from health professionals] about it that it makes you feel sick" Respondent 5; gum (Bowker 2016), as it could prepare women to deal with side effects more effectively.

"Yeah, totally delayed cos I keep saying oh I don't want to taste it yet, I'll give it another 10 minutes you know or I'll give it a bit longer. It is delaying it cos you think I'm not looking forward to the taste of it so I'll just wait a bit longer." Respondent 3; inhalator (Bowker 2016)

"I was just more worried about the side effects obviously because I'm quite early on in pregnancy, and especially with morning sickness anyway, I didn't know that it [NRT] would cause - obviously [it] made me feel more nauseous and [I] vomited quite a few times when I had the gum. So just would have been nice to have a heads up about it that it makes you feel sick" Respondent 5; gum (Bowker 2016)

Commonly experienced side effects associated with patches included skin irritation or burning (Bauld 2017; Bowker 2016; England 2016; Mantzari 2012; Taylor 2010); strange dreams (Ashwin 2010; England 2016; Pledger 2015); and headaches, hallucinations and paranoia (Taylor 2010). Women also often reported issues with patches leaving marks or adhering poorly to the skin (Ashwin 2010; Fallin 2016b; Pledger 2015). NRT patch side effects were considered difficult to manage and led some women to discontinue these early (Bauld 2017; Bowker 2016; Mantzari 2012; Taylor 2010).

Some women perceived NRT gum, inhalators, and microtabs as unpleasant tasting, and in a few they caused mouth irritation or exacerbated nausea and/or vomiting, which led to women delaying doses or discontinuing use (Bovill 2018; Bowker 2016; Butterworth 2014; England 2016; Mantzari 2012; Taylor 2010). One study noted that women developed strategies to help them manage these, including taking mints or sipping water (Bowker 2016).

\section{Theme 5: influence of others - women's readiness to use nicotine-containing products in pregnancy is influenced by the perceived views of and support from other people}

In 14 studies, the influence of health professionals, but also family and friends, was found to be an important factor affecting women's views on NRT and on their readiness to use it (Ashwin 2010; Bauld
2017; Borland 2013; Bovill 2018; Bowker 2016; Butterworth 2014; Gamble 2015; Glover 2012; Hauck 2013; Herbec 2014; Mantzari 2012; Pledger 2015; Radley 2013; Taylor 2010). Four studies focusing on e-cigarettes also contributed data to this theme (Bauld 2017; Bowker 2018; Fallin 2016b; Grant 2020).

\section{Finding 12: women who report receiving clear and consistent reassurance from health professionals about NRT safety in pregnancy feel this can facilitate NRT use}

Health professionals were perceived as a key source of information and advice on safety and use of NRT, and women reported generally following their advice. Five studies reported that receiving reassurance about NRT safety in pregnancy from a health professional (e.g. midwife or a stop smoking practitioner) was the key factor that helped alleviate safety concerns, improve acceptability of NRT and/or make women feel more at ease to initiate NRT use in pregnancy (Ashwin 2010; Bauld 2017; Bowker 2016; Gamble 2015; Taylor 2010).

"No, I mean I double checked that everything was okay for me to use it while I was pregnant. Yeah. So I thought it didn't concern me, because I had been told it was safe to use." W9 (Ashwin 2010)

"I made doubly sure. I was like 'they are safe?' and she goes, 'I wouldn't be prescribing them to you if they weren't safe in pregnancy.' " Area B, pregnant woman 16, smoker (Bauld 2017)

Two studies reported that never-users also felt they would try NRT if they received sufficient reassurance about safety from a health professional (Hotham 2002; Taylor 2010).

"I would try, as long as you could convince me it was safe. Have a discussion on it - how it affects the baby - what patches do - the positives and negatives about them..." G1 (Hotham 2002)

\section{Finding 13: women who report experiencing lack of support towards NRT use from health professionals are reluctant to use NRT in pregnancy}

Five studies reported instances in which women felt unconvinced about safety or were discouraged from NRT use in pregnancy as a result of misinformation, misunderstanding or a health professional's active discouragement/apparent lack of confidence in advising on NRT use in pregnancy (Borland 2013; Bowker 2016; Gamble 2015; Hotham 2002; Mantzari 2012). Sometimes the advice women received did not adequately address their specific concerns (Bowker 2016).

"I said to her, erm, er, 'yeah about me being pregnant and still carrying the lozenges', she's like 'Yeah?' I said 'I've got patches at home can I still use them, like can I start on them again rather than give me more, they're from last year they're still in date though?' And she said, 'I've never dealt with a pregnant woman before.' Participant 34, control group (Mantzari 2012)

"They told me here not to do that and they wouldn't give me the patch because I was pregnant." Postpartum woman, Central region (Borland 2013)

"I can remember the conversation we had about it and [the smoking cessation advisor] was letting me know where I can put [the patches] and whatnot, but to myself I just thought no, that's just a bit tooyou know you sit there thinking about it. I don't know, it's weird, I just think it's too close to the baby to be having all that nicotine going in."

Factors influencing the uptake and use of nicotine replacement therapy and e-cigarettes in pregnant women who smoke: a qualitative 12

Copyright (c) 2020 The Cochrane Collaboration. Published by John Wiley \& Sons, Ltd. 
Respondent 10; patches. This participant was not convinced about the safety of using her nicotine patch even after being advised about it; she decided to revert back to smoking as she felt that the harms of using her patch on her lower back would be too dangerous for her baby (Bowker 2016).

Seven studies suggested that women felt dissatisfied with the support and advice from health professionals. Receiving inadequate support and advice about NRT in pregnancy was perceived as a barrier to NRT use and smoking cessation in general (Borland 2013; Bovill 2018; Bowker 2016; Gamble 2015; Glover 2012; Hauck 2013; Mantzari 2012). Five studies with predominantly Aboriginal, Torres Strait Island and Maori women presented negative experiences of health professional counselling, including perceived lack of support, inconsistent messages about safety and lack of expertise with regards to NRT and smoking cessation in general affecting these communities (Borland 2013; Bovill 2018; Gamble 2015; Glover 2012; Hauck 2013). These studies suggested that misinformation or hesitation about recommending NRT hindered their quit attempts by confusing women about whether NRT is safe or permitted in pregnancy. Similar views were presented in some studies with predominantly white British women (Bowker 2016; Mantzari 2012), but in these studies, women also reported many positive experiences with smoking cessation support (Ashwin 2010; Bauld 2017; Bowker 2016; Butterworth 2014).

"They say 'do you want to quit smoking?' and you tell them you do but it's like 'we'll encourage you to but we're not going to properly support you to do it'" W16 (Bovill 2018)

"She gave me the patch where I wanted the highest patch that I could have because I've been smoking $24 / 7$, they actually told me the most I could have was a $20 \mathrm{mg}$ patch, which now I've been told by the midwife that's not true... The patch didn't seem to be working. And then when I told my midwife it didn't work and she said it was, erm, that I could have more than a 20 mg patch. . I wouldn't be smoking now if the pharmacist had given me the right amount". Participant 09, control group (Mantzari 2012)

Five studies reported that women specifically expressed the need for more support and guidance on NRT use (Bovill 2018; Bowker 2016; Herbec 2014; Pledger 2015; Taylor 2010).

\section{Finding 14: women feel discouraged from using NRT in pregnancy by the perceived views and experiences of other people (non-health professionals)}

Four studies contributed data on the perceived influence of family and friends on attitudes towards NRT or readiness to use NRT in pregnancy (Bovill 2018; England 2016; Hotham 2002; Taylor 2010). In most cases, reports from women suggested that the experiences of family and friends served as a barrier to using NRT. In some cases anecdotal accounts of a friend or family member having a bad experience with NRT, such as experiencing unpleasant side effects, tended to put women off using it in their own quit attempt (England 2016; Hotham 2002; Taylor 2010). In other cases (Taylor 2010), women felt actively discouraged from NRT use by their family or by the fact that they did not know many people who had used NRT (Bovill 2018).

"Everyone I know that has quit smoking has just gone cold turkey, like they haven't used anything." W2 (Bovill 2018)
"[I wouldn't want to use NRT] from stories that I've heard off other people nightmares and hot sweats and things like that." Pregnant woman 1; recent quitter (Taylor 2010)

Only one study reported that women felt their family and friends would support their use of NRT to quit in pregnancy (Taylor 2010).

"Yes, my family would approve [of me using NRT], definitely." Pregnant woman 12; recent quitter (Taylor 2010)

Some women in this study also reported feeling embarrassed and judged to be seen using NRT (particularly inhalators) while pregnant, as much as they would if they smoked in public. This feeling of being judged and self-consciousness sometimes served as a barrier to using NRT in public (Taylor 2010).

"They see you walking street and you've got that thing in your mouth [inhalator], they'll think, 'hold on a minute, that's not good, she's not allowed to do that, you'd proper get some weird looks... I don't care what people think." Pregnant woman 4; smoker (Taylor 2010)

\section{Finding 15: women's readiness to use e-cigarettes in pregnancy is influenced by the advice they report receiving from their health professionals}

In four studies most women reported that their health professionals did not endorse the use of e-cigarettes in pregnancy (Bauld 2017; Bovill 2018; Fallin 2016b; Grant 2020). Media reports recalled by the women also tended to be negative, in particular highlighting product malfunctions and health scares, and women did not report verifying this information with their health professionals (Bowker 2018; Fallin 2016b).

Lack of information about safety and discouragement from health professionals often led to pregnant women's reluctance to try ecigarettes or a desire to stop using them (Bauld 2017; Bowker 2016; Bowker 2018)

"[I tried] an e-cig[arette] which was really good. . It's good to have this you know the smoke coming out and going through all the motions, but I wasn't allowed anything like that during pregnancy because they have not tested things like that properly yet." Area A, pregnant woman 18, non-smoker (Bauld 2017)

Bowker 2018 reported that women felt more confident using NRT than e-cigarettes because they believed NRT was recommended by health professionals; women in this study were reluctant to start using e-cigarettes until safety of the product was established and clearly communicated.

"Yeah and I think obviously if there was some sort of government stamp on it or you know, you don't buy toys without having something, you don't buy anything without, even the bad stuff you know, you buy a packet of cigarettes and the government have put what it can do to you on it, with all the pictures. Whereas there's nothing, is there? There's no nothing, no good, no bad, no nothing." 15 antenatal smoker and never user (Bowker 2018)

On the other hand, some pregnant women decided to continue using e-cigarettes (Bowker 2016), or they showed interest in using them despite discussing 'unknown risks' with their health professionals (Bauld 2017). One participant decided to continue using e-cigarettes based on her own 'online research', which satisfied her that vaping was safer than smoking (Grant 2020). 
"The doctors and the health visitors all say: 'Are you going to cut down?' And I say: 'No, I don't think it's harming my child' so I am happy to stay on them and that's it really... it hasn't got any of the harmful chemicals like tar and all you know. . . it's my decision and I'm happy with this like you know?" Becky (Grant 2020)

Two studies reported that some women were encouraged to use ecigarettes by their health professional (Bowker 2018; Fallin 2016b).

"And then I completely just quit and picked up the e-cig and worked with it while I was kind of pregnant but I was kind of scared but I talked to my doctor about it and they said it was fine you know, so." (Fallin 2016b)

Overall, there were mixed reports about women's experiences of health professionals' stance on e-cigarette safety, and, apart from a small number of participants in three studies (Bauld 2017; Bowker 2018; Grant 2020), women tended to consider their health professionals' advice when making a decision to use e-cigarettes in pregnancy.

\section{Finding 16: women's readiness to use e-cigarettes in pregnancy is influenced by other people (non-health professionals)}

There was limited evidence about the role of family and friends in the studies, but two studies mentioned that family and friends encouraged pregnant women to use e-cigarettes to quit smoking (Bauld 2017; Bowker 2018).

"They [family] were a lot happier about me using that [e-cigarette] than obviously smoking. My Mum actually bought me the e-cigarette and she never ever bought me cigarettes in my life." 08 antenatal smoker and current e-cigarette user (Bowker 2018)

In addition, two studies also noted that women felt judged by other members of the public when using e-cigarettes, which reduced their willingness to use e-cigarettes in public places (Bowker 2018; Grant 2020). Some women said they felt embarrassed and uncomfortable to be seen using an e-cigarette while pregnant or out with children, similar to when smoking.

"And I smoke my e-cig and some people might not, not that that bothers me at all, but they might look at me and like judge but it doesn't bother me but it's still a factor in the pregnancy." Becky (Grant 2020)

\section{Theme 6: characteristics of nicotine-containing products can influence women's readiness to use them in pregnancy}

Finding 17: perceived characteristics of the NRT product, such as cost, convenience and ability to mimic a cigarette, can influence uptake and continuous use of NRT in pregnancy

Eleven studies contributed data to how the characteristics of NRT products can influence women's views and readiness to use them (Ashwin 2010; Bauld 2017; Bowker 2016; (removed Bowker 2018) Butterworth 2014; England 2016; Fallin 2016a; Fallin 2016b; Hotham 2002; Pledger 2015; Radley 2013; Taylor 2010). The key characteristics that influenced women's attitudes towards NRT use were attractiveness, convenience of use, cost, and behavioural substitution.

Some women found NRT fairly discreet and easy to use (Ashwin 2010; Bowker 2016; Butterworth 2014; Taylor 2010). Overall, NRT, particularly inhalators and patches, was viewed as unattractive, boring, medicinal and hard to hide. Some women felt that patches did not adhere to skin properly and left unattractive marks (Ashwin 2010; Butterworth 2014; England 2016; Fallin 2016b; Pledger 2015; Taylor 2010). One study mentioned that the appearance was one of the main reasons for discontinuing the use of inhalator (Butterworth 2014).

In one Australian study where women had to pay for NRT, some perceived the cost to be prohibitive (Hotham 2002). In two UK studies, authors reported that women were unaware that NRT would be provided free of charge (Bauld 2017; Taylor 2010).

Women often chose their product based on its ability to mimic the traditional cigarette; some women found that inhalators helped manage the behavioural aspects of their addiction, such as the hand-to-mouth action (Ashwin 2010; Bauld 2017; Bowker 2016; Taylor 2010). Some also felt that inhalators allowed them to continue socialising with friends who smoked (Bowker 2016; Butterworth 2014; Taylor 2010).

"I don't know what to do with my hands when I'm not smoking - so that's why I used the inhaler because it's something in my hands and it can help - feels like I'm smoking a fag [cigarette] kind of thing." Respondent 2; inhalator (Bowker 2016)

Patches were perceived as least like cigarettes. This was problematic for some women (England 2016; Fallin 2016a; Hotham 2002; Taylor 2010), but beneficial to others, as they did not remind them of cigarettes (Bowker 2016).

"The hands thing. You're going to the pub. You're still getting your nicotine, but with your coffee? It's the hands." G3; about patches (Hotham 2002)

\section{Finding 18: perceived characteristics of e-cigarettes, such as cost, convenience and ability to mimic a cigarette, can influence uptake and continuous use of e-cigarettes in pregnancy}

Five studies contributed data on how women perceived the characteristics of e-cigarettes affected their readiness to use them (Bauld 2017; Bowker 2018; Butterworth 2014; England 2016; Fallin 2016b). The appearance of e-cigarettes was often viewed positively by the women, with some describing them as 'cool' or 'cute' (England 2016). They especially liked the smaller, slicker, more convenient products (Bowker 2018). They also found the selection of flavours particularly exciting and satisfactory (England 2016; Fallin 2016b).

"Today, I feel like a menthol, tomorrow I'll feel like strawberry, the next day I feel like unicorn." (Fallin 2016b)

Women disliked having to refill e-cigarettes where the fluid was sold separately and required frequent charging, especially as chargers could be difficult to replace if lost (Bauld 2017; Fallin 2016b).

Cost influenced women's decisions to use e-cigarettes. E-cigarettes were not free of charge to any of the women who participated in studies. Some women believed e-cigarettes were good value (Bowker 2018; England 2016), while others felt they were more expensive than smoking (Bauld 2017; Butterworth 2014).

"I had one of them e-cig[arette] things you know the ones with the oil, and it lasted 3 weeks and then I got rid of it because it was rubbish to be fair. It was, you had to charge it all the time and then you had to 
buy the fluid and then it just ended up costing like the same amount as regular cigarettes. It was - there was no point." Area B, pregnant woman 17, smoker (Bauld 2017)

E-cigarettes were believed to provide good behavioural substitution for smoking traditional cigarettes (Bauld 2017; Bowker 2016; Bowker 2018; Butterworth 2014; England 2016; Fallin 2016b).

"[I tried] an e-cig[arette] which was really good. . . It's good to have this you know the smoke coming out and going through all the motions." (Bauld 2017)

Some women, however, found these products not as satisfying as smoking, which was a source of frustration, while others found it too much like the cigarette or a cue to smoking (Bowker 2018; Fallin 2016b).

"I think not smoking at all was less frustrating than trying to get the satisfaction of a real cigarette from an e-cigarette." (Fallin 2016b)

"One thing I missed when I have quit smoking is inhaling the smoke, so when I used an e-cigarette obviously you've got that kind of experience of inhaling the vapour. It was too much, it was too similar to having a cigarette, so it made me miss it even more." 01 antenatal ex-smoker and ex-e-cigarette user (Bowker 2018)

\section{Analytical themes}

We identified three analytical themes representing the key determinants explaining uptake of and adherence to NRT and e-cigarettes; each potentially acted as a barrier or facilitator to use. Similar descriptive themes emerged from NRT and e-cigarette studies, but some issues only appeared to relate to NRT. Overall, we felt that the determinants of e-cigarette and NRT use were relatively similar, and that even more similarities, and perhaps some differences, might have been apparent had there been more data on e-cigarettes.

\section{Women consider health professionals' advice when making decisions about NRT or e-cigarette use in pregnancy}

Findings (F) contributing to this theme: F12 (moderate confidence), F13 (high confidence), F15 (high confidence).

When pregnant women perceive that health professionals endorse NRT or e-cigarettes as smoking cessation aids, they feel more confident about using them. Conversely, when health professionals provide inconsistent or unclear information about safety or appropriateness of using these products, women can be less willing to use them.

\section{Women see protecting their unborn baby as a priority}

Findings contributing to this theme: $\mathrm{F} 1$ (moderate confidence), F2 (moderate confidence), F3 (high confidence), F4 (moderate confidence), F5 (low confidence), F6 (moderate confidence), F7 (moderate confidence).

The degree to which women perceive NRT and e-cigarettes to be acceptable and safe cessation aids influences how much they use them. Women who believed that these were safer than smoking were more willing to use them in quit attempts. However, where women perceived that NRT or e-cigarettes were at least as harmful as smoking, their concern for the effect these might have on their unborn babies hindered their acceptance of them as quit aids during pregnancy. Some women lacked understanding of which tobacco smoke components cause most harm, with many believing this to be nicotine. Many were concerned about the possible addictiveness of nicotine and worried that NRT and e-cigarettes could deliver higher, and therefore less safe, nicotine doses than cigarettes.

Nicotine-related fears can deter women from using NRT or ecigarettes. Such fears may stem from the perceived lack of evidence regarding safety of NRT and e-cigarettes and/or from negative opinions about NRT and e-cigarettes expressed by family and friends, and sometimes by health professionals. The belief that there is insufficient safety evidence was particularly apparent in relation to e-cigarettes. However, women in some NRT studies, including recent ones, expressed fears about nicotine and hence about NRT safety, despite NRT being increasingly recommended internationally as a cessation aid in pregnancy (ACOG 2017; BarZeev 2018; CAN-ADAPTT 2011; NZ Ministry of Health 2014; NICE 2010).

\section{Women's previous experience using NRT influences their motivation to use NRT in pregnancy}

Findings contributing to this theme: F8 (moderate confidence), F9 (moderate confidence), F10 (low confidence), F11 (high confidence), F14 (high confidence), F16 (moderate confidence), F17 (moderate confidence), F18 (moderate confidence).

Past positive experiences with NRT, or those of their family and friends, can influence pregnant women's beliefs about likely effectiveness of NRT, encouraging them to try it. Conversely, previous negative experiences of using NRT in unsuccessful quit attempts, ineffective management of withdrawal symptoms or experience of unpleasant side effects, or family and friends' reports of similar issues can discourage pregnant women from trying NRT. After initiating NRT, there are many reasons why women might find it unhelpful and discontinue it early. For example, they might use insufficient NRT to ameliorate nicotine cravings due to concerns about nicotine; when they subsequently continue to experience cravings, women may believe NRT is not helping them. For ecigarettes, there is less evidence on how past experience influences future use; available data suggests a similar relationship to that for NRT, but more research could confirm or refute this.

\section{Integrating the findings from this synthesis with the findings of the relevant Cochrane effectiveness review}

Here we consider how findings from this qualitative evidence synthesis (QES) might relate to those from a Cochrane Review that investigated effectiveness of pharmacological treatments for smoking cessation in pregnancy (Coleman 2015, updated Claire 2020). The following issues from that review are relevant here.

- There were no completed trials of e-cigarettes in pregnancy.

- All participants in review trials agreed to being randomly allocated to NRT or control (placebo or behavioural support only), which implies that they did not hold strong negative beliefs about NRT.

- Descriptions of counselling about NRT use were very brief.

- NRT was borderline effective compared to control.

- Study design was the only factor found to influence NRT effectiveness estimates. Trials that were not placebo-controlled produced higher effectiveness estimates than those with

Factors influencing the uptake and use of nicotine replacement therapy and e-cigarettes in pregnant women who smoke: a qualitative 
placebo control; review authors concluded that this was due to bias.

- Where studies reported adherence to NRT, this was universally low. However, as adherence reporting was inconsistent, intrastudy comparisons were not possible.

As there were no e-cigarette trials, this section only relates QES findings on NRT to the Cochrane effectiveness review.

With respect to the determinants of women's decisions to start NRT, we consider that findings from the qualitative studies in this QES have limited transferability to the context of RCTs. All women enrolled in RCTs included in Coleman 2015 (updated Claire 2020) had to understand standardised information on NRT, received counselling about NRT from trained health professionals and, following this process, agree to use NRT, placebo or to only receive behavioural support. Conversely, women recruited to QES qualitative studies are less likely to have received any formal advice on NRT, and information from health professionals' may have been less comprehensive or consistent than that given in RCTs. In some QES studies, women reported inadequate or inaccurate advice from health professionals, and some health professionals were negative about NRT. While women in trials may have had similar previous experiences, any negative impressions of NRT as a result would have likely been addressed when they enrolled in the trial. In this QES, the influence of health professionals' advice was a key determinant of women's decisions about NRT use, so we feel the differences outlined above are important and that QES studies' findings are not directly transferable to trial participants' decisions around the use of NRT.

Although we do not think it is appropriate to equate the initiation of NRT in an RCT versus routine health care, we consider that QES findings are relevant to why women decide to carry on or stop using this after starting NRT. In smoking cessation RCTs, participants receive most behavioural support in initial consultations. Afterward, trial participants who use NRT often have relatively little contact with health professionals, so women are likely to make decisions on continuing or stopping NRT without further professional advice; this is similar to the conditions of routine health care (Bowker 2016). Hence, we believe that QES findings are much more transferable to, and likely to help explain, women's adherence to NRT in both routine care and RCTs, and we propose using QES findings to help understand why adherence to NRT in effectiveness review trials was so low (Coleman 2015, updated Claire 2020). This is an important issue because when pregnant women adhere more strongly to NRT, they have a better chance of becoming abstinent (Raupach 2014). To facilitate investigation of how QES findings might explain trial participants' adherence to NRT, we created a matrix showing the extent to which key QES findings are represented within interventions used for each trial in the effectiveness review (see Appendix 6). Across most effectiveness review trials, this demonstrates the following key issues.

- All effectiveness review trials included behavioural support, but trial reports gave little detail about the information on NRT included in this support (Coleman 2015, updated Claire 2020).

- Initial and follow-up counselling in trials was usually delivered by the same health professionals, so it is likely to have been consistent.

- Few trials offered participants a choice of NRT types.
QES findings show that pregnant women value health professionals' clear advice about NRT and are more likely to follow this when it addresses any concerns they may have about nicotine use in pregnancy. It is unclear if support delivered in the effectiveness review trials included this specific advice, as details provided in trial reports were very scanty. However, as most studies finished recruiting over nine years ago and there was only limited literature on NRT safety then, this seems unlikely (Coleman 2015, updated Claire 2020). Another issue, which is unclear from trial descriptions, is the degree to which information about NRT might have been delivered consistently. Again, QES findings suggest that this is important to pregnant women. In most of the RCTs included in the effectiveness reviews (Coleman 2015, updated Claire 2020), both initial and follow-up behavioural support was delivered by a single team of smoking cessation-trained health professionals. Although it is not explicitly stated or reported, it is highly likely that these teams delivered consistent messages about NRT. However, in two larger trials, routine healthcare staff provided follow-up counselling, whereas trial staff provided initial support; in these RCTs, messages given about NRT may have been less consistent (Berlin 2014; Coleman 2012). Appendix 6 also demonstrates the limited extent to which trial participants had a choice of NRT product (e.g. patch versus inhalator); the QES found that women reported product choice as being potentially influential in their decisions to start and subsequently continue using NRT. Only Pollak 2007 offered women a choice of NRT types (i.e. gum, lozenge, or patch). Other RCTs restricted women to only one NRT type, and although four trials offered varied NRT strengths, only one type of NRT was used in each study, and NRT selection was guided by the severity of women's nicotine dependence so they could not actually choose their NRT (Berlin 2014; El-Mohandes 2013; Oncken 2019; Pollak 2007).

QES findings suggest that to maximise participants' adherence to NRT, and potentially their chances of stopping smoking, future trials of NRT in pregnancy should develop interventions that increase participants' chances of receiving consistent, positive advice on NRT safety and which counter any inaccurate beliefs about nicotine or NRT. Additionally, researchers designing trials should consider offering participants a choice of NRT products.

\section{ISCUSSION}

\section{Summary of main findings}

This review included 21 studies that took place in five developed countries, predominantly the UK, followed by the USA, Australia, New Zealand, and Canada. We identified six descriptive themes and 18 individual findings situated within those themes, from which we developed three overarching analytical themes, representing the key determinants to uptake and adherence to NRT and/or ecigarettes in pregnancy. These analytical themes are related to the advice from health professionals on NRT or e-cigarette use in pregnancy, women's desire to protect their unborn baby from harm, and the role of past experiences with NRT on motivation to use it in pregnancy. Each of these determinants can either hinder or facilitate uptake and adherence to these products, depending on women's individual experiences. Women who perceive that the advice and support from health professionals endorses NRT or ecigarette use in pregnancy, who believe that NRT or e-cigarettes are less harmful for their developing baby than smoking, who have successfully used these products in the past, or who have received positive messages from peers about these, are likely to

Factors influencing the uptake and use of nicotine replacement therapy and e-cigarettes in pregnant women who smoke: a qualitative 
have more positive views on using NRT or e-cigarettes in pregnancy. Conversely, women who have opposite beliefs and experiences are less likely to consider using NRT or e-cigarettes in pregnancy or are more likely to discontinue using them.

\section{Summary of integrating the findings from this synthesis with the findings from Cochrane effectiveness review}

The contexts of included studies in the QES and in Coleman 2015 (updated Claire 2020) were not sufficiently similar to fully integrate the findings. QES findings are more relevant to RCT participants' adherence with NRT once this has been initiated than to RCT participants' decisions on whether to start using NRT. Although adherence with NRT is associated with cessation in pregnant women who are trying to stop smoking (Raupach 2014), the trials included in the effectiveness review did not consistently or clearly report NRT adherence outcomes, so we have not attempted to relate QES findings to these. Instead, we have investigated the extent to which RCTs reported using interventions, which were consistent with the key qualitative issues experienced by women in relation to NRT use in pregnancy. We suggest that future RCTs might encourage women's adherence to NRT by providing consistent and clear advice on NRT, which addresses any fears about nicotine use in pregnancy and offering a choice of NRT types.

\section{Overall completeness and applicability of the evidence Populations explored}

All studies involved pregnant women who had experience smoking during pregnancy. Not all participants had experience using NRT or e-cigarettes, so some studies provided insight into how women who smoked, but had not used NRT or e-cigarettes, perceived these. Most studies did not mention the socioeconomic characteristics of study participants; however, when reported, participants were described as coming from disadvantaged backgrounds, which is consistent with smoking during pregnancy being strongly associated with maternal deprivation.

\section{Geographical context}

All identified studies were conducted in high-income, predominantly English-speaking countries, and there are gaps in perspectives of women living in low- and middle-income countries. Rates of smoking in pregnancy were around $10 \%$ in the included countries (Bar-Zeev 2018; Drake 2018; Lange 2018; NHS Digital 2019) which is higher than global prevalence of $1.7 \%(95 \% \mathrm{Cl} 0.0$ to 4.5) (Lange 2018), so understanding barriers to using smoking cessation or harm reduction aids such as NRT and e-cigarettes in this context is important. All countries where studies took place had guidelines recommending use of NRT by pregnant women who were unable to quit without pharmacological support. However, for e-cigarettes they had environments of varying permissiveness. For example, UK health experts recommend that health professionals should support women who wish to use e-cigarettes to quit smoking, especially where other methods have failed (Smoking in Pregnancy Challenge Group 2019), while in some places, such as New South Wales (Australia), nicotine-containing e-cigarettes were illegal (NSW Government 2019). Studies investigating e-cigarette use were all set in either the UK or USA.

\section{Time of data collection}

NRT studies took place between 2002 and 2018, with most completed within the last five years of this period. These offer contemporary evidence whilst also providing an understanding of how views on NRT might have changed as the evidence base for using this in pregnancy has grown. For example, studies conducted before 2010 cited the lack of evidence for the safety of NRT in pregnancy as a barrier to NRT use more forcefully. Compared to NRT, e-cigarettes have been brought to market more recently, so studies included in the QES were also very recent and revealed that women's views on using e-cigarettes were less consistent, with much more uncertainty about safety.

\section{Confidence in the findings}

We used GRADE-CERQual to assess confidence in findings. Of the 11 findings related to NRT, we had high confidence in 4 and moderate confidence in 7. Of the seven findings related to e-cigarettes, one was of high confidence, four of moderate confidence, and two of low confidence. Lower confidence in e-cigarette findings was attributable to there being fewer studies and data. When studies contributing to a finding came from only one country or from a few very similar countries, we downgraded findings for relevance issues. We most frequently downgraded findings for adequacy when few studies contributed to the finding or those that did contributed only small amounts of data. We deemed the overall quality of the included studies acceptable, and while we detected some methodological issues, such as insufficient reporting of data collection or data analysis, we felt that these were rarely severe enough to significantly affect confidence in findings. Consequently, we noted only minor/moderate concerns due to methodological issues. We noted issues with coherence when there were opposing cases within a theme; these were usually minor.

\section{Agreements and disagreements with other studies or reviews}

To our knowledge, there are no qualitative systematic reviews investigating determinants of NRT and e-cigarette uptake and use in pregnancy; however, there are some similarities between our study and others. A qualitative systematic review including 38 studies provided insights into the determinants of smoking cessation in pregnant women, and some findings are similar (Flemming 2015). For example, the authors of that review also found that health professionals' advice could be perceived as a barrier or facilitator to successful cessation in pregnancy. They noted that pregnant women perceived consistently supportive interactions with their health professionals to be a facilitator to smoking cessation and that negative or ambivalent attitudes, halfhearted support, and insufficient practical help served as barriers to successful quit attempts. Similar to QES findings, women in this review also reported their desire to protect their baby as a motivator to change their smoking behaviour (Flemming 2015).

Another qualitative systematic review investigated the barriers and facilitators to delivering effective smoking advice from health professionals' perspective (Flemming 2016). Health professionals (predominantly midwives, health visitors and obstetricians) recognised that helping pregnant women quit smoking was a key part of their role. However, they also believed that their wishes to maintain positive relationships with women could make this task difficult. This and other barriers could lead to health professionals addressing women's smoking inconsistently or with mixed messages, such as advising women to cut down rather than stop smoking completely. Women's desire to protect their babies was also an identified facilitator to delivering support;

Factors influencing the uptake and use of nicotine replacement therapy and e-cigarettes in pregnant women who smoke: a qualitative 
health professionals felt more confident when delivering smoking cessation messages that included the benefits of quitting for the baby.

A recent qualitative study in 26 UK health professionals who deliver smoking cessation in pregnancy focused on how health professionals' believe their support and advice about using NRT can influence pregnant women's use of this (Thomson 2019). A reported barrier to women's NRT use was women receiving misinformation about NRT safety or appropriateness from friends, family, and health professionals. Similar to findings from this QES, participants also noted that pregnant women's past negative experiences with NRT could deter them from using this. Professionals reported a belief that when women overestimated the effects of NRT and underestimated the importance of willpower, their quit attempts were more likely to fail.

There was only sparse literature on the determinants of e-cigarette use in pregnancy, presumably because these are relatively new products. There are no published effectiveness trials of e-cigarettes in pregnancy, although one is underway (Hajek 2019b). One nonsystematic review of qualitative and quantitative studies from the USA investigating women's views on e-cigarette use in pregnancy included seven studies (McCubbin 2017): four qualitative (two included in this QES) and three cross-sectional surveys. The authors concluded that while participants believed e-cigarettes were generally safer than smoking, they were less certain about their safety in pregnancy, which echoes findings of this QES. The authors noted the scarcity of the evidence and highlighted the need for further research in this field.

\section{Limitations of the qualitative evidence findings}

Most studies contributed few relevant data to the findings of this review. Data from primary studies were relatively limited, with few studies contributing rich data to help answer study questions and some only contributing very small amounts. Very few studies of either NRT or e-cigarettes specifically investigated determinants of use. Furthermore, most did not state a theoretical perspective, and findings were mostly presented at the manifest level of the data. This made it challenging to move beyond primary studies' findings, so analytical themes remain close to descriptive ones. Most evidence came from UK-based studies, and two studies from the USA and Australia substantially supported their findings. Few studies reported findings on determinants of e-cigarette use, and therefore some identified determinants of NRT use (e.g. beliefs about addictiveness or side effects) were not found within the available data to apply to e-cigarettes. It is possible that with more studies focusing specifically on determinants of NRT or e-cigarette use in pregnancy, additional determinants could be identified. Furthermore, the available evidence was insufficient to detect all differences in determinants of NRT and e-cigarette use. Undescribed differences may exist due to diverse ways of obtaining and/or accessing NRT and e-cigarettes, as well as varying social and cultural perceptions of these products. For example, in the UK, unusually, e-cigarette use is encouraged in non-pregnant people for harm reduction, but in pregnancy it is only encouraged to help women stop smoking when they cannot do so using other means (Smoking in Pregnancy Challenge Group 2019). In some other countries, for example Canada and Australia, nicotine-containing e-cigarettes are banned or restricted (Yong 2017). This division within the public health community regarding views on safety of ecigarettes as nicotine replacement/harm reduction products versus a product that may be harmful and addictive in its own right, may further contribute to the scarcity of the evidence base.

The included studies had some methodological limitations. Most did not use a theoretical perspective to guide the data collection and analysis, and findings were typically presented at the manifest level of the data. We also noted some issues with reporting of researchers' reflexivity, data collection, analysis, and sample characteristics. Overall, studies were of acceptable quality; however, these methodological issues could potentially pose a threat to the reliability and validity of the findings of included studies (Morse 2002).

We also note limitations relating to quality assessment in reviews of qualitative studies. There is still some controversy surrounding quality assessment tools for qualitative studies, and the methodology is developing (Noyes 2018; Santiago-Delefosse 2016). The current guidance suggests that scores for quality assessment in qualitative studies are meaningless (Munthe-Kaas 2018; Noyes 2018). Instead, review authors should report the methodological limitations of primary studies with an indication how these limitations can impact the interpretation of findings.

\section{AUTHORS' CONCLUSIONS}

\section{Implications for practice}

Clear, consistent messages from health professionals about the relative safety and effectiveness of NRT or e-cigarettes compared to smoking could potentially improve women's uptake and adherence to these products and may help some women to stop smoking. Furthermore, information on the most effective ways of using these products could also potentially improve adherence and increase smoking cessation.

\section{Implications for further research}

To better understand pregnant women's decisions to use and adhere to NRT and e-cigarettes, future qualitative studies that specifically address determinants of use are needed. To understand more about pregnant trial participant's adherence to NRT and e-cigarettes, trials should be accompanied by qualitative studies that aim to understand factors influencing adherence to NRT and/ or e-cigarettes. Interview studies, focus groups, and case studies could help shed light on this issue. Furthermore, a strong evidence base for the safety of NRT and/or e-cigarettes in pregnancy could enable health professionals to more confidently deliver messages about their safety. Needed research includes rigorously conducted randomised control trials, with follow-up past childbirth in order to track pregnancy and infant outcomes. Care should also be taken to ensure that practitioners routinely collect data on exposure to NRT, e-cigarettes and smoking to enable accurate outcomes in studies using routine data. The findings of this QES point to an apparent gap in evidence, which should be addressed by more research in low- and middle-income countries, as well as countries where smoking prevalence in pregnancy is the highest, for example in Ireland or Bulgaria (Lange 2018).

\section{ACK N O WLEDGEMENTS}

This project received funding through a National Institute for Health Research (NIHR) Programme for Applied Research (Programme number RP-PG-0615-20003). Professor Coleman is a National Institute for Health Research (NIHR) Senior Investigator. The views 
expressed are those of the author(s) and not necessarily those of the NIHR or the Department of Health and Social Care. We also gratefully acknowledge the funding from the National Institute for Health and Care Excellence (NICE).

This review was published in collaboration with the Cochrane Tobacco Addiction Group, Cochrane Qualitative and Implementation Methods Group, and Cochrane's Editorial and Methods Department (EMD) Editorial Service. Helen Wakeford made comments on the review and managed the editorial process. We gratefully acknowledge Information Specialist Anne
Parkhill for her assistance with the literature searches. Information Specialist Robin Featherstone provided additional guidance on the conduct and reporting of our search methods. We would also like to acknowledge guidance on evidence synthesis provided by Ruth Garside, Cochrane Qualitative and Implementation Methods Group.

We would like to thank the peer reviewers Jane Noyes, Kate Flemming, Caitlin Notley and Gregory Hartwell for their helpful feedback, Lisa Bero and Paul Aveyard for acting as sign-off editors and Meggan Harris for copy-editing the review. 


\section{REFERE N CE S}

\section{References to studies included in this review}

Ashwin 2010 \{published data only\}

Ashwin C, Watts K. Exploring the views of women on using nicotine replacement therapy in pregnancy. Midwifery 2010; 26(4):401-6.

\section{Bauld 2017 \{published data only\}}

Bauld L, Graham H, Sinclair L, Flemming K, Naughton F, Ford A, et al. Barriers to and facilitators of smoking cessation in pregnancy and following childbirth: literature review and qualitative study. Health Technology Assessment 2017; 21(36):1-158. [DOI: 10.3310/hta21360]

Borland 2013 \{published data only\}

Borland T, Babayan A, Irfan S, Schwartz R. Exploring the adequacy of smoking cessation support for pregnant and postpartum women. BMC Public Health 2013; 13:472.

\section{Bovill 2018 \{published data only\}}

Bovill M, Gruppetta M, Cadet-James Y, Clarke M, Bonevski B, Gould GS. Wula (Voices) of Aboriginal women on barriers to accepting smoking cessation support during pregnancy: Findings from a qualitative study. Women and Birth: Journal of the Australian College of Midwives 2018; 31(1):10-6.

Bowker 2016 \{published data only\}

Bowker K, Campbell KA, Coleman T, Lewis S, Naughton F, Cooper S. Understanding pregnant smokers' adherence to nicotine replacement therapy during a quit attempt: a qualitative study. Nicotine \& Tobacco Research 2016; 18(5):906-12.

\section{Bowker 2018 \{published data only\}}

Bowker K, Orton S, Cooper S, Naughton F, Whitemore R, Lewis $S$, et al. Views on and experiences of electronic cigarettes: a qualitative study of women who are pregnant or have recently given birth. BMC Pregnancy and Childbirth 2018; 18(1):233.

\section{Butterworth 2014 \{published data only\}}

Butterworth SJ, Sparkes E, Trout A, Brown K. Pregnant smokers' perceptions of specialist smoking cessation services. Journal of Smoking Cessation 2014; 9(2):85-97.

\section{England 2016 \{published data only\}}

England LJ, Tong VT, Koblitz A, Kish-Doto J, Lynch MM, Southwell BG. Perceptions of emerging tobacco products and nicotine replacement therapy among pregnant women and women planning a pregnancy. Preventive Medicine Reports 2016; 4:481-5.

\section{Fallin 2016a \{published data only\}}

Fallin A, Miller A, Ashford K. Smoking among pregnant women in outpatient treatment for opioid dependence: a qualitative Inquiry. Nicotine \& Tobacco Research 2016; 18(8):1727-32.

Fallin 2016b \{published data only\}

Fallin A, Miller A, Assef S, Ashford K. Perceptions of electronic cigarettes among medicaid-eligible pregnant and postpartum women. Journal of Obstetric, Gynecologic \& Neonatal Nursing 2016; 45(3):320-5.

\section{Gamble 2015 \{published data only\}}

Gamble J, Grant J, Tsourtos G. Missed opportunities: a qualitative exploration of the experiences of smoking cessation interventions among socially disadvantaged pregnant women. Women and Birth 2015; 28(1):8-15.

\section{Glover 2012 \{published data only\}}

Glover M, Kira A. Pregnant Māori smokers' perception of cessation support and how it can be more helpful. Journal of Smoking Cessation 2012; 7(2):65-71.

\section{Grant 2020 \{published data only\}}

Grant A, Morgan M, Gallagher D, Mannay D. Smoking during pregnancy, stigma and secrets: visual methods exploration in the UK. Women and Birth 2020; 33(1):70-6. [DOI: 10.1016/ j.wombi.2018.11.012]

\section{Hauck 2013 \{published data only\}}

Hauck Y, Ronchi F, Lourey B, Lewis L. Challenges and enablers to smoking cessation for young pregnant Australian women: a qualitative study. Birth 2013; 40(3):202-8.

\section{Herbec 2014 \{published data only\}}

Herbec A, Beard E, Brown J, Gardner B, Tombor I, West R. The needs and preferences of pregnant smokers regarding tailored Internet-based smoking cessation interventions: a qualitative interview study. BMC Public Health 2014; 14:1070.

Hotham 2002 \{published data only\}

Hotham ED, Atkinson ER, Gilbert AL. Focus groups with pregnant smokers: barriers to cessation, attitudes to nicotine patch use and perceptions of cessation counselling by care providers. Drug \& Alcohol Review 2002; 21(2):163-8.

\section{Mantzari 2012 \{published data only\}}

Mantzari E, Vogt F, Marteau TM. The effectiveness of financial incentives for smoking cessation during pregnancy: is it from being paid or from the extra aid? BMC Pregnancy and Childbirth 2012; 12:24.

\section{Naughton 2013 \{published data only\}}

Naughton F, Eborall H, Sutton S. Dissonance and disengagement in pregnant smokers: a qualitative study. Journal of Smoking Cessation 2013; 8(01):24-32.

\section{Pledger 2015 \{published data only\}}

Pledger AB. Exploring the experiences of pregnant women using an NHS stop smoking service: a qualitative study. Perspectives in Public Health 2015; 135(3):138-44.

\section{Radley 2013 \{published data only\}}

Radley A, Ballard P, Eadie D, MacAskill S, Donnelly L, Tappin D. Give It Up For Baby: outcomes and factors influencing uptake of a pilot smoking cessation incentive scheme for pregnant women. BMC Public Health 2013; 13:343. 
Taylor 2010 \{published data only\}

Taylor J. Beliefs about NHS Stop Smoking Services and Nicotine Replacement Therapy in Pregnancy: Exploring the Potential Role of the Theory of Planned Behaviour in Promoting Uptake of Smoking Cessation Services [PhD thesis]. Nottingham (UK): University of Nottingham, 2010.

\section{References to studies excluded from this review}

Anderson 2002 \{published data only\}

Anderson $\mathrm{RH}$. Making the sale: communicating the importance of smoking cessation to pregnant patients. West Virginia Medical Journal 2002; 98(1):18-21.

Ashford 2008 \{published data only\}

Ashford K. Successful postpartum smoking abstinence. Southern Online Journal of Nursing Research 2008; 8(2):1p-p.

Ashford 2011 \{published data only\}

Ashford K, Hahn E, Hall L, Peden AR, Rayens MK. Postpartum smoking abstinence and smoke-free environments. Health Promotion Practice 2011; 12(1):126-34.

\section{Askew 2019 \{published data only\}}

Askew DA, Guy J, Lyall V, Egert S, Rogers L, Pokino LA, et al. A mixed methods exploratory study tackling smoking during pregnancy in an urban Aboriginal and Torres Strait Islander primary health care service. BMC Public Health 2019; 19:343.

\section{Balwicki 2017 \{published data only\}}

Balwicki L, Smith DM, Pierucka M, Goniewicz ML, ZarzecznaBaran M, Jedrzejczyk T, et al. Factors associated with quitting among smoking pregnant women from small town and rural areas in Poland. Nicotine \& Tobacco Research 2017; 19(5):647-51.

\section{Bottorff 2006 \{published data only\}}

Bottorff JL, Kalaw C, Johnson JL, Stewart M, Greaves L, Carey J. Couple dynamics during women's tobacco reduction in pregnancy and postpartum. Nicotine \& Tobacco Research 2006; 8(4):499-509.

\section{Britton 2017 \{published data only\}}

Britton GR, Collier R, McKitrick S, Sprague LM, Rhodes-Keefe J, Feeney $A$, et al. CE: original research: the experiences of pregnant smokers and their providers. American Journal of Nursing 2017; 117(6):24-34.

\section{Bryce 2009 \{published data only\}}

Bryce A, Butler C, Gnich W, Sheehy C, Tappin DM. CATCH: development of a home-based midwifery intervention to support young pregnant smokers to quit. Midwifery 2009; 25(5):473-82.

\section{Bull 2007 \{published data only\}}

Bull L, Burke R, Walsh S, Whitehead E. Social attitudes towards smoking in pregnancy in East Surrey: a qualitative study of smokers, former smokers and non-smokers. Journal of Neonatal Nursing 2007; 13(3):100-6.
Bull 2008 \{published data only\}

Bull L, Burke R, Walsh S, Whitehead E. The perceived effectiveness of smoking cessation interventions aimed at pregnant women: a qualitative study of smokers, former smokers and non-smokers. Journal of Neonatal Nursing 2008; 14(3):72-8.

Colomar 2015 \{published data only\}

Colomar M, Tong VT, Morello P, Farr SL, Lawsin C, Dietz PM, et al. Barriers and promoters of an evidenced-based smoking cessation counseling during prenatal care in Argentina and Uruguay. Maternal and Child Health Journal 2015; 19(7):1481-9.

Constantine 2014 \{published data only\}

Constantine NA, Slater JK, Carroll JA, Antin TMJ. Smoking cessation, maintenance, and relapse experiences among pregnant and postpartum adolescents: a qualitative analysis. Journal of Adolescent Health 2014; 55(2):216-21.

\section{Cottrell 2007 \{published data only\}}

Cottrell L, Gibson M, Harris C, Rai A, Sobhan S, Berry T, et al. Examining smoking and cessation during pregnancy among an Appalachian sample: a preliminary view. Substance Abuse Treatment, Prevention, and Policy 2007; 2:14. [DOI: 10.1186/1747-597X-2-14]

\section{Davidson-Harden 2009 \{published data only\}}

Davidson-Harden J. Predicting Smoking Behaviour among Pregnant Smokers Using the Reasons Model and Selfdetermination Theory. Waterloo (Canada): University of Waterloo, 2009.

\section{Edwards 1998 \{published data only\}}

Edwards N, Sims-Jones N. Smoking and smoking relapse during pregnancy and postpartum: results of a qualitative study. Birth 1998; 25(2):94-100.

\section{Gillam 2009 \{published data only\}}

Gillam S. Expecting to Quit: An Implementation Evaluation of a Smoking Cessation Intervention for Pregnant and Parenting Women. Montreal (Canada): McGill University, 2009.

\section{Glover 2014 \{published data only\}}

Glover M, Nosa V, Gentles D, Watson D, Paynter J. Do New Zealand Maori and Pacific 'walk the talk' when it comes to stopping smoking? A qualitative study of motivation to quit. Journal of Smoking Cessation 2014; 9(2):68-75.

\section{Goszczynska 2016 \{published data only\}}

Goszczynska E, Knol-Michalowska K, Petrykowska A. How do pregnant women justify smoking? A qualitative study with implications for nurses' and midwives' antitobacco interventions. Journal of Andvanced Nursing 2016; 72(7):1567-78.

\section{Gould 2013 \{published data only\}}

Gould GS, Munn J, Avuri S, Hoff S, Cadet-James Y, McEwen A, et al. "Nobody smokes in the house if there's a new baby in it": Aboriginal perspectives on tobacco smoking in pregnancy and in the household in regional NSW Australia. Women and Birth 2013; 26(4):246-53. 
Gould 2017a \{published data only\}

Gould GS, Bovill M, Clarke MJ, Gruppetta M, Cadet-James Y, Bonevski B. Chronological narratives from smoking initiation through to pregnancy of Indigenous Australian women: a qualitative study. Midwifery 2017; 52:27-33.

Gould 2017b \{published data only\}

Gould GS, Bar-Zeev Y, Bovill M, Atkins L, Gruppetta M, Clarke MJ, et al. Designing an implementation intervention with the Behaviour Change Wheel for health provider smoking cessation care for Australian Indigenous pregnant women. Implementation Science 2017; 12(1):114.

\section{Griffis 2016 \{published data only\}}

Griffis H, Matone M, Kellom K, Concors E, Quarshie W, French B, et al. Home visiting and perinatal smoking: a mixed-methods exploration of cessation and harm reduction strategies. BMC Public Health 2016; 16(1):764.

\section{Haslam 2001 \{published data only\}}

Haslam C, Draper ES. A qualitative study of smoking during pregnancy. Psychology, Health \& Medicine 2001; 6(1):95-9.

\section{Herberts 2012 \{published data only\}}

Herberts C, Sykes C. Midwives' perceptions of providing stopsmoking advice and pregnant smokers' perceptions of stopsmoking services within the same deprived area of London. Journal of Midwifery \& Women's Health 2012; 57(1):67-73.

\section{Hoek 2014 \{published data only\}}

Hoek J, Gifford H, Maubach N, Newcombe R. A qualitative analysis of messages to promote smoking cessation among pregnant women. BMJ Open 2014; 4(11):e006716.

\section{Homish 2012 \{published data only\}}

Homish GG, Eiden RD, Leonard KE, Kozlowski LT. Socialenvironmental factors related to prenatal smoking. Addictive Behaviors 2012; 37(1):73-7.

\section{Hotham 2005 \{published data only\}}

Hotham ED, Gilbert AL, Atkinson ER. Case studies of three pregnant smokers and their use of nicotine replacement therapy. Midwifery 2005; 21(3):224-32.

\section{Howard 2013 \{published data only\}}

Howard LM, Bekele D, Rowe M, Demilew J, Bewley S, Marteau TM. Smoking cessation in pregnant women with mental disorders: a cohort and nested qualitative study. BJOG: An International Journal of Obstetrics and Gynaecology 2013; 120(3):362-70.

\section{Kahr 2015 \{published data only\}}

Kahr MK, Padgett S, Shope CD, Griffin EN, Xie SS, Gonzalez PJ, et al. A qualitative assessment of the perceived risks of electronic cigarette and hookah use in pregnancy. BMC Public Health 2015; 15:1273.

\section{Kennison 2003 \{published data only\}}

Kennison LH. Smoking \& Pregnancy: Reconciling Incompatibilities. Florida (US): University of Florida, 2003.
Koshy 2010 \{published data only\}

Koshy P, Mackenzie M, Tappin D, Bauld L. Smoking cessation during pregnancy: the influence of partners, family and friends on quitters and non-quitters. Health \& Social Care in the Community 2010; 18(5):500-10.

Lawson 1991 \{published data only\}

Lawson EJ. Smoking and Smoking Cessation Among Lowincome Pregnant Adolescents. Lexington (KY): University of Kentucky, 1991.

\section{Lowry 2004 \{published data only\}}

Lowry RJ, Hardy S, Jordan C, Wayman G. Using social marketing to increase recruitment of pregnant smokers to smoking cessation service: a success story. Public Health 2004; 118(4):239-43.

\section{Mann 2018 \{published data only\}}

Mann R, Faflik F. Survey of smoking cessation services and pregnant women's views on use of electronic cigarettes in pregnancy. Journal of Health Visiting 2018; 6(1):32-9.

\section{Maubach 2013 \{published data only\}}

Maubach N, Hoek JA, Edwards R, Gifford H, Erick S, Newcombe R. 'The times are changing': New Zealand smokers' perceptions of the tobacco endgame. Tobacco Control 2013; 22(6):395-400.

\section{McCurry 2002 \{published data only\}}

McCurry N, Thompson K, Parahoo K, O'Doherty E, Doherty A. Pregnant women's perception of the implementation of smoking cessation advice. Health Education Journal 2002; 61(1):20-31.

McLeod 2003 \{published data only\}

McLeod D, Benn C, Pullon S, Viccars A, White S, Cookson T, et al. The midwife's role in facilitating smoking behaviour change during pregnancy. Midwifery 2003; 19(4):285-97.

\section{Modeste 2004 \{published data only\}}

Modeste N, Lee J, Lim VJ, Anjejo D. Factors associated with intention to quit smoking among African American pregnant women. Californian Journal of Health Promotion 2004; 2(1):98-106.

\section{Naughton 2013a \{published data only\}}

Naughton F, Jamison J, Sutton S. Attitudes towards SMS text message smoking cessation support: a qualitative study of pregnant smokers. Health Education Research 2013; 28(5):911-22.

\section{Nguyen 2012 \{published data only\}}

Nguyen SN, Von Kohorn I, Schulman-Green D, Colson ER. The importance of social networks on smoking: perspectives of women who quit smoking during pregnancy. Maternal and Child Health Journal 2012; 16(6):1312-8.

\section{Park 2009 \{published data only\}}

Park ER, Chang Y, Quinn VP, Ross K, Rigotti NA. Perceived support to stay quit: what happens after delivery? Addictive Behaviors 2009; 34(12):1000-4.

Factors influencing the uptake and use of nicotine replacement therapy and e-cigarettes in pregnant women who smoke: a qualitative 
Passey 2018 \{published data only\}

Passey M, Stirling J. Evaluation of 'Stop Smoking in its Tracks': an intensive smoking cessation program for pregnant Aboriginal women incorporating contingency-based financial rewards. Public Health Research \& Practice 2018; 28(2):e28011804.

\section{Petersen 2010 \{published data only\}}

Petersen Z, Steyn K, Everett-Murphy K, Emmelin M. Pregnant women's responses to a tailored smoking cessation intervention: turning hopelessness into competence. Global Health Action 2010; 3(1):5379.

\section{Pletsch 1996 \{published data only\}}

Pletsch PK, Johnson MK. The cigarette smoking experience of pregnant Latinas in the United States. Health Care for Women International 1996; 17(6):549-62.

\section{Pletsch 2003 \{published data only\}}

Pletsch PK, Morgan S, Pieper AF. Context and beliefs about smoking and smoking cessation. MCN: The American Journal of Maternal Child Nursing 2003; 28(5):320-5.

\section{Pletsch 2004 \{published data only\}}

Pletsch PK, Kratz AT. Why do women stop smoking during pregnancy? Cigarettes taste and smell bad. Health Care for Women International 2004; 25(7):671-9.

\section{Quinn 2006 \{published data only\}}

Quinn G, Ellison BB, Meade C, Roach CN, Lopez E, Albrecht T, et al. Adapting smoking relapse-prevention materials for pregnant and postpartum women: formative research. Maternal and Child Health Journal 2006; 10(3):235-45.

\section{Ronchi 2018 \{published data only\}}

Ronchi F, Lewis L, Hauck YL, Doherty DA. Exploring young pregnant smokers' experiences with a self-nominated nonsmoking buddy. Midwifery 2018; 59:68-73.

\section{Tod 2003 \{published data only\}}

Tod AM. Barriers to smoking cessation in pregnancy: a qualitative study. British Journal of Community Nursing 2003; 8(2):56-64.

\section{Wigginton 2017 \{published data only\}}

Wigginton B, Gartner C, Rowlands I. Is it safe to vape? Analyzing online forums discussing e-cigarette use during pregnancy. Women's Health Issues 2017; 27(1):93-9.

\section{Wood 2008 \{published data only\}}

Wood L, France K, Hunt K, Eades S, Slack-Smith L. Indigenous women and smoking during pregnancy: knowledge, cultural contexts and barriers to cessation. Social Science and Medicine 2008; 66(11):2378-89.

\section{Wu 2017 \{published data only\}}

Wu J, Tombor I, Shahab L, West R. Usability testing of a smoking cessation smartphone application ('SmokeFree Baby'): a thinkaloud study with pregnant smokers. Digital Health 2017; 3:1-9. [DOI: 10.1177/2055207617704273]

\section{Additional references \\ ACOG 2017 \\ ACOG: the American College of Obstetrics and Gyneacology 2017. Committee Opinion No.721 Smoking Cessation during Pregnancy. acog.org/Clinical-Guidance-and-Publications/ Committee-Opinions/Committee-on-Obstetric-Practice/ Smoking-Cessation-During-Pregnancy (accessed 1 February 2019).}

\section{Ames 2019}

Ames $\mathrm{H}$, Glenton C, Lewin S. Purposive sampling in a qualitative evidence synthesis: a worked example from a synthesis on parental perceptions of vaccination communication. BMC Medical Research Methodology 2019; 19(1):26.

\section{Bar-Zeev 2018}

Bar-Zeev Y, Lim LL, Bonevski B, Gruppetta M, Gould GS. Nicotine replacement therapy for smoking cessation during pregnancy. Medical Journal of Australia 2018; 208(1):46-51.

\section{Barnett-Page 2009}

Barnett-Page E, Thomas J. Methods for the synthesis of qualitative research: a critical review. BMC Medical Research Methodology 2009; 9(1):59.

\section{Berlin 2014}

Berlin I, Grangé G, Jacob N, Tanguy ML. Nicotine patches in pregnant smokers: randomised, placebo controlled, multicentre trial of efficacy. BMJ 2014; 348:g1622.

\section{Breland 2019}

Breland A, McCubbin A, Ashford K. Electronic nicotine delivery systems and pregnancy: Recent research on perceptions, cessation, and toxicant delivery. Birth Defects Research 2019; 111(17):1287-93.

\section{CAN-ADAPTT 2011}

. Canadian Smoking Cessation Clinical Practice Guidelines: Summary Statements; 2011. Canadian Action Network for the Advancement, Dissemination and Adoption of Practiceinformed Tobacco Treatment, Centre for Addiction and Mental Health; Available at www.can-adaptt.net (accessed prior to 8 May 2020).

\section{Chamberlain 2017}

Chamberlain C, O'Mara-Eves A, Porter J, Coleman T, , Thomas J, . Psychosocial interventions for supporting women to stop smoking in pregnancy. Cochrane Database of Systematic Reviews 2017, Issue 2. [DOI: 10.1002/14651858.CD001055.pub5]

\section{Claire 2020}

Claire R, Chamberlain C, Davey MA, Cooper SE, Berlin I, Leonardi-Bee J, Coleman T. Pharmacological interventions for promoting smoking cessation during pregnancy. Cochrane Database of Systematic Reviews 2020, Issue 3. [DOI: 10.1002/14651858.CD010078.pub3] 


\section{Cnattingius 2004}

Cnattingius S. The epidemiology of smoking during pregnancy: smoking prevalence, maternal characteristics, and pregnancy outcomes. Nicotine and Tobacco Research 2004; 6(S2):S125-S40.

\section{Coleman 2012}

Coleman T, Cooper S, Thornton JG, Grainge MJ, Watts K, Britton J, et al. A randomized trial of nicotine-replacement therapy patches in pregnancy. New England Journal of Medicine 2012; 366(9):808-18.

\section{Coleman 2015}

Coleman T, Chamberlain C, , Cooper Sue E, LeonardiBee J. Pharmacological interventions for promoting smoking cessation during pregnancy. Cochrane Database of Systematic Reviews 2015, Issue 12. [DOI: 10.1002/14651858.CD010078.pub2]

\section{Cooper 2014}

Cooper S, Taggar J, Lewis S, Marlow N, Dickinson A, Whitemore $\mathrm{R}$, et al. Effect of nicotine patches in pregnancy on infant and maternal outcomes at 2 years: follow-up from the randomised, double-blind, placebo-controlled SNAP trial. Lancet Respiratory Medicine 2014; 2(9):728-37.

\section{Cooper 2019}

Cooper S, Orton S, Campbell K, Ussher M, Coleman-Haynes N, Whitemore R, et al. Attitudes to e-cigarettes and cessation support for pregnant women from English stop smoking services: a mixed methods study. International Journal of Environmental Research and Public Health 2019; 16(1):110.

\section{Covidence [Computer program]}

Veritas Health Innovation Covidence. Version accessed 1 February 2019. Melbourne, Australia: Veritas Health Innovation.Available at covidence.org.

\section{Croucher 2003}

Croucher K, Quilgars D, Wallace A, . Paying the Mortgage: A Systematic Literature Review of Safety Nets for Homeowners. University of York, Department of Social Policy and Social Work, 2003. Available at www.york.ac.

\section{Dhalwani 2014}

Dhalwani NN, Szatkowski L, Coleman T, Fiaschi L, Tata LJ. Prescribing of nicotine replacement therapy in and around pregnancy: a population-based study using primary care data. British Journal of General Practice 2014; 64(626):e554-60.

\section{Drake 2018}

Drake P, Driscoll A, Mathews T. Cigarette smoking during pregnancy: United States, 2016. Hyattsville (MD): National Center for Health Statistics, 2018. NCHS Data Brief, no 305. [https://www.cdc.gov/nchs/data/databriefs/db305.pdf]

\section{El-Mohandes 2013}

El-Mohandes AA, Windsor R, Tan S, Perry DC, Gantz MG, Kiely M. A randomized clinical trial of trans-dermal nicotine replacement in pregnant African-American smokers. Maternal and Child Health Journal 2013; 17(5):897-906.

\section{EndNote X8 [Computer program]}

EndNote X8. Clarivate Analytics, 2016.Available at endnote.com.

\section{Filippidis 2016}

Filippidis FT, Laverty AA, Gerovasili V, Vardavas Cl. Two-year trends and predictors of e-cigarette use in 27 European Union member states. Tobacco Control 2016; 26(1):98-104.

\section{Flemming 2015}

Flemming K, McCaughan D, Angus K, Graham H. Qualitative systematic review: barriers and facilitators to smoking cessation experienced by women in pregnancy and following childbirth. Journal of Advanced Nursing 2015; 71(6):1210-26.

\section{Flemming 2016}

Flemming K, Graham H, McCaughan D, Angus K, Sinclair L, Bauld L. Health professionals' perceptions of the barriers and facilitators to providing smoking cessation advice to women in pregnancy and during the post-partum period: a systematic review of qualitative research. BMC Public Health 2016; 16(1):290.

\section{Gravely 2014}

Gravely S, Fong GT, Cummings KM, Yan M, Quah ACK, Borland R, et al. Awareness, trial, and current use of electronic cigarettes in 10 countries: findings from the ITC Project. International Journal of Environmental Research and Public Health 2014; 11(11):11691.

\section{Hajek 2019a}

Hajek P, Phillips-Waller A, Przulj D, Pesola F, Myers Smith K, Bisal N, et al. A randomized trial of e-cigarettes versus nicotinereplacement therapy. New England Journal of Medicine 2019; 380(7):629-37.

\section{Hajek 2019b}

Hajek P, Przulj D, Naughton F, Myers Smith K, Cooper S, Sinclair $L$, et al. Helping pregnant smokers quit: multicentre RCT of electronic cigarettes vs usual care. journalslibrary.nihr.ac.uk/programmes/hta/155785\#/ (accessed 20 November 2019).

\section{Hartmann-Boyce 2016}

Hartmann-Boyce J, McRobbie H, Bullen C, Begh R, Stead LF, Hajek P. Electronic cigarettes for smoking cessation.

Cochrane Database of Systematic Reviews 2016, Issue 9. [DOI: 10.1002/14651858.CD010216.pub3]

\section{Hartmann-Boyce 2018}

Hartmann-Boyce J, Chepkin SC, Ye W, Bullen C, Lancaster T. Nicotine replacement therapy versus control for smoking cessation. Cochrane Database of Systematic Reviews 2018, Issue 5. [DOI: 10.1002/14651858.CD000146.pub4]

\section{Hickson 2018}

Hickson C, Lewis S, Campbell KA, Cooper S, Berlin I, Claire R, et al. Comparison of nicotine exposure during pregnancy when smoking and abstinent with nicotine replacement therapy: systematic review and meta-analysis. Addiction 2018; 114(3):406-24. 


\section{Hollands 2013}

Hollands GJ, Sutton S, McDermott MS, Marteau TM, Aveyard P. Adherence to and consumption of nicotine replacement therapy and the relationship with abstinence within a smoking cessation trial in primary care. Nicotine \& Tobacco Research 2013; 15(9):1537-44.

\section{Hotham 2006}

Hotham ED, Gilbert AL, Atkinson ER. A randomised-controlled pilot study using nicotine patches with pregnant women. Addictive Behaviors 2006; 31(4):641-8.

\section{Husk 2016}

Husk K, Lovell R, Cooper C, Stahl-Timmins W, Garside R. Participation in environmental enhancement and conservation activities for health and well-being in adults: a review of quantitative and qualitative evidence. Cochrane Database of Systematic Reviews 2016, Issue 5. [DOI: 10.1002/14651858.CD010351.pub2]

\section{IARC 2004}

International Agency for Research on Cancer. IARC Monographs on the Evaluation of Carcinogenic Risks to Humans. Volume 83: Tobacco Smoke and Involuntary Smoking. Lyon: World Health Organization, IARC, 2004.

\section{Kapaya 2019}

Kapaya M, Denise VD, Tong VT, England L, Ruffo N, Cox S, et al. Use of electronic vapor products before, during, and after pregnancy among women with a recent live birth - Oklahoma and Texas, 2015. Morbidity and Mortality Weekly Report 2019; 68(8):189-94.

\section{Kapur 2001}

Kapur B, Hackman R, Selby P, Klein J, Koren G. Randomized, double-blind, placebo-controlled trial of nicotine replacement therapy in pregnancy. Current Therapeutic Research-Clinical and Experimental 2001; 62(4):274-8.

\section{Kurti 2017}

Kurti AN, Redner R, Lopez AA, Keith DR, Villanti AC, Stanton CA et al. Tobacco and nicotine delivery product use in a national sample of pregnant women. Preventive Medicine 2017; 104:50-6.

\section{Lange 2018}

Lange S, Probst C, Rehm J, Popova S. National, regional, and global prevalence of smoking during pregnancy in the general population: a systematic review and meta-analysis. Lancet Global Health 2018; 6(7):e769-e76.

\section{Leonardi-Bee 2011}

Leonardi-Bee J, Jere ML, Britton J. Exposure to parental and sibling smoking and the risk of smoking uptake in childhood and adolescence: a systematic review and meta-analysis. Thorax 2011; 66(10):847-55.

\section{Lewin 2015}

Lewin S, Glenton C, Munthe-Kaas H, Carlsen B, Colvin CJ, Gülmezoglu $\mathrm{M}$, et al. Using qualitative evidence in decision making for health and social interventions: an approach to assess confidence in findings from qualitative evidence syntheses (GRADE-CERQual). PLOS Medicine 2015; 12(10):e1001895.

\section{Liu 2019}

Liu B, Xu G, Rong S, Santillan DA, Santillan MK, Snetselaar LG, et al. National estimates of e-cigarette use among pregnant and nonpregnant women of reproductive age in the United States, 2014-2017. JAMA Pediatrics 2019; 173(6):600-2. [DOI: 10.1001/ jamapediatrics.2019.0658]

\section{Mark 2015}

Mark KS, Farquhar B, Chisolm MS, Coleman-Cowger VH, Terplan M. Knowledge, attitudes, and practice of electronic cigarette use among pregnant women. Journal of Addiction Medicine 2015; 9(4):266-72.

\section{McCubbin 2017}

McCubbin A, Fallin-Bennett A, Barnett J, Ashford K. Perceptions and use of electronic cigarettes in pregnancy. Health Education Research 2017; 32(1):22-32.

\section{McNeill 2015}

McNeill A, Brose LS, Calder R, Hitchman SC, Hajek P, McRobbie H. E-cigarettes: an evidence update; a report commissioned by Public Health England; 2015. www.gov.uk/ government/publications/e-cigarettes-an-evidence-update (accessed prior to 8 May 2020).

\section{McNeill 2018}

McNeill A, Brose LS, Calder R, Bauld L, Robson D. E-cigarettes and heated tobacco products: evidence review; Public Health England; 2018. www.gov.uk/government/publications/ecigarettes-and-heated-tobacco-products-evidence-review (accessed prior to 8 May 2020).

\section{Mills 2010}

Mills E, Wu P, Lockhart I, Wilson K, Ebbert JO. Adverse events associated with nicotine replacement therapy (NRT) for smoking cessation. A systematic review and meta-analysis of one hundred and twenty studies involving 177,390 individuals. Tobacco Induced Diseases 2010; 8(1):8.

\section{Mirbolouk 2018}

Mirbolouk M, Charkhchi P, Kianoush S, Uddin SM, Orimoloye OA, Jaber R, et al. Prevalence and distribution of e-cigarette use among U.S. adults: behavioral risk factor surveillance system, 2016. Annals of Internal Medicine 2018; 169(7):429-38.

\section{Morse 2002}

Morse JM, Barrett M, Mayan M, Olson K, Spiers J. Verification strategies for establishing reliability and validity in qualitative research. International journal of qualitative methods 2002; 1(2):13-22.

\section{Munthe-Kaas 2018}

Munthe-Kaas H, Bohren MA, Glenton C, Lewin S, Noyes J, , et al. Applying GRADE-CERQual to qualitative evidence synthesis findings-paper 3: how to assess methodological limitations. Implementation science 2018; 13(Suppl 1):9.

Factors influencing the uptake and use of nicotine replacement therapy and e-cigarettes in pregnant women who smoke: a qualitative 


\section{NHS Digital 2019}

NHS Digital. Statistics on Women's Smoking Status at Time of Delivery, England, Quarter 2, 2019-20. Available at digital.nhs.uk/data-and-information/publications/statistical/ statistics-on-women-s-smoking-status-at-time-of-deliveryengland/statistics-on-womens-smoking-status-at-time-ofdelivery-england-quarter-2-2019-20.

\section{NICE 2010}

National Institute for Health and Clinical Excellence (NICE). Quitting smoking in pregnancy and following childbirth. NICE Public Health Guidance 26; 2010. Available at http:// guidance.nice.org.uk/PH26/Guidance/pdf/English.

\section{Noyes 2018}

Noyes J, Booth A, Flemming K, Garside R, Harden A, Lewin S, et al. Cochrane Qualitative and Implementation Methods Group guidance series-paper 3: methods for assessing methodological limitations, data extraction and synthesis, and confidence in synthesized qualitative findings. Journal of Clinical Epidemiology 2018; 97:49-58.

\section{NSW Government 2019}

. Electronic cigarettes. https://wwwhealthnswgovau/tobacco/ Pages/e-cigarettesaspx (accessed on 12 November 2019).

\section{NVivo [Computer program]}

QSR International Pty Ltd. NVivo. Version 12. QSR International Pty Ltd., 2018.Available at www.qrsinternational.com.

\section{NZ Ministry of Health 2014}

Ministry of Health. The New Zealand guidelines for helping people to stop smoking. www.health.govt.nz/publication/newzealand-guidelines-helping-people-stop-smoking (accessed on 1 February 2019).

\section{Oncken 2008}

Oncken C, Dornelas E, Greene J, Sankey H, Glasmann A, Feinn R, et al. Nicotine gum for pregnant smokers: a randomized controlled trial. Obstetrics \& Gynecology 2008; 112(4):859-67.

\section{Oncken 2019}

Oncken C, Dornelas EA, , Sankey HZ, Kranzler HR, Mead EL, et al. Randomized trial of nicotine inhaler for pregnant smokers. American Journal of Obstetrics \& Gynecology MFM 2019; 1(1):19-23.

\section{Pollak 2007}

Pollak KI, Oncken CA, Lipkus IM, Lyna P, Swamy GK, Pletsch PK, et al. Nicotine replacement and behavioral therapy for smoking cessation in pregnancy. American Journal of Preventive Medicine 2007; 33(4):297-305.

\section{Raupach 2014}

Raupach T, Brown J, Herbec A, Brose L, West R. A systematic review of studies assessing the association between adherence to smoking cessation medication and treatment success. Addiction 2014; 109(1):35-43.

\section{Santiago-Delefosse 2016}

Santiago-Delefosse M, Gavin A, Bruchez C, Roux P, Stephen S. Quality of qualitative research in the health sciences: analysis of the common criteria present in 58 assessment guidelines by expert users. Social Science \& Medicine 2016; 148:142-51.

\section{Shahab 2017}

Shahab L, Goniewicz ML, Blount BC, Brown J, McNeill A, Alwis U. Nicotine, carcinogen, and toxin exposure in longterm e-cigarette and nicotine replacement therapy users: a cross-sectional study. Annals of Internal Medicine 2017; 166(6):390-400.

\section{Smoking in Pregnancy Challenge Group 2019}

Smoking in Pregnancy Challenge Group. Use of electronic cigarettes before, during and after pregnancy. A guide for maternity and other healthcare professionals; 2019. smokefreeaction.org.uk/wp-content/uploads/2019/08/2019Challenge-Group-ecigs-briefing-FINAL.pdf (accessed prior to 8 May 2020).

\section{Thomas 2008}

Thomas J, Harden A. Methods for the thematic synthesis of qualitative research in systematic reviews. BMC Medical Research Methodology 2008; 8(1):45.

\section{Thomson 2019}

Thomson R, McDaid L, Emery J, Naughton F, Cooper S, Dyas J, et al. Knowledge and education as barriers and facilitators to nicotine replacement therapy use for smoking cessation in pregnancy: a qualitative study with health care professionals. International Journal of Environmental Research and Public Health 2019; 16(10):1814.

\section{Wallace 2004}

Wallace A, Croucher K, Quilgars D, Baldwin S. Meeting the challenge: developing systematic reviewing in social policy. Policy \& Politics 2004; 32(4):455-70.

\section{West 2019}

West R, Proudfoot H, Mohr G, Beard E, Brown J. Trends in electronic cigarette use in England; October 2019. www.smokinginengland.info/sts-documents/ (accessed 1 November 2019).

\section{WHO 2008}

World Health Organization. Report on the Global Tobacco Epidemic - the M-Power Package. Geneva: World Health Organization, 2008.

\section{Wisborg 2000}

Wisborg K, Henriksen TB, Jespersen LB, Secher NJ. Nicotine patches for pregnant smokers: a randomized controlled study. Obstetrics \& Gynecology 2000; 96(6):967-71.

\section{Yong 2017}

Yong HH, Hitchman SC, Cummings KM, Borland R, Gravely SM, McNeill A, et al. Longitudinal findings from the ITC four country survey. Nicotine \& Tobacco Research 2017; 19(11):1268-76. 
CHARACTERISTICS OF STUDIES

Characteristics of included studies [ordered by study ID]

Ashwin 2010

\section{Study characteristics}

Notes

\section{Context:}

UK, urban and rural populations covered by one hospital trust as the lead provider of maternity care

Focus:

NRT

\section{Participants:}

Number of participants: 10

NRT/e-cig use: each participant had used NRT for 1-180 days (average 45)

Maternal status: all pregnant

Most $(n=8)$ used patches (7-15 mg), 2 used gum

Smoking status: no. of cigarettes smoked at the start of pregnancy: 5-20 (range), 5 smoked an average of 20 cigarettes per day

Most $(n=8)$ participants commenced smoking before age 17

Age range: $25-39$ years

\section{Methods:}

Study objectives: to raise professional awareness of women's concerns regarding smoking in pregnancy and the use of NRT

Women were encouraged to offer their views on multiple aspects of NRT use in pregnancy

Study period: not provided

Theoretical perspective: phenomenological theoretical approach

Sampling: a purposive sample of a larger group of women who had previously accessed the local stop smoking service

Data collection and analysis: semi-structured interviews, thematic analysis

\section{Key themes relevant to the review:}

1. Choice of product

2. Thoughts surrounding quit day with NRT

3. Length of time product used

4. Information

5. Anxieties regarding use of NRT

\section{Sources of support}

Employed by/associated with: Academic Division of Midwifery, PGCE, Nottingham University Hospital NHS Trust

Funding: none declared 


\section{Study characteristics}

\section{Notes}

\section{Context:}

UK, urban and rural, area A - Scotland; area B - England

\section{Focus:}

NRT and e-cigarettes

\section{Participants:}

Number of participants: 41

NRT/e-cig use: not reported

Maternal status: all pregnant, 10 interviewed again postpartum

Gestation: mean $=19$ weeks

$15 \%$ reported stopping smoking

All of area $A(n=20)$ and $20 \%$ area B were engaged with stop smoking services by the time of interview 5 participants from each area were interviewed again between 5-12 weeks postpartum but no relevant data

Age at interview: mean 26 years

\section{Methods:}

Study objectives: to explore pregnant women's perspectives and experiences of the barriers to and facilitators of smoking cessation, and elicit their views on existing services and interventions to support cessation

Women offered their views on NRT as part of the wider scope of the interviews.

Study period: November 2013 - December 2014

Theoretical perspective: social-ecological framework theoretical perspective

Sampling: women were recruited through maternity or stop smoking services. For the second interview, purposive sampling was undertaken, taking into account maternal age, deprivation and smoking status (continuing smokers or quitters).

Data collection and analysis: semi-structured interviews, thematic analysis

\section{Key themes relevant to the review:}

1. Nicotine replacement therapy (Chapter 6)

2. Electronic cigarettes (Chapter 11)

\section{Sources of support}

Employed by/associated with: University of Stirling; UK Centre for Tobacco and Alcohol Studies (UKCTAS); University of York; University of East Anglia; University of Cambridge; University of Glasgow

Funding: British Heart Foundation; Cancer Research UK; the Economic and Social Research Council; MRC; NIHR (under UK Clinical Research Collaboration) 
Borland 2013

\section{Study characteristics}

Notes

\section{Context:}

Canada, urban and rural

Focus:

NRT

\section{Participants:}

Number of participants: 29

NRT/e-cig use: not reported

Maternal status: 10 pregnant, 19 postpartum

Smoking status: current/former smokers or making a quit attempt

Age: range $15-49$ years, mean 22.1 years

Education: 21 less than high school, 3 high school, 5 more than high school

Marital status: 18 had a partner, 11 were single

Ethnicity: 11 Aboriginal, 11 white, 4 Black, 1 West Indian, 1 Latin American, 1 not reported

Key informants - individuals with insight into the needs of pregnant or postpartum women who smoke were also interviewed, but are not relevant to this review

\section{Methods:}

Study objectives: to examine cessation needs, barriers to the provision and uptake of cessation support and directions for policy, practice, and programming

Study period: February 2011 - May 2011

Theoretical perspective: unclear

Sampling: participants were purposefully recruited, with promotion through the provincial cessation helpline and gatekeepers working with the target population at local community agencies

Data collection and analysis: semi-structured interviews, thematic interpretive analysis

\section{Key themes relevant to the review:}

1. Inconsistent practice

2. Engagement and acceptability issues

\section{Sources of support}

Employed by/associated with: University of Toronto; Centre for Addiction and Mental Health, Canada Funding: Ontario Ministry of Health and Long-Term Health

\section{Study characteristics}




\section{Focus:}

NRT

\section{Participants:}

Number of participants: 20

NRT/e-cig use: 8 had used or were using medication to help them quit (unclear as to whether this includes NRT)

Maternal status: 6 pregnant ( 1 in first trimester, 2 in second, 3 in the third), 14 recently given birth ( 2 gave birth 5-12 weeks ago; 7 gave birth 3 months to 1 year ago; 2 gave birth over a year ago; 3 = other)

Smoking status: 11 current smokers. Cigarettes per day: 8 smoked $\leq 10,3$ smoked 11-20

10 participants had made at least 1 quit attempt

Age: range $=17-38$ years, mean 27 years

Ethnicity: $100 \%$ Aboriginal or Torres Strait Islander

\section{Methods:}

Study objectives: to privilege the voices of Aboriginal women, smokers and ex-smokers in the Hunter New England area, collecting their experiences of smoking during pregnancy and of receiving smoking cessation care

Study period: August 2015 - January 2016

Theoretical perspective: unclear

Sampling: some participants were recruited through Aboriginal health networks and a smoking cessation trial. The remainder were recruited through use of the researcher's familiarity with Aboriginal community networks, and a university project

Data collection and analysis: therapeutic yarning interviews, inductive thematic analysis

\section{Key themes relevant to the review:}

Attitudes towards NRT

\section{Sources of support}

Employed by/associated with: University of Newcastle, AU; James Cook University, AU; Clarence Specialist Clinic, AU

Funding:

RACGP Family Medical Care, Education and Research Grant

Australian Heart foundation Indigenous Scholarships

NHMRC

Cancer Institute NSW Early Career Research Fellowship

\section{Sources of support}

Employed by/associated with: University of Newcastle, Australia; James Cook University, Australia; Clarence Specialist Clinic, Australia

Funding:

RACGP Family Medical Care, Education and Research Grant

Factors influencing the uptake and use of nicotine replacement therapy and e-cigarettes in pregnant women who smoke: a qualitative 
Bovill 2018 (Continued)

\author{
Australian Heart foundation Indigenous Scholarships \\ NHMRC \\ Cancer Institute NSW Early Career Research Fellowship
}

Bowker 2016

\title{
Study characteristics
}

\section{Notes}

\section{Geographical context:}

UK, context unclear

\section{Focus:}

NRT and e-cigarettes

\section{Participants:}

Number of participants: 14

NRT/e-cig use: $64 \%$ using NRT at time of interview. Forms of NRT used: $36 \%$ patches, $7 \%$ gum, $7 \%$ microtab, $43 \%$ inhalator, $7 \%$ patches, mouth spray and inhalator. E-cig use in pregnancy: $36 \%$ of participants

Maternal status: all pregnant

Gestation: mean 14 weeks

Number of cigarettes smoked before quit attempts: mean 14 per day

Smoking status: all participants smoked during their quit attempt; $72 \%$ were smoking at time of the interview

Age: mean 28 years

Partner smoking status: $64 \%$ smoker, $27 \%$ non-smoker, $7 \%$ no partner

Ethnicity: 93\% white, $7 \%$ mixed British and Caribbean

\section{Methods:}

Study objectives: to understand the experience of pregnant women using NRT who discontinue NRT early or do not use the medication as it is recommended

Study period: May 2014 - December 2014

Theoretical perspective: unclear

Sampling: 2 stop smoking services were used as participant identification centres. Potentially eligible women - those who had recently been prescribed NRT and used it during their quit attempt, but not as recommended - were informed about the study

Data collection and analysis: semi-structured interviews, inductive thematic analysis

\section{Key themes relevant to the review:}

1. Expectations of NRT

2. Experience of using NRT (perceived effects of NRT use, concomitant smoking and side effects)

3. Safety concerns

4. Experience of e-cigarettes

Factors influencing the uptake and use of nicotine replacement therapy and e-cigarettes in pregnant women who smoke: a qualitative 
Bowker 2016 (Continued)

\section{Sources of support}

Employed by/associated with: University of Nottingham; University of Cambridge

Funding: National Institute for Health Research School for Primary Care Research

Bowker 2018

\section{Study characteristics}

\section{Notes}

\section{Geographical context:}

UK, wide range of geographical locations within England and Scotland

\section{Focus:}

e-cigarettes

\section{Participants:}

Number of participants: 30

NRT/e-cig use: 9 current e-cig users, 11 ex-users, 10 never users; 7 of the 9 current e-cig users were dual users

Maternal status: 15 pregnant ( $\mathrm{t} 3$ in 1st trimester, 7 in 2nd trimester, 5 in 3rd trimester), 15 postpartum (6 were $0-3$ months postpartum, 9 were $4-6$ months postpartum)

Smoking status: 16 current smokers, 14 ex-smokers

Age: range $21-38$ years

Education: $70 \%$ did not continue education beyond 18

Employed: 83\%

Living with partner: $70 \%$

Ethnicity: $83 \%$ white British

\section{Methods:}

Study objectives: to explore pregnant and postpartum women's views and experiences of e-cigarettes Study period: October 2015 - October 2016

Theoretical perspective: unclear

Sampling: participants were purposively sampled from the following groups: e-cig users, e-cig ex-users, each trimester of pregnancy and for varying stages of the postpartum period (up to 6 months). Recruitment adverts were placed on various websites and at stop smoking services, antenatal clinics and health visitor clinics in locations across England and Scotland

Data collection and analysis: semi-structured interviews, thematic framework analysis

\section{Key themes relevant to the review:}
1. Motivations for use
2. Social stigma
3. Using the e-cig
4. Consumer aspects
5. Harm perceptions 
Bowker 2018 (Continued)

\section{Sources of support}

Employed by/associated with: University of Nottingham; University of Cambridge; University of Stirling; St Georges University of London; UKCTAS

Funding: CR UK; NIHR

\section{Study characteristics}

Notes

\section{Geographical context:}

UK, North Solihull, England, urban

Focus:

NRT

\section{Participants:}

Number of participants: 19

NRT/e-cig use: not reported

Maternal status: 16 pregnant (5 in 1st trimester, 5 in 2nd trimester, 6 in 3rd trimester, mean gestation 21 weeks), 3 postpartum (had given birth in the past 10 months)

Smoking status: $74 \%$ current smokers (smoked between 1-30 cigarettes per day), $26 \%$ ex-smokers with experience of 2 weeks - 5 months cessation. All had smoked for all or part of their pregnancy

$11 \%$ had used a stop smoking service

Age: range $17-35$ years, mean 25 years

Education: $21 \%$ no completed education, $32 \%$ completed compulsory education, $47 \%$ completed $1-5$ years of higher education

Employment status: 58\% unemployed/never worked, 21\% carers, $16 \%$ employed, $5 \%$ not stated

Marital status: 53\% parenting with partner, $47 \%$ parenting alone

Ethnicity: 95\% white British, 5\% non-white/Caribbean

\section{Methods:}

Study objectives: to report on the views held by past and current service users and non-users regarding existing stop smoking services for pregnant women in Solihull, West Midlands.

Study period: January 2011 - May 2011 (recruitment of participants)

Theoretical perspective: unclear

Sampling: women within two postcode areas were targeted, based on regional statistics indicating high rates of smoking in pregnancy. Participants were invited to participate at their initial contact with smoking cessation services or from community midwife visiting lists

Data collection and analysis: focus groups, thematic analysis

\section{Key themes relevant to the review:}

1. Advantages of current services: non-judgmental support

2. Initiatives to encourage participation (offering suitable NRT subtheme)

Factors influencing the uptake and use of nicotine replacement therapy and e-cigarettes in pregnant women who smoke: a qualitative 
Butterworth 2014 (Continued)

\section{Sources of support}

Employed by/associated with: Coventry University; Solihull NHS Care Trust

Funding: no funding received

Conflict of Interests: none reported

\section{Study characteristics}

Notes

\section{Geographical context:}

US, Memphis (Tennessee), Philadelphia, (Pennsylvania), Oklahoma City (Oklahoma), Billings, (Montana), urban

\section{Focus:}

NRT and e-cigarettes

\section{Participants:}

Number of participants: 59

NRT/e-cig use: $28 \%$ of pregnant smokers and $19 \%$ of pregnant quitters used 'other tobacco products', a category including e-cigs

Pregnant smokers ( $n=32$ ): Smoking status: $66 \%$ smoked every day, $28 \%$ used other tobacco products (including e-cigs, snus, chewing tobacco)

Age: $41 \% 18-23$ years, 44\% 24-29 years, $13 \% 30-35$ years, 3\% 36-40 years

Education: $19 \%$ less than high school, $53 \%$ high school or equivalent, $28 \%$ some college

Ethnicity: 41\% white, 19\% African American, 13\% Native American, 28\% Hispanic

Pregnant quitters ( $n=27)$ : Smoking status: $19 \%$ used other tobacco products (including e-cigs, snus, chewing tobacco)

Age: $7 \%$ 18-23, 22\% 24-29, 33\% 30-35, 37\% 36-40

Education: $15 \%$ high school or equivalent, $59 \%$ some college, $22 \%$ college graduate

Ethnicity: 51\% white, 29\% African American, 3\% Native American, 15\% Latin American

The third group, smokers planning a pregnancy, are not relevant to this review

\section{Methods:}

Study objectives: to assess how women perceive emerging non-combusted tobacco products and NRT use in general and during pregnancy, to assess how women perceive the health risks associated with these

Study period: not provided

Theoretical perspective: unclear

Sampling: market research facilities recruited participants using their databases. Respondents were then screened for eligibility by telephone

Data collection and analysis: focus groups, thematic analysis 


\section{Key themes relevant to the review:}

Prior experiences with tobacco and NRT (perceptions related to non-combustible tobacco and NRT, general, subthemes = product familiarity, product appeal), specific and non-specific to pregnancy

\section{Sources of support}

Employed by/associated with: Centres for Disease Prevention and Control, USA; Centre for Tobacco Products, US Food and Drug Administration, USA; RTI International, USA

Funding:

Food and Drug Administration under Interagency agreement

RTI International

\section{Study characteristics}

Notes

\section{Geographical context:}

USA, unclear context

Focus:

NRT

\section{Participants:}

Number of participants: 19 (22 including 3 lifelong non-smokers)

NRT/e-cig use: not reported

Maternal status: participants ranged from 11 weeks gestation to postpartum (up to 6 weeks)

Smoking status: $86 \%$ current smokers, $14 \%$ lifelong non-smokers

Age: range 22-37 years, mean 28 years

Past pregnancies: range 1-15, mean 4, and mean of 2 living children, range 0-7 children

Ethnicity: $100 \%$ white

\section{Methods:}

Study objectives: to describe facilitators and barriers to engaging in tobacco treatment among pregnant, opioid-dependent women receiving medication-assisted treatment (MAT).

Study period: not provided

Theoretical perspective: unclear

Sampling: participants were recruited from group prenatal care sessions at a maternal fetal medicine clinic

Data collection and analysis: focus groups, thematic analysis

\section{Key themes relevant to the review:}

Lack of success with NRT

\section{Sources of support}

Employed by/associated with: University of Kentucky, USA

Factors influencing the uptake and use of nicotine replacement therapy and e-cigarettes in pregnant women who smoke: a qualitative evidence synthesis (Review)

Copyright (C) 2020 The Cochrane Collaboration. Published by John Wiley \& Sons, Ltd. 
Fallin 2016a (Continued)

\author{
Funding: none reported \\ Conflict of interest: none reported
}

Fallin 2016b

\title{
Study characteristics
}

\section{Notes}

\section{Geographical context:}

USA, unclear context

\section{Focus:}

e-cigarettes

\section{Participants:}

Number of participants: 12

NRT/e-cig use: not reported, but all participants smoked either cigarettes or e-cigs

Maternal status: 8 pregnant, 4 newly postpartum

Smoking status: all reported smoking (cigarettes or e-cigs) 3 months before pregnancy or during pregnancy

Marital status: $58.3 \%$ single

Ethnicity: $75 \%$ white

\section{Methods:}

Study objectives: to describe perceptions and beliefs about e-cigarette use during pregnancy among pregnant and newly postpartum women in Kentucky

Study period: not provided

Theoretical perspective: unclear

Sampling: women who had taken part in the first phase of the study (a survey completed by a convenience sample of pregnant women), and had consented to being contacted for additional studies, were invited to attend a focus group, providing they met the eligibility criteria

Data collection and analysis: focus groups, content analysis

\section{Key themes relevant to the review:}

1. Attraction to e-cig as a harm reduction strategy

2. Uncertainty regarding the health effects of e-cigs

3. Ambivalence regarding novel product characteristics

4. Behaviours reflected dual use and often complete relapse to traditional cigarettes

5. Lack of success with NRT

\section{Sources of support}

Employed by/associated with: University of Kentucky, USA

Funding: NIH; American Cancer Society Institutional Research Grant; Centres for Medicare and Medicaid Services; Centres for Medicare and Medicaid Innovation 
Australia, urban

Focus:

NRT

\section{Participants:}

Number of participants: 6

NRT/e-cig use: not reported

Maternal status: all pregnant

Gestation: range 20-35 weeks, mean 27 weeks

Smoking status at recruitment: all daily smokers, with experience of at least one health worker delivered intervention for smoking cessation during their pregnancy

Smoking status at interview: 4 smoking, 1 had quit in the last 4 weeks, 1 quit without support

Age: range $18-38$ years, mean 24.33 years

Previous pregnancies: 4 having 1st baby, 1 having 3rd, 1 having 4th

All were socioeconomically disadvantaged - all held a government health card (indicator of low income). All participants lived in public housing

Marital status: all women had partners, 3 cohabiting, 3 living with parents

\section{Methods:}

Study objectives: to explore and describe women's experiences of smoking cessation intervention(s), perceptions of smoking cessation intervention efficacy, and views for improving smoking cessation interventions in pregnancy

Study period: not provided

Theoretical perspective: feminist

Sampling: purposive sample - 5 women were identified and recruited from a smoking cessation service database. One other was recruited opportunistically via snowball sampling

Data collection and analysis: semi-structured interviews, inductive thematic analysis

\section{Key themes relevant to the review:}

What NRT women want

\section{Sources of support}

Employed by/associated with: Flinders University, Australia

Work undertaken as a dissertation for Masters of Public Health (Public Health Research) 
Glover 2012

\section{Study characteristics}

Notes

\section{Geographical context:}

New Zealand, urban and rural

Focus:

NRT

\section{Participants:}

Number of participants: 60

NRT/e-cig use: not reported

Maternal status: all pregnant (43\% 2nd trimester, $40 \% 3 \mathrm{rd})$

Smoking status: mostly current smokers (one recently stopped smoking on becoming pregnant)

Cigarettes per day: range 1-28, mean 9, 32\% smoked 1st cigarette within 5 minutes of waking

Age range: $17-43$ years

Previous pregnancies: $38 \%$ having 1 st baby

$68 \%$ lived in urban centres

Education: $23 \%$ no formal qualifications

Employment status: $38 \%$ had some employment, $80 \%$ eligible for community services card - an indicator of low income

Marital status: $88 \%$ with a partner

Ethnicity: 100\% Maori

\section{Methods:}

Study objectives: to investigate pregnant Maori smokers' perception of cessation services and products and identify how they may be improved

Study period: October 2002 - November 2003

Theoretical perspective: unclear

Sampling: participants were recruited through Maori health services, the researcher's networks and newspaper advertisements from various urban and rural areas of New Zealand's North Island

Data collection and analysis: semi-structured interviews, inductive thematic analysis

\section{Key themes relevant to the review:}

1. Health education resources

2. Nicotine replacement therapy

\section{Sources of support}

Employed by/associated with: University of Auckland, New Zealand

Funding: not reported 


\section{Study characteristics}

Notes

\section{Geographical context:}

South Wales, UK. Unclear as to whether urban/rural setting

Focus:

e-cigarettes

\section{Participants:}

Number of participants: 10 (9 completed both interview phases). This number of participants was deemed appropriate by the authors due to the highly in-depth nature of the study

NRT/e-cig use: 1 participant used an e-cig.

Maternal status: all pregnant

Gestation: mean gestation 12.9 weeks (range 6-29 weeks)

Smoking status: 2 smoked at time of interview, 1 was using an e-cig, 5 abstinent, 1 did not mention smoking

Age: range $24-34$ years, mean 28.8 years

Previous pregnancies: 9 already had children, one participant gave birth as a teenager, another in 30s, rest occurred in $20 \mathrm{~s}$

Socioeconomic status: all living in areas of the highest quintile of deprivation and claiming means tested benefits (welfare)

\section{Methods:}

Study objectives: to gain an in-depth understanding of the health issues affecting 10 low-income pregnant women from deprived areas of south Wales, UK

Study period: March 2016 - August 2016

Theoretical perspective: an interpretivist paradigm guided by feminist principles

Sampling: recruitment of participants was achieved through a variety of avenues external to health services, including community settings, online advertising and flyers in deprived areas

Data collection and analysis: 3 creative tasks based on visual methods, and elicitation interviews, thematic analysis.

\section{Key themes relevant to the review:}

1. Demographics and (self-reported) smoking status

2. Social networks, hidden smoking during pregnancy and morality

3. Interaction with maternity healthcare services

\section{Sources of support}

Employed by/associated with: Cardiff University; Queen's University Belfast; UK

Aimee Grant was previously the Research and Policy Officer at Action on Smoking and Health (ASH)

Funding: Wellcome Trust 
Hauck 2013

\section{Study characteristics}

Notes

Geographical context:

Australia, urban

Focus:

NRT

\section{Participants:}

Number of participants: 36

NRT/e-cig use: not reported

Maternal status: all pregnant

Smoking status: all smokers

Age: range $16-24$ years $(50 \% 16-17$ years)

Parity: $78 \%$ in first pregnancy

Ethnicity: 14\% Aboriginal, all English-speaking

\section{Methods:}

Study objectives: to gain insight into the perceived challenges and enablers young pregnant women encounter when attempting to modify their smoking

Study period: July 2011 - June 2012

Theoretical perspective: unclear

Sampling: participants were recruited by a research assistant whilst attending an antenatal clinic appointment

Data collection and analysis: interviews, thematic analysis

\section{Key themes relevant to the review:}

Something you could take

\section{Sources of support}

Employed by/associated with: Curtin University and King Edward Memorial Hospital, Australia

Funding: Women and Infants Research Foundation

\section{Study characteristics}

Geographical context:
UK, nationwide recruitment of participants
Focus:
NRT
Participants:

Factors influencing the uptake and use of nicotine replacement therapy and e-cigarettes in pregnant women who smoke: a qualitative 
Number of participants: 13. Data saturation appeared to be reached, and no new themes emerged in the final 3 interviews

NRT/e-cig use: not reported

Maternal status: all pregnant

Smoking status: $54 \%$ reported they had quit at time of interview, $69 \%$ had previously made a quit attempt

Age: range 20-41 years, mean 31 years

Marital status: $92 \%$ married

Previous pregnancies: $38 \%$ 1st pregnancy, $62 \%$ multigravida

Ethnicity: 92\% white British

\section{Methods:}

Study objectives: to explore the needs and preferences of pregnant women seeking online stop smoking support (with an aim to identify features and components of Internet-based smoking cessation interventions that might be most attractive to this population)

Study period: not provided

Theoretical perspective: unclear

Sampling: participants were women randomised to the intervention arm of a smoking cessation trial (MumsQuit)

Data collection and analysis: semi-structured interviews, framework analysis variant

\section{Key themes relevant to the review:}

Smoking cessation medication

\section{Sources of support}

Employed by/associated with: University College London; National Centre for Smoking Cessation and Training, London, UK

UCL Tobacco and Alcohol Research Group

Funding: National Prevention Research Initiative

The Funding Partners relevant to this award are (in alphabetical order): Alzheimer's Research Trust; Alzheimer's Society; Biotechnology and Biological Sciences Research Council; British Heart Foundation; Cancer Research UK; Chief Scientist Office, Scottish Government Health Directorate; Department of Health; Diabetes UK; Economic and Social Research Council; Engineering and Physical Sciences Research Council; Health \& Social Care Research \& Development Office for Northern Ireland; Medical Research Council; the Stroke Association; Welsh Assembly Government. British Heart Foundation PhD Studentship; Society for the Study of Addiction; Cancer Research UK

Conflict of interests: Pfizer. RW undertakes consultancy and research for and receives travel funds and hospitality from manufacturers of medications for smoking cessation. He also undertakes training for smoking cessation advisors and has a share of a patent for a novel nicotine delivery device.

\section{Study characteristics}

Factors influencing the uptake and use of nicotine replacement therapy and e-cigarettes in pregnant women who smoke: a qualitative 
Hotham 2002 (Continued)

\author{
Australia, urban
}

Focus:

NRT

\title{
Participants:
}

Number of participants: 19

NRT/e-cig use: not reported (NRT was not approved for use in pregnancy in Australia at the time the study was conducted)

Maternal status: all pregnant

Smoking status: women who smoked $(n=9)$ or who had quit before or early in pregnancy $(n=10)$

\section{Methods:}

Study objectives: to explore barriers to quitting smoking for pregnant women, their attitudes to use of patches and their perceptions of care provider counselling

Study period: not provided

Theoretical perspective: unclear

Sampling: convenience sample: a researcher approached women at 5 successive antenatal clinics at a large obstetrics hospital in South Australia. Over 250 women were approached to take part

Data collection and analysis: focus groups, thematic analysis

\section{Key themes relevant to the review:}

Attitudes of women towards the use of nicotine patches

\section{Sources of support}

Employed by/associated with: Women's and Children's Hospital Australia; Flinders University, Australia; University of South Australia

Funding: South Australian Smoking and Health Project (now QUIT SA)

\section{Mantzari 2012}

\section{Study characteristics}

Notes

\section{Geographical context:}

UK, urban

\section{Focus:}

NRT

\section{Participants:}

Number of participants: 36 (20 incentives arm, 16 control arm)

NRT/e-cig use: not reported

Maternal status at interview: 24 pregnant, 11 postpartum ( 6 in incentive group and 5 in control group); 1 participant miscarried 
Smoking status: at interview: 12 (33\%) women smoke-free (8 in intervention group, 4 in control group), $24(66 \%)$ smoking

Age: range $17-43$ years, mean 28 years

Employment status: mostly unemployed

Ethnicity: 94\% white

\section{Methods:}

Study objectives: to examine and compare the stop-smoking experiences of pregnant women who were versus were not incentivised for smoking cessation

Study period: September 2009 - May 2010 (recruitment of participants)

Theoretical perspective: unclear

Sampling: participants were recruited through an opportunistic sampling framework from a population of 115 women living in the greater Birmingham area who had been referred to the NHS Stop Smoking Services by their midwives and were either enrolled in a pilot scheme of incentivising smoking cessation or lived in a comparison area, and were therefore eligible to be part of a comparison cohort

Data collection and analysis: semi-structured interviews, framework analysis

\section{Key themes relevant to the review:}

Perceived inhibitors

\section{Sources of support}

Employed by/associated with: Kings College London

Funding: Wellcome Trust

\section{Naughton 2013}

\section{Study characteristics}

\section{Notes}

\section{Geographical context:}

UK, Cambridgeshire and Suffolk, England. Urban and rural

\section{Focus:}

NRT

\section{Participants:}

Number of participants: 20

NRT/e-cig use: not reported

Maternal status: 15 pregnant (75\%), 5 postpartum (25\%)

Age range: $16-40$ years

Gestation: 5\% 1-12 weeks, 30\% 13-28 weeks, 40\% 29-40 weeks

Smoking status: 13 (65\%) current smokers

Cigarettes per day in pregnancy: 35\% 0, 20\% 1-4, 30\% 5-9, 5\% 15-19, 10\% 20+

Factors influencing the uptake and use of nicotine replacement therapy and e-cigarettes in pregnant women who smoke: a qualitative 
Naughton 2013 (Continued)

Quit attempts: 1 participant quit during most recent pregnancy (but smoked for first 4); 6 quit when finding out they were pregnant; the remaining 13 smoked but had made numerous quit attempts

Previous births: $65 \%$ had no previous births

National Statistics socioeconomic classification (1-5): 45\% 1, 5\% 2, 5\% 3, 5\% 4, 40\% 5

Relationship status: $90 \%$ had a partner

Partner smoking status: $77.8 \%$ smoked

\section{Methods:}

Study objectives: to explore the accounts of pregnant smokers and quitters, to investigate the role of their smoking beliefs in influencing their smoking behaviour and the relationships of these with psychosocial factors related to pregnancy and antenatal care

Study period: March 2007 - July 2007

Theoretical perspective: grounded theory and constant comparative approach

Sampling: purposive sampling. Participants were recruited by community midwives from two GP practices in Cambridgeshire and Suffolk, UK. Midwife clinics and a 'SureStart' programme were attended by one of the authors towards the end of recruitment to identify further participants and ensure sample variation

Data collection and analysis: semi-structured interviews, framework analysis

\section{Key themes relevant to the review:}

Uncertainty about the mechanism of harm

\section{Sources of support}

Employed by/associated with: University of Cambridge; University of Leicester

Funding: Cancer Research UK

\section{Study characteristics}

\section{Notes}

\section{Geographical context:}

UK, unclear context

\section{Focus:}

NRT

\section{Participants:}

Number of participants: 6 . Data saturation was achieved so no more interviews were carried out. NRT/e-cig use: not reported

Maternal status: had been pregnant at time of contact with stop smoking service (between July 2012 and July 2013)

Smoking status: smoked at time of referral to stop smoking service

Age: range 18-35 years

Factors influencing the uptake and use of nicotine replacement therapy and e-cigarettes in pregnant women who smoke: a qualitative 
Pledger 2015 (Continued)

\section{Methods:}

Study objectives: to retrospectively examine the needs, motivations and experiences of pregnant women using an NHS stop smoking service. Identify enablers and barriers to stop smoking in expectant mothers

Study period: August 2013 - September 2013

Theoretical perspective: unclear

Sampling: purposive sample. The researcher contacted all eligible participants who had contacted an NHS stop smoking service in the preceding 12 months, identifying 82 potential participants

Data collection and analysis: semi-structured interviews, comparative analysis.

\section{Key themes relevant to the review:}

Experiences of using NHS stop smoking support

\section{Sources of support}

Employed by/associated with: University of Birmingham, UK

Funding: not reported

\section{Study characteristics}

\section{Notes}

\section{Geographical context:}

UK, Tayside, Scotland. Unclear as to whether it is a rural or urban population

\section{Focus:}

NRT

\section{Participants:}

Number of participants: 20

NRT/e-cig use: not reported. As part of the financial incentives scheme this study is part of, NRT was provided by pharmacist at an initial meeting.

Maternal status: all pregnant

Age: mean 25.7 years

Socioeconomic status: majority living in most deprived quintile

Previous pregnancies: over half $(n=12)$ of participants were having their 1 st child

\section{Methods:}

Study objectives: to seek the views and experiences of 2 participant groups with divergent levels of engagement to a pilot smoking cessation incentive scheme

Study period: early 2009

Theoretical perspective: unclear 
Radley 2013 (Continued)

Sampling: a cross-sectional sample of participants in the 'Give It Up For Baby' incentives scheme was identified using client databases to represent the 2 groups of interest: those that engaged regularly with the scheme, and those that registered but did not

Data collection and analysis: interviews, thematic analysis

\section{Key themes relevant to the review:}

Client typology

\section{Sources of support}

Employed by/associated with: NHS Tayside; University of Stirling; University of Dundee; University of Glasgow

Funding: NHS Tayside Board (allocated by Scottish Government)

\section{Study characteristics}

\section{Notes}

\section{Geographical context:}

UK, Nottingham, urban

Focus:

NRT

\section{Participants:}

Number of participants: 18

NRT/e-cig use: 7 of the pregnant sample and 2 of the postpartum sample reported past NRT use

\section{Pregnant sample $(n=14)$}

Gestation: range $=9-28$ weeks

Smoking status: 10 smokers, 4 recently quit. Cigarettes per day: average $=8.3$ had used a stop smoking service previously

Age: range $17-36$ years

Marital status: 8 cohabiting with partner, 1 married, 5 single

Employment status: 5 employed

Education: 7 National Vocational Qualifications/General Certificate of Secondary Education level, 1 Diploma/Higher National Diploma level, 1 degree level

Ethnicity: $100 \%$ white British

\section{Postpartum sample $(n=4)$}

6-20 months postpartum

Smoking status: 3 smoked throughout pregnancy, 1 quit during pregnancy. Mean cigarettes per day whilst pregnant $=9$

Age: range 21-32 years

Marital status: 3 cohabiting with partner, 1 married 


\author{
Employment status: 2 employed \\ Education: 2 National Vocational Qualifications/General Certificate of Secondary Education, 1 Business \\ and Technology Education Council/A Level, 1 degree level
}

Ethnicity: $100 \%$ white British

The third sample, NHS health professionals, is not relevant to this review

\section{Methods:}

Study objectives: to elicit salient beliefs women have about NRT

Study period: August 2006 - February 2007

Theoretical perspective: theory of planned behaviour framework

Sampling: purposive sampling (maximum variation sampling strategy) in order to recruit participants from across the social spectrum, recruited from antenatal clinics and SureStart centres

Data collection and analysis: semi-structured interviews, thematic analysis

\section{Key themes relevant to the review:}

1. Effective for quitting - beliefs about whether or not NRT would be effective in helping with smoking cessation

2. Side effects - beliefs about unwanted side effects accompanying NRT use

3. Improved health - beliefs that using NRT in pregnancy would improve the health of mother and baby

4. Not the same as quitting - beliefs that using NRT would not represent properly quitting smoking

5. Safety - beliefs that NRT might not be safe to use in pregnancy,

6. Unsure if allowed - beliefs that NRT might not be allowed in pregnancy

7. Knowledge about products - the amount of knowledge a pregnant woman has about NRT

\section{Sources of support}

Employed by/associated with: University of Nottingham, UK

Funding: MRC (PhD thesis)

NIH: National Institutes of Health; NHMRC: National Health and Medical Research Council (Australia); MAT: medication-assisted treatment; NRT: nicotine replacement therapy; RACGP: Royal Australian College of General Practitioners; UKCTAS: UK Centre for Tobacco and Alcohol Studies

Characteristics of excluded studies [ordered by study ID]

\begin{tabular}{ll}
\hline Study & Reason for exclusion \\
\hline Anderson 2002 & Not about NRT or e-cigarettes \\
\hline Ashford 2008 & No full text available \\
\hline Ashford 2011 & Not about NRT or e-cigarettes \\
\hline Askew 2019 & Not about NRT or e-cigarettes \\
\hline Balwicki 2017 & Not a qualitative study \\
\hline Bottorff 2006 & Not about NRT or e-cigarettes \\
\hline
\end{tabular}

Factors influencing the uptake and use of nicotine replacement therapy and e-cigarettes in pregnant women who smoke: a qualitative 


\begin{tabular}{|c|c|}
\hline Study & Reason for exclusion \\
\hline Britton 2017 & Not about NRT or e-cigarettes \\
\hline Bryce 2009 & Not about NRT or e-cigarettes \\
\hline Bull 2007 & Not about NRT or e-cigarettes \\
\hline Bull 2008 & Ineligible patient population \\
\hline Colomar 2015 & Not about NRT or e-cigarettes \\
\hline Constantine 2014 & Not about NRT or e-cigarettes \\
\hline Cottrell 2007 & Not about NRT or e-cigarettes \\
\hline Davidson-Harden 2009 & Not a qualitative study \\
\hline Edwards 1998 & Not about NRT or e-cigarettes \\
\hline Gillam 2009 & Not about NRT or e-cigarettes \\
\hline Glover 2014 & Ineligible patient population \\
\hline Goszczynska 2016 & Not about NRT or e-cigarettes \\
\hline Gould 2013 & Not about NRT or e-cigarettes in pregnancy \\
\hline Gould 2017a & Not a qualitative study \\
\hline Gould 2017b & Not about NRT or e-cigarettes \\
\hline Griffis 2016 & Not about NRT or e-cigarettes \\
\hline Haslam 2001 & Not about NRT or e-cigarettes \\
\hline Herberts 2012 & Not about NRT or e-cigarettes \\
\hline Hoek 2014 & Not about NRT or e-cigarettes \\
\hline Homish 2012 & Not a qualitative study \\
\hline Hotham 2005 & Inegible study design \\
\hline Howard 2013 & Not about NRT or e-cigarettes \\
\hline Kahr 2015 & Ineligible patient population \\
\hline Kennison 2003 & Not about NRT or e-cigarettes \\
\hline Koshy 2010 & Not about NRT or e-cigarettes \\
\hline Lawson 1991 & No full text available \\
\hline Lowry 2004 & Not about NRT or e-cigarettes \\
\hline Mann 2018 & Not a qualitative study \\
\hline
\end{tabular}

Factors influencing the uptake and use of nicotine replacement therapy and e-cigarettes in pregnant women who smoke: a qualitative 


\begin{tabular}{|c|c|}
\hline Study & Reason for exclusion \\
\hline Maubach 2013 & Not about NRT or e-cigarettes \\
\hline McCurry 2002 & Not about NRT or e-cigarettes \\
\hline McLeod 2003 & Not about NRT or e-cigarettes \\
\hline Modeste 2004 & Ineligible study design \\
\hline Naughton 2013a & Not about NRT or e-cigarettes \\
\hline Nguyen 2012 & Not about NRT or e-cigarettes \\
\hline Park 2009 & Not about NRT or e-cigarettes \\
\hline Passey 2018 & Not about NRT or e-cigarettes \\
\hline Petersen 2010 & Not about NRT or e-cigarettes \\
\hline Pletsch 1996 & Not about NRT or e-cigarettes \\
\hline Pletsch 2003 & Not about NRT or e-cigarettes \\
\hline Pletsch 2004 & Not about NRT or e-cigarettes \\
\hline Quinn 2006 & Not about NRT or e-cigarettes \\
\hline Ronchi 2018 & Not about NRT or e-cigarettes \\
\hline Tod 2003 & Not about NRT or e-cigarettes \\
\hline Wigginton 2017 & Ineligible patient population \\
\hline Wood 2008 & Not about NRT or e-cigarettes \\
\hline Wu 2017 & Not about NRT or e-cigarettes \\
\hline
\end{tabular}

NRT: nicotine replacement therapy.

\section{ADDITIONAL TABLES}




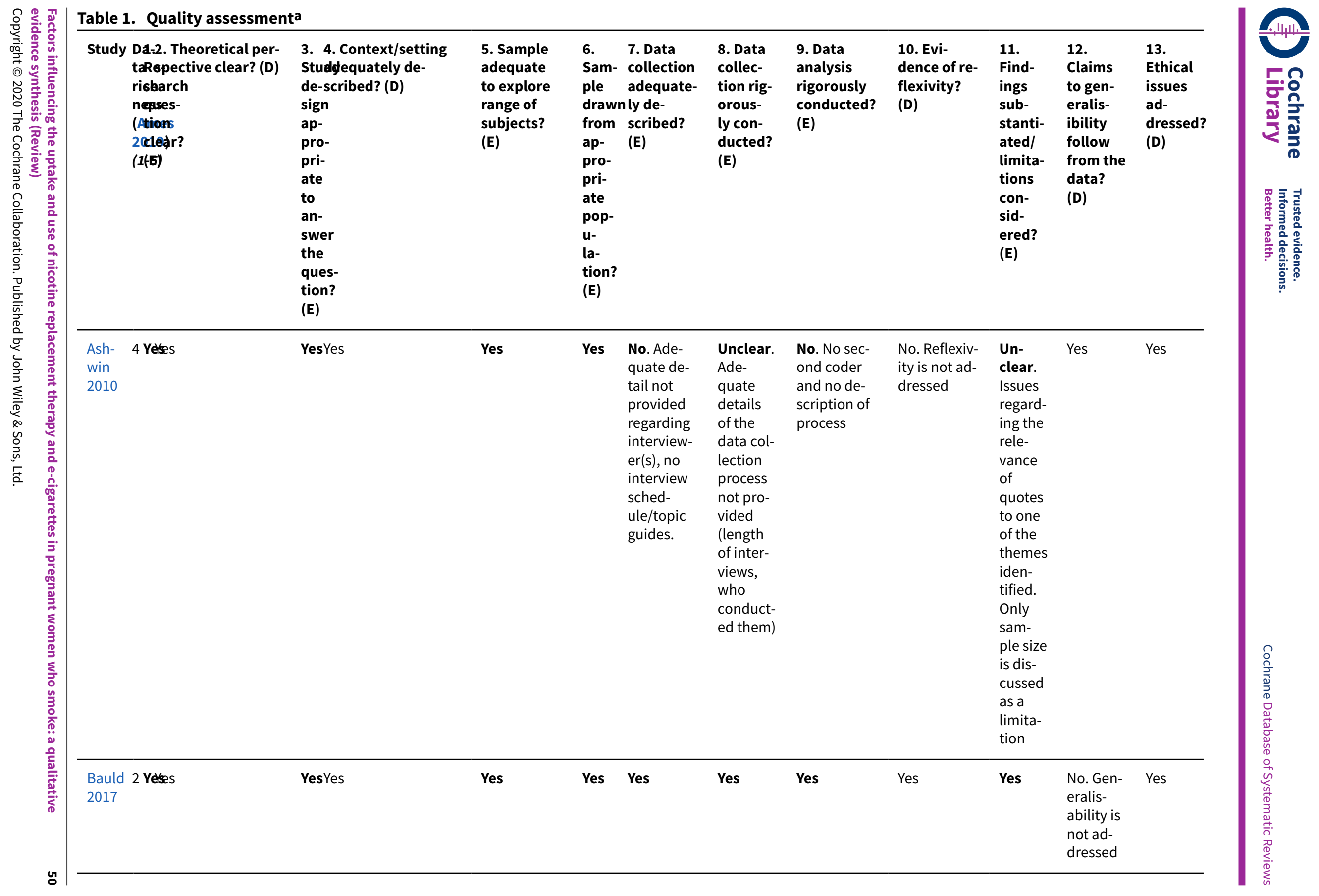




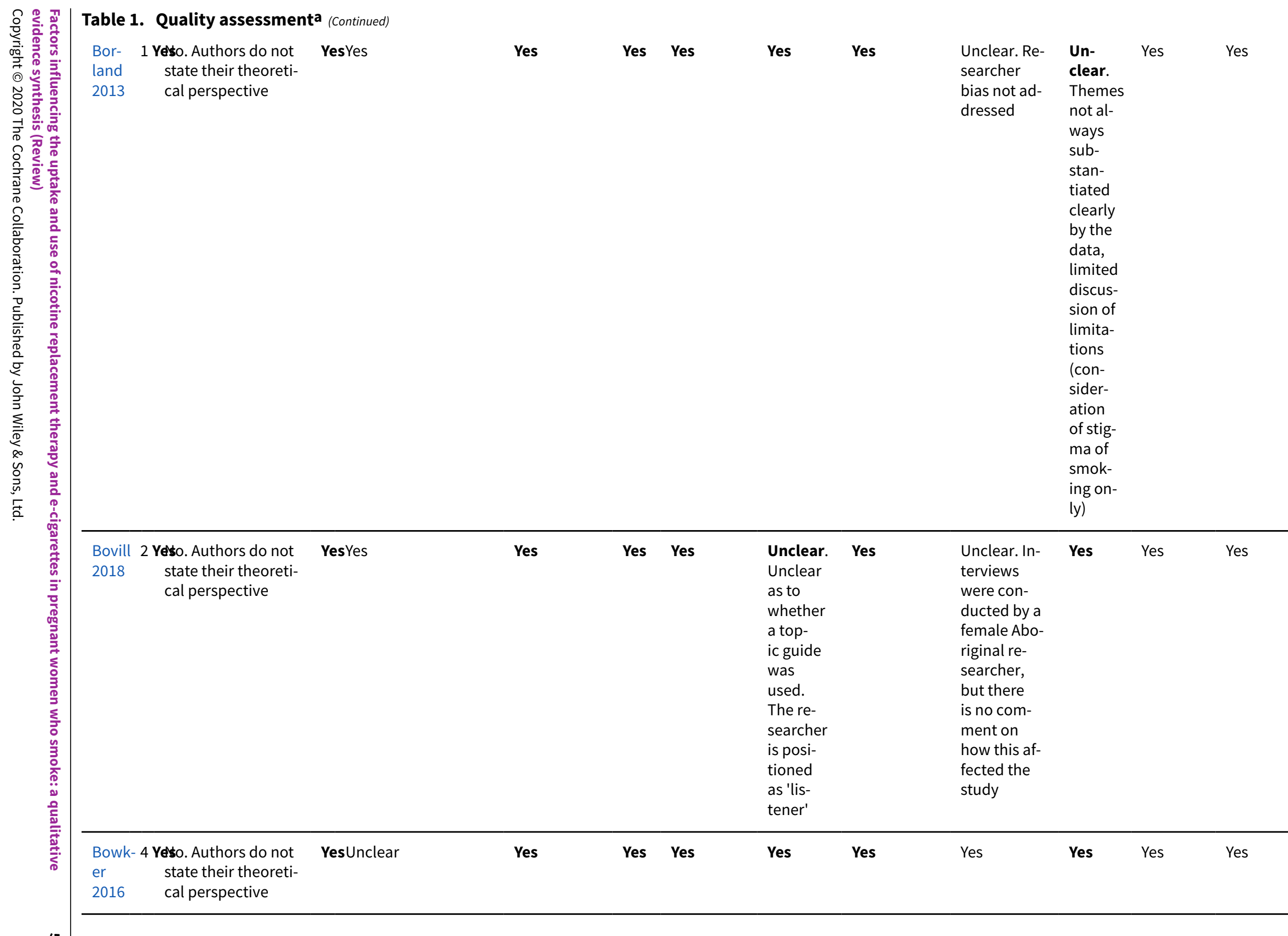




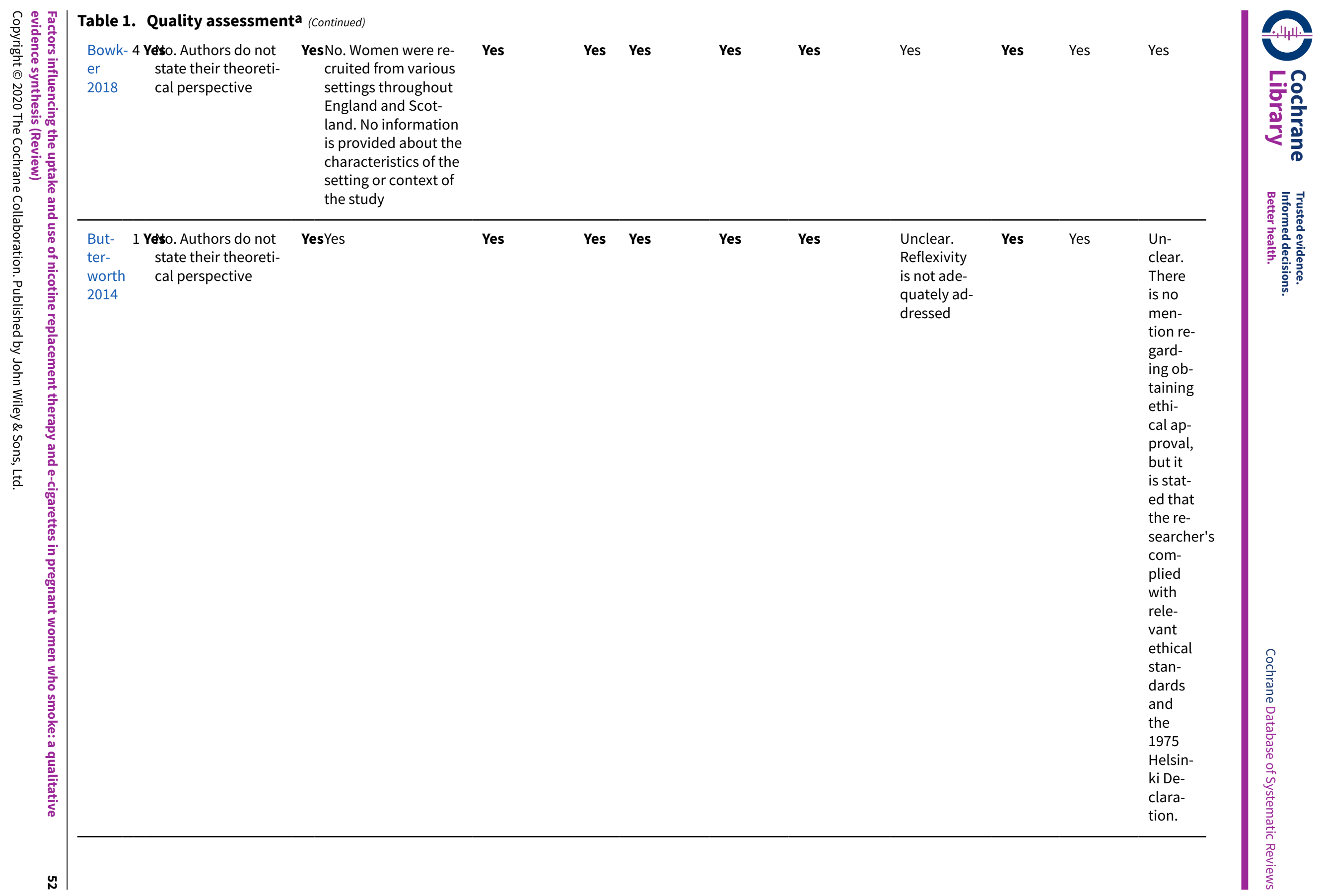




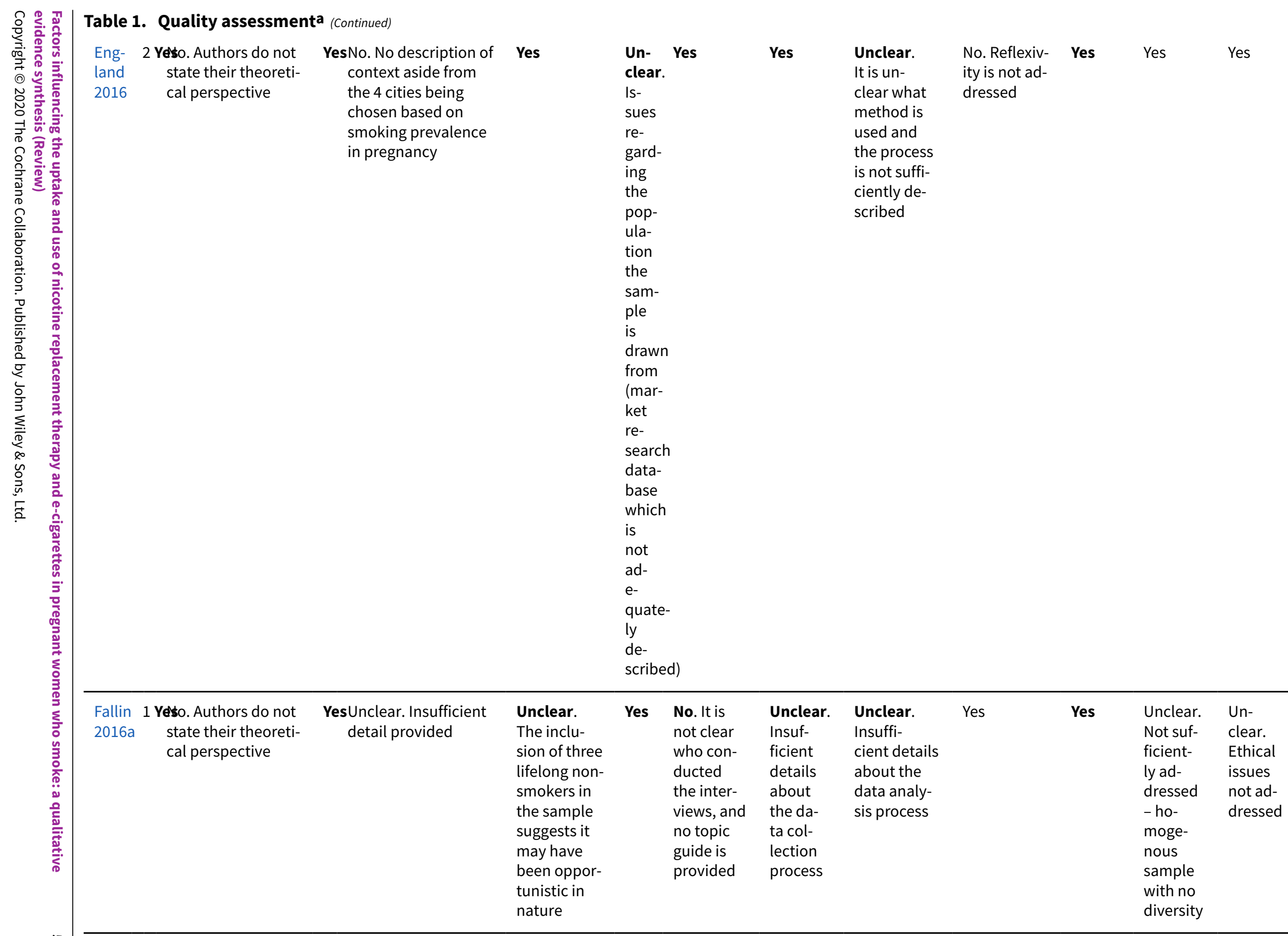




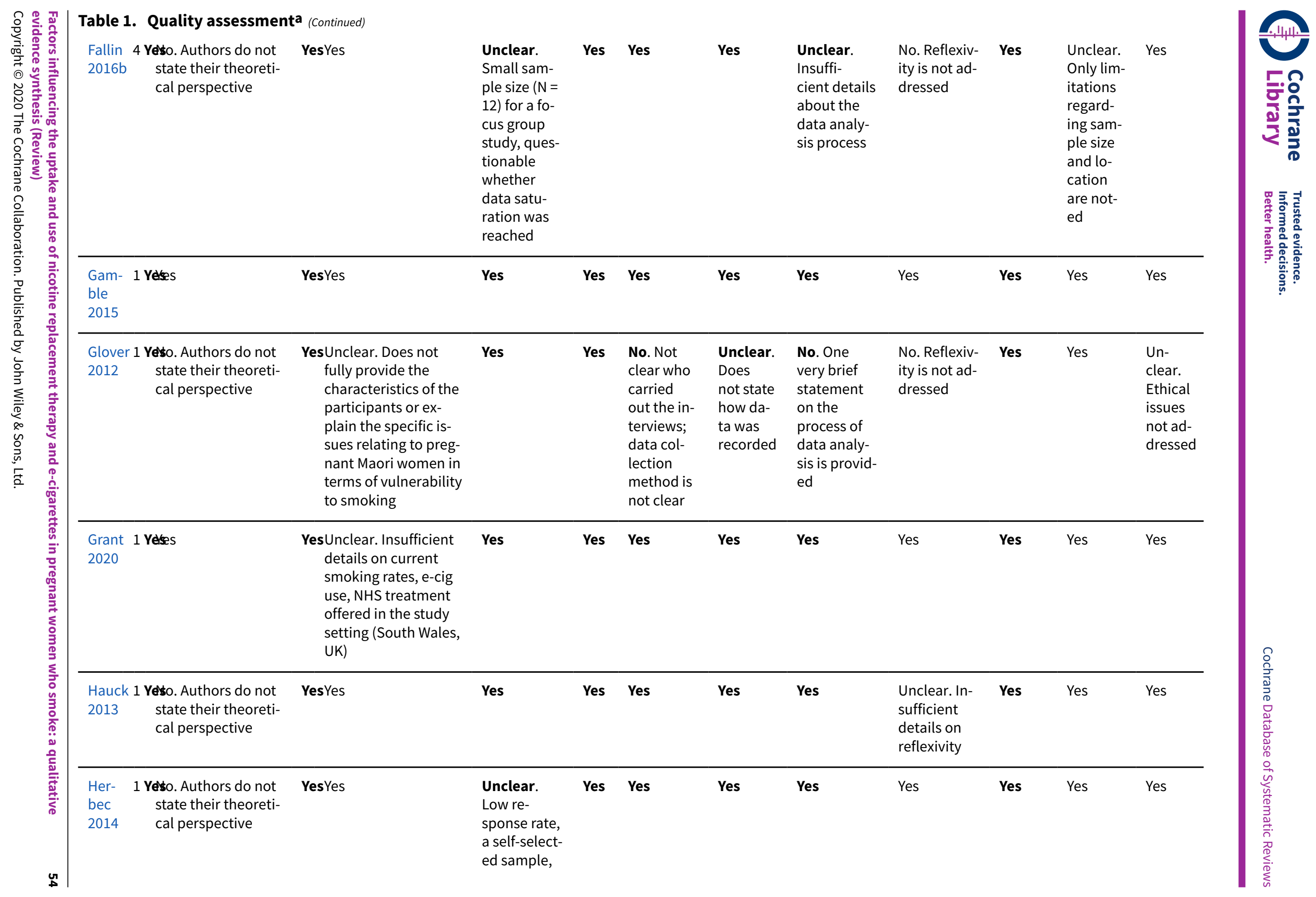




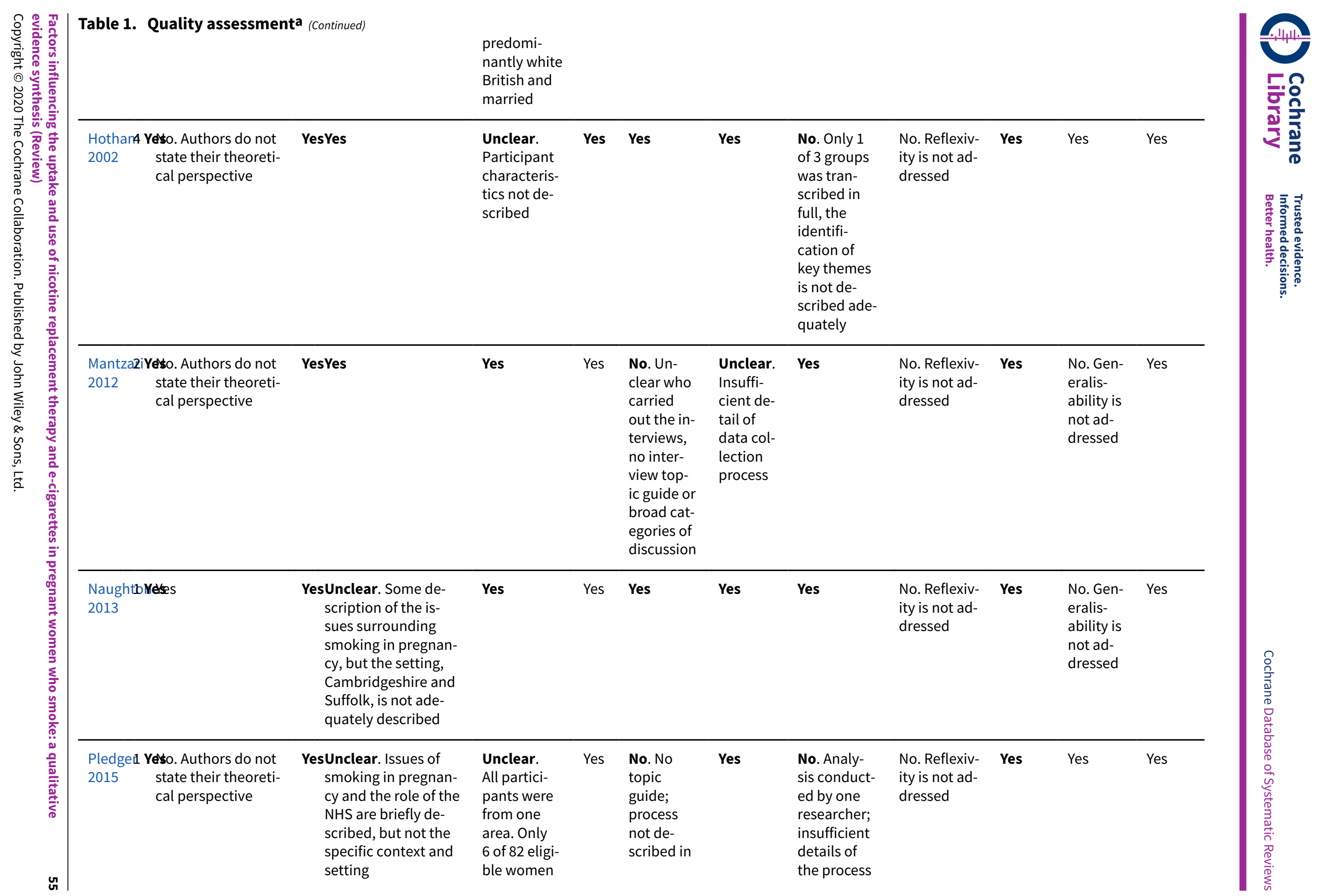




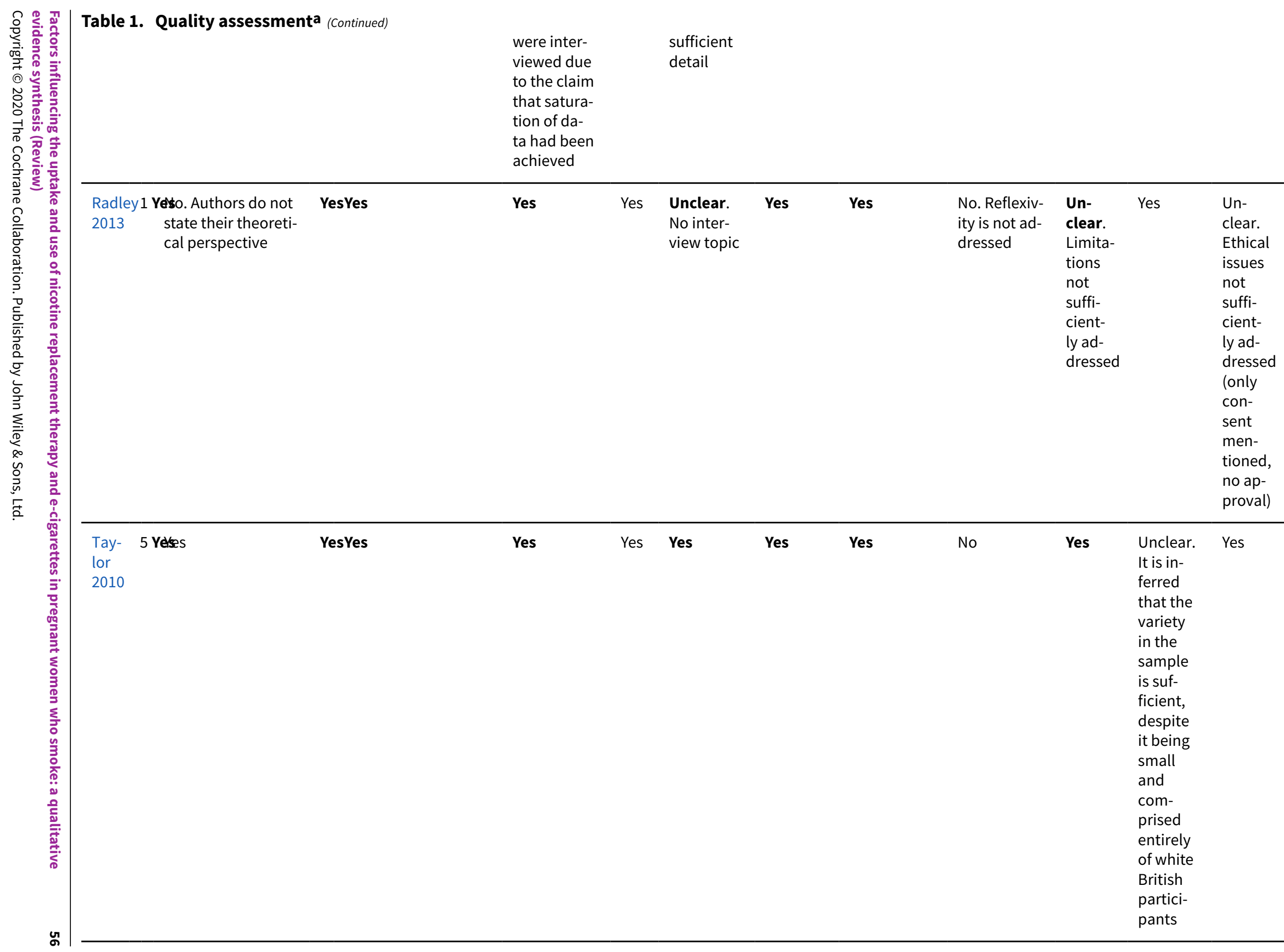



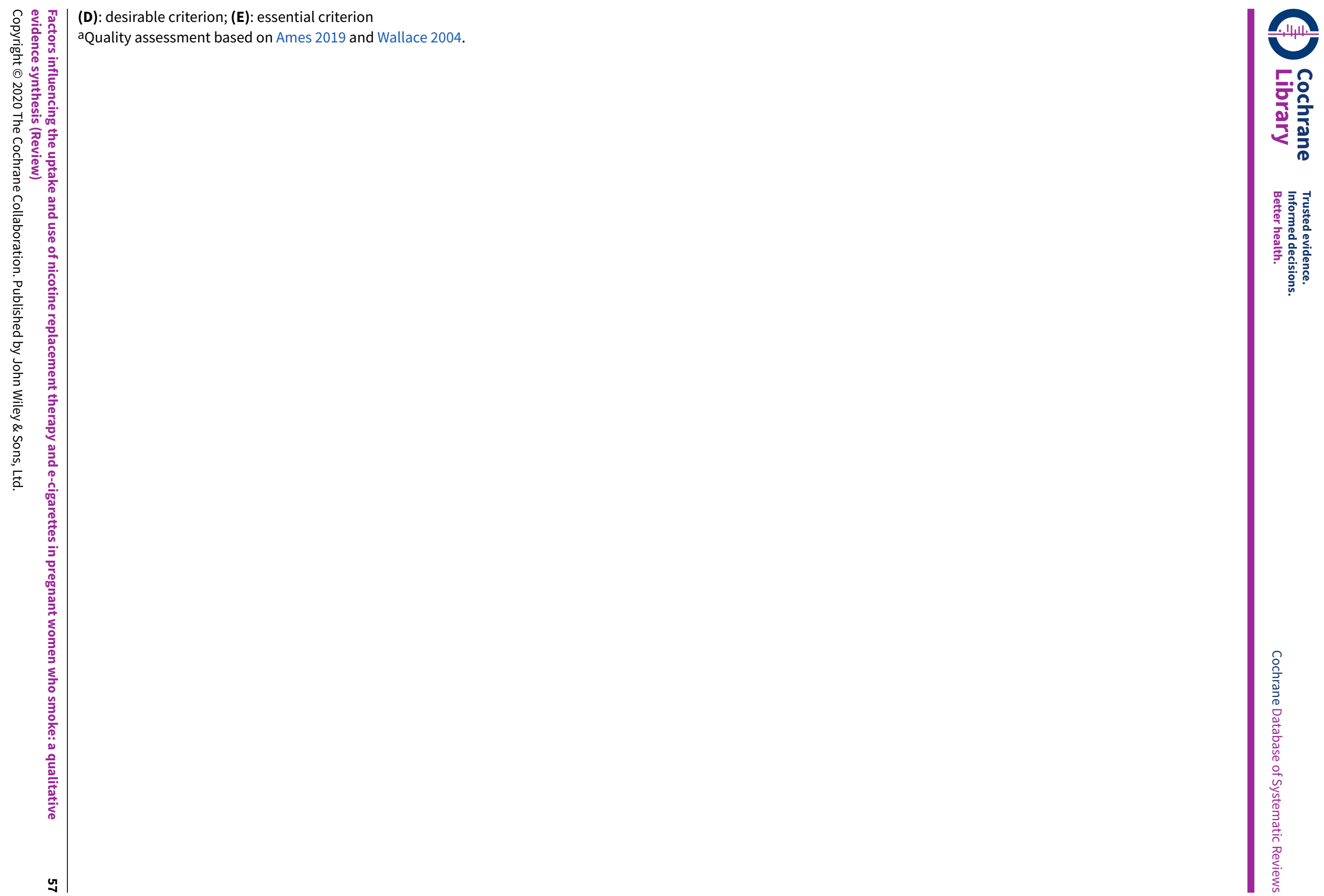
Table 2. Short overview of themes and findings

FACTORS INFLUENCING USE OF NRT IN PREGNANCY

FACTORS INFLUENCING E-CIGARETTE USE IN PREGNANCY

Theme 1: safety concerns about nicotine - women's beliefs about safety of nicotine-containing products influence their use in pregnancy

Finding 1 : women believe that NRT is safer than smoking in general.

Finding 2 : women are concerned that NRT can deliver an unsafe amount of nicotine.

Finding 3 : women are concerned that using NRT during pregnancy can harm their baby.
Finding 4 : women believe that e-cigarettes are safer than smoking in general.

Finding 5 : women are concerned that e-cigarettes can deliver an unsafe amount of nicotine.

Finding 6 : women are concerned that using e-cigarettes during pregnancy can harm their baby.

Theme 2: concerns about addictiveness of nicotine - women's beliefs about addictiveness of nicotine influence their use of NRT in pregnancy

Finding 7 : women report concerns that NRT is as addictive as smoking.

Theme 3: effectiveness of nicotine-containing products - women's beliefs about the effectiveness of nicotine-containing products influence their use in pregnancy

Finding 8 : past positive experiences of NRT can facilitate NRT use in pregnancy.

Finding 10 : women present mixed views on effec-

Finding 9 : past negative experiences with NRT can be a barrier to NRT use in tiveness of e-cigarettes. pregnancy.

Theme 4: side effects - women's beliefs about and experiences with side effects of NRT influence their use in pregnancy

Finding 11 : women who report experiencing and feeling unable to deal with side effects of NRT, perceive these as a barrier to NRT use in pregnancy.

Theme 5: influence of others - women's readiness to use nicotine-containing products in pregnancy is influenced by the perceived views of and support from other people

Finding 12 : women who report receiving clear and consistent reassurance from health professionals about NRT safety in pregnancy feel this can facilitate NRT use.

Finding 13 : women who report experiencing lack of support towards NRT use from health professionals are reluctant to use NRT in pregnancy.

Finding 14 : women feel discouraged from using NRT in pregnancy by the perceived views and experiences of other people (non-health-professionals).
Finding 15 : women's readiness to use e-cigarettes in pregnancy is influenced by the advice they report receiving from their health professionals.

Finding 16 : women's readiness to use e-cigarettes in pregnancy is influenced by other people (non-professionals).

Theme 6: characteristics of nicotine-containing products can influence women's readiness to use them in pregnancy

Finding 17 : perceived characteristics of the NRT product, such as cost, convenience and ability to mimic a cigarette, can influence uptake and continuous use of NRT in pregnancy.
Finding 18 : perceived characteristics of e-cigarettes, such as cost, convenience and ability to mimic a cigarette, can influence uptake and continuous use of e-cigarettes in pregnancy.

NRT: nicotine replacement therapy. 
Table 3. Summary of findings

\begin{tabular}{l} 
Finding Overall CERQual assessment Explanation for assessment Contributing studies \\
\hline Theme 1: safety concerns about nicotine - women's beliefs about safety of nicotine-containing products influence their readi- \\
ness to use it in pregnancy
\end{tabular}

\begin{tabular}{|c|c|c|c|c|}
\hline 1 & $\begin{array}{l}\text { Finding } \mathbf{1} \text {, NRT: } \\
\text { women be- } \\
\text { lieve that NRT } \\
\text { is safer than } \\
\text { smoking in the } \\
\text { general pop- } \\
\text { ulation; they } \\
\text { believe NRT } \\
\text { contains fewer } \\
\text { harmful chem- } \\
\text { icals than tra- } \\
\text { ditional ciga- } \\
\text { rettes. }\end{array}$ & Moderate confidence & $\begin{array}{l}\text { Moderate concerns regard- } \\
\text { ing relevance and minor con- } \\
\text { cerns about methodological } \\
\text { issues, coherence, and ade- } \\
\text { quacy }\end{array}$ & $\begin{array}{l}\text { Ashwin 2010; Bauld 2017; } \\
\text { Bowker 2016; Hotham 2002; } \\
\text { Naughton 2013; Taylor } 2010\end{array}$ \\
\hline 2 & $\begin{array}{l}\text { Finding } \mathbf{2}, \mathbf{N R T} \text { : } \\
\text { women report } \\
\text { concerns that } \\
\text { NRT can deliv- } \\
\text { er an unsafe } \\
\text { amount of nico- } \\
\text { tine, higher } \\
\text { than a tradi- } \\
\text { tional cigarette, } \\
\text { for example be- } \\
\text { cause of con- } \\
\text { stant delivery } \\
\text { from a patch } \\
\text { or from higher } \\
\text { dose patches. }\end{array}$ & Moderate confidence & $\begin{array}{l}\text { Moderate concerns about ad- } \\
\text { equacy and minor concerns } \\
\text { about methodical issues }\end{array}$ & $\begin{array}{l}\text { Borland 2013; Bowker 2016; } \\
\text { Butterworth 2014; England } \\
\text { 2016; Hotham 2002; Naughton } \\
\text { 2013; Taylor } 2010\end{array}$ \\
\hline 3 & $\begin{array}{l}\text { Finding } 3, \text { NRT } \\
\text { : women report } \\
\text { concerns that } \\
\text { using NRT dur- } \\
\text { ing pregnancy } \\
\text { is unsafe for the } \\
\text { baby, due to } \\
\text { perceived lack } \\
\text { of information } \\
\text { about nicotine } \\
\text { safety for the } \\
\text { fetus. }\end{array}$ & High confidence & - & $\begin{array}{l}\text { Ashwin 2010; Bauld 2017; Bor- } \\
\text { land 2013; Bovill 2018; Bowk- } \\
\text { er 2016; Butterworth 2014; Eng- } \\
\text { land 2016; Glover 2012; Hotham } \\
\text { 2002; Naughton 2013; Radley } \\
\text { 2013; Taylor } 2010\end{array}$ \\
\hline 4 & $\begin{array}{l}\text { Finding 4, e- } \\
\text { cigarettes : } \\
\text { women believe } \\
\text { that e-ciga- } \\
\text { rettes are safer } \\
\text { than smoking } \\
\text { in the gener- } \\
\text { al population; } \\
\text { they believe } \\
\text { e-cigarettes } \\
\text { contain fewer }\end{array}$ & Moderate confidence & $\begin{array}{l}\text { Moderate concerns about co- } \\
\text { herence and minor concerns } \\
\text { about methodological issues } \\
\text { and adequacy }\end{array}$ & $\begin{array}{l}\text { Bauld 2017; Bowker 2018; Eng- } \\
\text { land 2016; Fallin 2016b; Grant } \\
2020\end{array}$ \\
\hline
\end{tabular}

Factors influencing the uptake and use of nicotine replacement therapy and e-cigarettes in pregnant women who smoke: a qualitative 
Table 3. Summary of findings (Continued)

harmful chem-

icals than tra-

ditional ciga-

rettes.

\begin{tabular}{|c|c|c|c|c|}
\hline 5 & $\begin{array}{l}\text { Finding 5, e- } \\
\text { cigarettes: } \\
\text { women report } \\
\text { concerns that } \\
\text { e-cigarettes can } \\
\text { deliver unsafe } \\
\text { an amount of } \\
\text { nicotine (high- } \\
\text { er than a tra- } \\
\text { ditional ciga- } \\
\text { rette), for ex- } \\
\text { ample due to } \\
\text { the belief that } \\
\text { unlike smoking, } \\
\text { vaping has no } \\
\text { discernable end } \\
\text { point. }\end{array}$ & Low confidence & $\begin{array}{l}\text { Moderate concerns about rel- } \\
\text { evance and adequacy, and } \\
\text { minor concerns about coher- } \\
\text { ence and methodological is- } \\
\text { sues }\end{array}$ & $\begin{array}{l}\text { Bowker 2018; England 2016; } \\
\text { Fallin 2016b }\end{array}$ \\
\hline 6 & $\begin{array}{l}\text { Finding 6, e- } \\
\text { cigarettes : } \\
\text { women report } \\
\text { concerns that } \\
\text { using e-ciga- } \\
\text { rettes during } \\
\text { pregnancy is } \\
\text { unsafe for the } \\
\text { baby, due to } \\
\text { perceived lack } \\
\text { of information } \\
\text { about nicotine } \\
\text { safety for the } \\
\text { fetus. }\end{array}$ & Moderate confidence & $\begin{array}{l}\text { Moderate concerns about rel- } \\
\text { evance and minor concerns } \\
\text { about adequacy }\end{array}$ & $\begin{array}{l}\text { Bauld 2017; Bowker 2016; } \\
\text { Bowker 2018; Fallin 2016b }\end{array}$ \\
\hline
\end{tabular}

Theme 2: concerns about addictiveness of nicotine - women's beliefs about addictiveness of nicotine influence their readiness to use NRT in pregnancy

\begin{tabular}{llll}
\hline 7 & $\begin{array}{l}\text { Finding 4, NRT: women report con- } \\
\text { cerns that NRT is as addictive as } \\
\text { smoking. }\end{array}$ & $\begin{array}{l}\text { Moder- } \\
\text { ate confi- } \\
\text { dence }\end{array}$ & $\begin{array}{l}\text { Moderate concerns about rel- } \\
\text { evance and adequacy, minor } \\
\text { concerns about methodolog- } \\
\text { ical issue }\end{array}$
\end{tabular}

Theme 3: beliefs about effectiveness of nicotine-containing products - women's beliefs about the effectiveness of nicotine-containing products influence their use in pregnancy

\begin{tabular}{|c|c|c|c|c|}
\hline 8 & $\begin{array}{l}\text { Finding } \mathbf{8 , N R T} \text { : women who had } \\
\text { positive experience with NRT or } \\
\text { who knew someone that had report } \\
\text { greater readiness to use it in pregnan- } \\
\text { cy. }\end{array}$ & Moderate confidence & $\begin{array}{l}\text { Moderate con- } \\
\text { cerns about rel- } \\
\text { evance and mi- } \\
\text { nor concerns } \\
\text { about adequa- } \\
\text { cy and method- } \\
\text { ological issues }\end{array}$ & $\begin{array}{l}\text { Bauld 2017; Bowker 2016; But- } \\
\text { terworth 2014; Pledger 2015; } \\
\text { Taylor } 2010\end{array}$ \\
\hline 9 & $\begin{array}{l}\text { Finding } \mathbf{9 ,} \boldsymbol{N R T} \text { : women who had } \\
\text { past negative experiences with NRT, } \\
\text { or heard from others who had nega- }\end{array}$ & Moderate confidence & $\begin{array}{l}\text { Moderate con- } \\
\text { cerns about } \\
\text { methodologi- }\end{array}$ & $\begin{array}{l}\text { Ashwin 2010; Bauld 2017; Bowk- } \\
\text { er 2016; England 2016; Fallin }\end{array}$ \\
\hline
\end{tabular}

Factors influencing the uptake and use of nicotine replacement therapy and e-cigarettes in pregnant women who smoke: a qualitative 
Table 3. Summary of findings (Continued)

tive experiences with NRT being inef-

fective were reluctant to use NRT in pregnancy. cal issues and minor concerns about adequa-

cy

\begin{tabular}{llll}
\hline 10 & Finding 10, e-cigarettes : women \\
present mixed views on effectiveness & Low confidence & Serious con- & Bauld 2017; Bowker 2016; \\
of e-cigarettes. & cerns about & Bowker 2018; Grant 2020 \\
& adequacy and & moderate con- \\
& cerns about rel- \\
& evance
\end{tabular}

\section{Theme 4: side effects associated with NRT - women's beliefs about and experiences with side effects of NRT influence their} readiness to use NRT in pregnancy

\begin{tabular}{|c|c|c|c|c|}
\hline 11 & $\begin{array}{l}\text { Finding 11, NRT : women report that } \\
\text { experiencing and feeling unable to } \\
\text { deal with side effects of NRT is a bar- } \\
\text { rier to using it in pregnancy. }\end{array}$ & High confidence & - & $\begin{array}{l}\text { Ashwin 2010; Bauld 2017; Bovill } \\
\text { 2018; Bowker 2016; Butterworth } \\
\text { 2014; England 2016; Mantzari } \\
\text { 2012; Pledger 2015; Taylor } 2010\end{array}$ \\
\hline
\end{tabular}

Theme 5: influence of others - women's readiness to use nicotine-containing products in pregnancy is influenced by the perceived views of and support from other people

\begin{tabular}{|c|c|c|c|c|}
\hline 12 & $\begin{array}{l}\text { Finding } 12, \mathbf{N R T} \text { : women report that } \\
\text { receiving clear and consistent reas- } \\
\text { surance from health professionals } \\
\text { about NRT safety in pregnancy can } \\
\text { facilitate NRT use. }\end{array}$ & Moderate confidence & $\begin{array}{l}\text { Minor concerns } \\
\text { about method- } \\
\text { ological issues, } \\
\text { relevance and } \\
\text { adequacy }\end{array}$ & $\begin{array}{l}\text { Ashwin 2010; Bauld 2017; Bowk- } \\
\text { er 2016; Gamble 2015; Hotham } \\
\text { 2002; Taylor } 2010\end{array}$ \\
\hline
\end{tabular}

$13 \quad$ Finding 13, NRT : women report that experiencing lack of support towards NRT use in pregnancy from health professionals is a barrier to NRT use.

High confidence $-$

Borland 2013; Bovill 2018; Bowker 2016; Gamble 2015; Glover 2012; Hauck 2013; Herbec 2014; Hotham 2002; Mantzari 2012; Pledger 2015; Taylor 2010

\section{$14 \quad$ Finding 14, NRT : women feel dis-} couraged from NRT use in pregnancy by the perceived views and experiences of other people (non-healthprofessionals).
Bovill 2018; England 2016;

Hotham 2002; Taylor 2010
Moderate confidence

Moderate concerns about adequacy and $\mathrm{mi}$ nor concerns about methodological issues and relevance

\section{Finding 15, e-cigarettes: women's} readiness to use e-cigarettes in pregnancy is influenced by the advice they report receiving from health professionals.

\section{High confidence}

$-$
Bauld 2017; Bowker 2016; Bowker 2018; Fallin 2016b; Grant 2020

\begin{tabular}{|c|c|c|c|c|}
\hline 16 & $\begin{array}{l}\text { Finding } 16 \text {, e-cigarettes : women's } \\
\text { readiness to use e-cigarettes in preg- } \\
\text { nancy is influenced by other people } \\
\text { (non-health professionals). }\end{array}$ & Moderate confidence & $\begin{array}{l}\text { Moderate con- } \\
\text { cerns about rel- } \\
\text { evance and ad- } \\
\text { equacy }\end{array}$ & $\begin{array}{l}\text { Bauld 2017; Bowker 2018; Grant } \\
2020\end{array}$ \\
\hline
\end{tabular}

\section{Theme 6: characteristics of nicotine-containing products - women's views on characteristics of the nicotine-containing prod-} ucts can influence their readiness to use these in pregnancy 
Table 3. Summary of findings (Continued)

17

Finding 17, NRT : perceived charac teristics of the NRT product, such as cost, convenience and ability to mimic a cigarette, can influence uptake and continuous use of NRT in pregnancy.
High confidence $-$

Ashwin 2010; Bauld 2017; Bowk er 2016; Bowker 2018; Butterworth 2014; England 2016; Fallin 2016a; Fallin 2016b; Hotham 2002; Pledger 2015; Radley 2013; Taylor 2010

Minor concerns about methodological issues, relevance and adequacy
Bauld 2017; Bowker 2018; Eng-

land 2016; Fallin 2016b
Moderate confidence characteristics of e-cigarettes, such as cost, convenience and ability to mimic a cigarette, can influence uptake and continuous use of e-cigarettes in pregnancy.

NRT: nicotine replacement therapy. 


\begin{tabular}{|c|c|c|c|c|c|c|c|c|c|c|c|c|c|c|c|c|c|c|c|}
\hline Study & $\begin{array}{l}\text { Main study focus } \\
\text { (NRT/e-cig) }\end{array}$ & $\begin{array}{l}\text { Find } \\
\text { ing } \\
1 \\
N R T\end{array}$ & $\begin{array}{l}y-\text { Find } \\
\text { ing } \\
2 \\
N R T\end{array}$ & $\begin{array}{l}\text { I-Find- } \\
\text { ing } \\
3 \\
N R T\end{array}$ & $\begin{array}{l}\text { Fin } \\
\text { ing } \\
4 \\
e- \\
\text { cig }\end{array}$ & $\begin{array}{c}d-F i \\
\text { in } \\
5 \\
e- \\
c i\end{array}$ & $\begin{array}{c}d \text {-Fir } \\
\text { ing } \\
6 \\
\mathrm{e}- \\
\text { cig }\end{array}$ & & $\begin{array}{l}\text { Findinc } \\
\text { inging } \\
78 \\
\text { NRTRT }\end{array}$ & $\begin{array}{c}d \text {-Find } \\
\text { ing } \\
9 \\
\text { NRT }\end{array}$ & $\begin{array}{l}y-\text { Find } \\
\text { ing } \\
10 \\
\text { e- } \\
\text { cig }\end{array}$ & $\begin{array}{l}\text {-Find } \\
\text { ing } \\
11 \\
N R T\end{array}$ & $\begin{array}{l}y \text {-Find } \\
\text { ing } \\
12 \\
\text { NRT }\end{array}$ & $\begin{array}{l}\text { I-Find- } \\
\text { ing } \\
13 \\
N R T\end{array}$ & $\begin{array}{l}\text { Find } \\
\text { ing } \\
14 \\
N R T\end{array}$ & $\begin{array}{l}\text {-Find } \\
\text { ing } \\
15 \\
\text { e- } \\
\text { cig }\end{array}$ & $\begin{array}{l}\text { d-Find } \\
\text { ing } \\
16 \\
\text { e- } \\
\text { cig }\end{array}$ & $\begin{array}{l}\text {-Find- } \\
\text { ing } \\
17 \\
\text { NRT }\end{array}$ & $\begin{array}{l}\text { Find- } \\
\text { ing } \\
18 \\
\text { e- } \\
\text { cig }\end{array}$ \\
\hline Ashwin 2010 & NRT & $x$ & & $x$ & & & & $\mathrm{x}$ & $x$ & $x$ & & $x$ & $x$ & & & & & $x$ & \\
\hline Bauld 2017 & NRT & $x$ & & $x$ & $x$ & & $x$ & & $x$ & $x$ & $x$ & $x$ & $x$ & & & $x$ & $x$ & $x$ & $x$ \\
\hline Borland 2013 & NRT & & $x$ & $x$ & & & & & & & & & & $x$ & & & & & \\
\hline Bovill 2018 & NRT & & & $x$ & & & & & & & & $x$ & & $x$ & $x$ & & & & \\
\hline Bowker 2016 & NRT & $x$ & $x$ & $x$ & & & $x$ & $\mathrm{x}$ & $x \quad x$ & $x$ & $x$ & $x$ & $x$ & $x$ & & $x$ & & $x$ & \\
\hline Bowker 2018 & e-cig & & & & $x$ & $x$ & $x$ & & & & $x$ & & & & & $x$ & $x$ & $x$ & $x$ \\
\hline Butterworth 2014 & NRT & & $x$ & $x$ & & & & & $x$ & & & $x$ & & & & & & $x$ & \\
\hline England 2016 & Both & $x$ & $x$ & $x$ & $x$ & $x$ & & $x$ & $x$ & $x$ & & $x$ & & & $x$ & & & $x$ & $x$ \\
\hline Fallin 2016a & NRT & & & & & & & & & $x$ & & & & & & & & $\mathrm{x}$ & \\
\hline Fallin 2016b & e-cig & & & & $\mathrm{x}$ & $x$ & $x$ & & & & & & & & & $x$ & & $x$ & $x$ \\
\hline Gamble 2015 & NRT & & & & & & & & & & & & $x$ & $x$ & & & & & \\
\hline Glover 2012 & NRT & & & $x$ & & & & & & & & & & $x$ & & & & & \\
\hline Grant 2020 & e-cig & & & & $x$ & & & & & & $x$ & & & & & $x$ & $x$ & & \\
\hline Hauck 2013 & NRT & & & & & & & & & & & & & $x$ & & & & & \\
\hline Herbec 2014 & NRT & & & & & & & & & & & & & $x$ & & & & & \\
\hline Hotham 2002 & NRT & $x$ & $x$ & $x$ & & & & & & $x$ & & & $x$ & $x$ & $x$ & & & $x$ & \\
\hline Mantzari 2012 & NRT & & & & & & & & & $x$ & & $x$ & & $x$ & & & & & \\
\hline Naughton 2013 & NRT & $x$ & $\mathrm{x}$ & $\mathrm{x}$ & & & & & & & & & & & & & & & \\
\hline
\end{tabular}




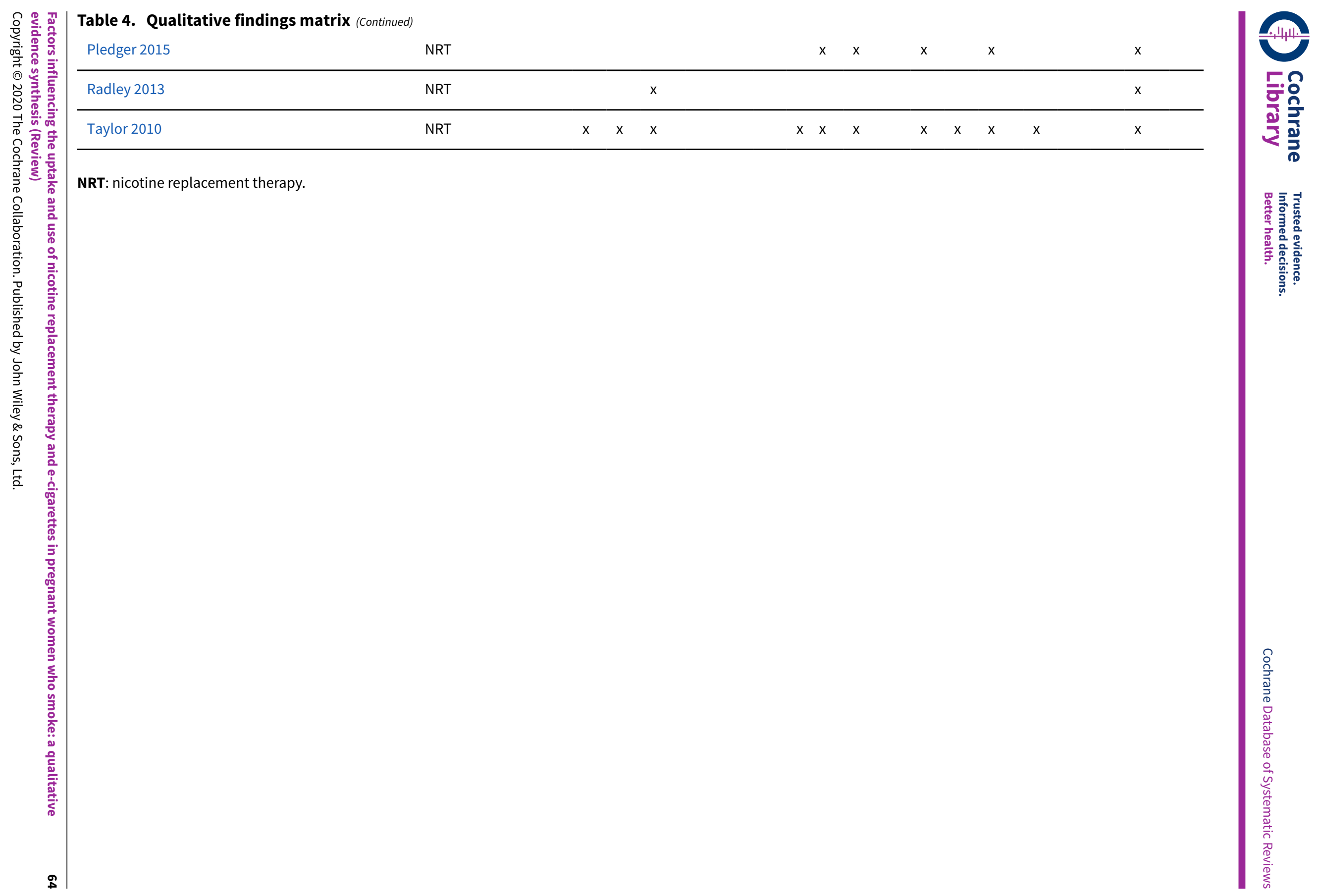




\section{APPEN DICES}

\section{Appendix 1. Search strategies}

\section{MEDLINE Ovid (1946 to 1 February 2019)}

1. Pregnancy/

2. exp Pregnancy Outcomes/

3. Pregnancy Trimesters/

4. Pregnant Women/

5. Prenatal Care/

6. Postpartum Period/

7. pregnan*.tw,kf.

8. (ante*natal or antenatal).tw,kf.

9. (pre*natal or prenatal).tw,kf.

10. (postpartum or post ${ }^{\star}$ partum).tw,kf

11. (postnatal or post*natal).tw,kf.

12. "Tobacco Use Cessation"/

13. "Tobacco Use Cessation Products"/

14. Nicotinic Agonists/

15. Smoking Cessation Agents/

16. Nicotine Chewing Gum/

17. NRT.ti,ab.

18. nicotine replacement.tw,kf.

19. ((nicotine or tobacco) adj2 (gum* or lozenge* or patch* or spray $\left.\left.{ }^{\star}\right)\right) . t w, k f$.

20. (pharmaco* adj2 (nicotine or tobacco or smoking)).tw,kf.

21. smoking cessation.tw,kf.

22. Electronic Nicotine Delivery Systems/

23. vaping/

24. e-cig*.tw,kf.

25. ecig.tw,kf.

26. electronic cigarette ${ }^{\star} . \mathrm{tw}, \mathrm{kf}$.

27. electronic nicotine.tw,kf.

28. (nicotine and vap $\left.{ }^{\star}\right) . t w, k f$.

29. exp ANIMALS/ not HUMANS

30. 1 or 2 or 3 or 4 or 5 or 6 or 7 or 8 or 9 or 10 or 11

31. 12 or 13 or 14 or 15 or 16 or 17 or 18 or 19 or 20 or 21 or 22 or 23 or 24 or 25 or 26 or 27 or 28

Factors influencing the uptake and use of nicotine replacement therapy and e-cigarettes in pregnant women who smoke: a qualitative

Copyright $\odot 2020$ The Cochrane Collaboration. Published by John Wiley \& Sons, Ltd. 
32.30 and 31

33. 32 not 29

NB: No filters for qualitative terms will be used, as these are not consistently effective across databases.

CINAHL EBSCO (Cumulative Index to Nursing and Allied Health Literature; 1937 to 1 February 2019)

S29 S26 AND S27 (Limiters: Medline and animal studies excluded)

S28 S26 AND S27

S27 (S11 OR S12 OR S13 OR S14 OR S15 OR S16 OR S17 OR S18 OR S19 OR S20 OR S21 OR S22 OR S23 OR S24 OR S25)

S26 (S1 OR S2 OR S3 OR S4 OR S5 OR S6 OR S7 OR S8 OR S9 OR S10)

S25 TI ("nicotine" and "vap*”) OR AB ("nicotine" and "vap*”) OR ("nicotine" and "vap"”)

S24 TI electronic nicotine OR AB electronic nicotine OR electronic nicotine

S23 TI electronic cigarette OR AB electronic cigarette OR electronic cigarette

S22 TI ecig* OR AB ecig*

S21 TI e-cig* OR AB e-cig*

S20 TI e-cigarette* OR AB e-cigarette*

S19 TI vap* OR AB vap*

S18 (MH "Electronic Cigarettes")

S17 "smoking cessation"

S16 TI (nicotine and (gum or lozenge* or spray* or patch $\left.{ }^{\star}\right)$ ) OR AB (nicotine and (gum or lozenge* or spray* or patch $\left.{ }^{\star}\right)$ )

S15 TI nicotine replacement OR AB nicotine replacement

S14 TI NRT OR AB NRT

S13 (MH "Smoking Cessation")

S12 (MH “Nicotine Chewing Gum" OR (MH “Nicotine Patch”)

S11 (MH ("Nicotine Replacement Therapy") OR (MH “Tobacco Use Cessation Products+") OR (MH "Nicotinic Agonists+")

S10 TI postpartum OR AB postpartum

S9 TI postnatal OR AB postnatal

S8 TI prenatal OR AB prenatal

S7 TI ante*natal OR AB ante*natal

S6 TI antenatal OR AB antenatal

S5 TI pregnan* OR AB pregnan*

S4 (MH "Postnatal Period+)

S3 (MH “Expectant Mothers")

S2 (MH "Prenatal Care")

S1 (MH "Pregnancy+") OR (MH “Pregnancy in Adolescence+") OR (MH "Pregnancy Trimesters+") OR (MH "Pregnancy Outcomes")

PsycINFO Ovid (1967 to 1 February 2019)

1. exp PREGNANCY/ or exp ADOLESCENT PREGNANCY/ or exp PREGNANCY OUTCOMES/

Factors influencing the uptake and use of nicotine replacement therapy and e-cigarettes in pregnant women who smoke: a qualitative 
2. exp Prenatal Care/

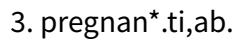

4. matern*.ti,ab.

5. antenatal.ti,ab.

6. prenatal.ti,ab.

7. post ${ }^{\star}$ partum.ti,ab.

8. post*natal.ti,ab.

9. exp Postnatal Period/ or exp Perinatal Period/

10. 1 or 2 or 3 or 4 or 5 or 6 or 7 or 8 or 9

11. exp Smoking Cessation/

12. NRT.ti,ab.

13. nicotine replacement.ti,ab.

14. nicotine gum ${ }^{\star} . t i, a b$.

15. nicotine lozenge*.ti,ab.

16. nicotine patch^.ti,ab.

17. nicotine spray ${ }^{\star} . t i, a b$.

18. (pharmaco* and (nicotine or tobacco or smoking)).ti,ab.

19. Smoking cessation.ti,ab.

20. exp Electronic Cigarettes/

21. e-cig*ti,ab.

22. ecig*.ti,ab.

23. electronic cigarette*.ti,ab.

24. electronic nicotine.ti,ab.

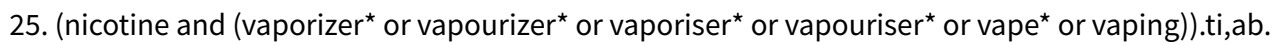

27. $\exp$ ANIMALS/ not HUMANS/

28. 10 and 26

29. 28 not 27

Appendix 2. Inclusion and exclusion criteria

\section{Inclusion criteria}

\section{Study type}

- Primary qualitative study

- Uses qualitative data collection methods (such as focus groups, interviews, open-ended questionnaires, diaries and other appropriate narrative method

- Uses qualitative data analysis methods (such as interpretative phenomenological analysis, thematic, narrative, framework or similar analysis)

\section{Exclusion criteria}

- Quantitative study

- Mixed methods study without a distinct qualitative component

- Study where only descriptive statistics (non-qualita-

Factors influencing the uptake and use of nicotine replacement therapy and e-cigarettes in pregnant women who smoke: a qualitative

Copyright (c) 2020 The Cochrane Collaboration. Published by John Wiley \& Sons, Ltd. 
(Continued)

- Mixed-methods studies that include a distinct qualitative component, as described above

tive methods) were used to analysed qualitative data

\section{Phenomenon of interest}

- Studies that explore experiences, views or opinions on NRT or e-cigarettes, of women who either smoked in pregnancy, and/or vaped/used NRT in pregnancy, as means to smoking cessation or harm reduction

Participants

- Pregnant women who smoke or smoked at any point of their pregnancy or

- Women in the postpartum period, who smoked at any point during their pregnancy

- Study participants would not need to have experience of using NRT or e-cigarettes, as we are broadly interested in determinants of use/not use rather than just women's views formed after using NRT or e-cigarettes (but if they don't have experience of using NRT or e-cigs in pregnancy, they must have experience of smoking in pregnancy).

\section{Setting}

- Any setting

\section{Appendix 3. Wallace criteria for appraising qualitative evidence}

\begin{tabular}{|c|c|c|}
\hline Question & & $\begin{array}{l}\text { Essential or desir- } \\
\text { able? }\end{array}$ \\
\hline 1 & Is the research question clear? & Essential \\
\hline 2 & Is the theoretical or ideological perspective of the author (or funder) explicit & Desirable \\
\hline 3 & Is study design appropriate to answer the question? & Essential \\
\hline 4 & Is the context or setting adequately described? & Desirable \\
\hline 5 & Sample adequate to explore range of subjects or settings? & Essential \\
\hline 6 & Sample drawn from appropriate population? & Essential \\
\hline 7 & Data collection adequately described? & Essential \\
\hline 8 & Data collection rigorously conducted? & Essential \\
\hline 9 & Data analysis rigorously conducted? & Essential \\
\hline 10 & Is there evidence of reflexivity? & Desirable \\
\hline 11 & Are findings substantiated by the data and limitations considered & Essential \\
\hline 12 & Claims to generalisability follow from the data? & Desirable \\
\hline 13 & Have ethical issues been addressed? & Desirable \\
\hline
\end{tabular}




\section{Appendix 4. Ames et al data richness scale}

\begin{tabular}{lll}
\hline Score & Measure & Example \\
\hline 1 & $\begin{array}{l}\text { Very few qualitative data present- } \\
\text { ed. Findings that are presented } \\
\text { are fairly descriptive }\end{array}$ & $\begin{array}{l}\text { For example, a mixed-methods study using open-ended survey questions } \\
\text { or a more detailed qualitative study where only part of the data relates to } \\
\text { the synthesis objective }\end{array}$ \\
\hline 2 & Some qualitative data presented & $\begin{array}{l}\text { For example, a limited number of qualitative findings from a mixed-meth- } \\
\text { ods or qualitative study }\end{array}$ \\
\hline 3 & A reasonable amount of qualita- & $\begin{array}{l}\text { For example, a typical qualitative research article in a journal with a small- } \\
\text { er word limit and often using simple thematic analysis }\end{array}$ \\
\hline 5 & $\begin{array}{l}\text { A good amount and depth of } \\
\text { qualitative data }\end{array}$ & $\begin{array}{l}\text { For example, a qualitative research article in a journal with a larger word } \\
\text { count that includes more content and setting descriptors and a more in- } \\
\text { depth presentation of the findings }\end{array}$ \\
\hline A large amount and depth of & $\begin{array}{l}\text { For example, from a detailed ethnography or a published qualitative arti- } \\
\text { cle }\end{array}$ \\
\hline
\end{tabular}

Appendix 5. GRADE QERQual evidence profiles of qualitative findings

GRADE CERQual evidence profile: finding 1

Finding 1 , NRT: women believe that NRT is safer than smoking in general population; they believe NRT contains fewer harmful chemicals than traditional cigarettes.

\section{Assessment for each CERQual component}

Methodological limitations Minor concerns: 2 studies moderate (unclear sampling adequacy, insufficiently described data collection or insufficiently rigorous data analysis) and all 6 studies had some minor issues

\begin{tabular}{ll}
\hline Coherence & Minor concerns: some opposing cases in 2 studies. \\
\hline Relevance & Minor concerns: most studies from the UK, but from diverse settings, 1 study from Australia. \\
\hline Adequacy & Moderate concerns: 6 studies contributed relatively thin data. \\
\hline Overall CERQual assessment & \\
\hline Moderate confidence & $\begin{array}{l}\text { Moderate concerns regarding relevance and minor concerns about methodological issues, coher- } \\
\text { ence, and adequacy }\end{array}$
\end{tabular}

\section{Contributing studies}

\begin{tabular}{ll}
\hline Study & Context \\
\hline Ashwin 2010 & England, UK; urban and rural; pregnant women; views on using NRT in pregnancy \\
\hline Bauld 2017 & $\begin{array}{l}\text { England and Scotland, UK; urban and rural; pregnant and postpartum women; perspectives and } \\
\text { experiences of barriers to and facilitators of smoking cessation }\end{array}$
\end{tabular}

Factors influencing the uptake and use of nicotine replacement therapy and e-cigarettes in pregnant women who smoke: a qualitative 
(Continued)

Bowker $2016 \quad$ England, UK; pregnant women; understanding pregnant smokers' adherence to NRT

Hotham $2002 \quad$ Australia; urban; pregnant women; pregnant smokers' barriers to cessation, attitudes to NRT and perceptions of cessation counselling

Naughton 2013

Cambridgeshire and Suffolk, England, UK; urban and rural; pregnant and postpartum women; dissonance and disengagement in pregnant smokers

Taylor 2010

UK; pregnant and postpartum women; beliefs about stop smoking services and NRT in pregnancy

\section{CERQual evidence profile: finding 2}

Finding 2 , NRT: women are concerned that NRT can deliver an unsafe amount of nicotine, higher than a traditional cigarette, for example because of constant delivery from a patch or from higher dose patches.

\begin{tabular}{ll}
\hline Assessment for each CERQual component \\
\hline Methodological limitations & $\begin{array}{l}\text { Minor concerns: } 2 \text { studies with moderate issues relating to data collection and or/analysis and all } 7 \\
\text { with minor methodological issues }\end{array}$ \\
\hline Coherence & No or very minor concerns \\
\hline Relevance & No or very minor concerns \\
\hline Adequacy & Moderate concerns: 6 studies contributed, but 3 reporting very thin data
\end{tabular}

\section{Overall CERQual assessment}

Moderate confidence Moderate concerns about adequacy and minor concerns about methodical issues

\section{Contributing studies}

\begin{tabular}{ll}
\hline Study & Context \\
\hline Borland 2013 & $\begin{array}{l}\text { Ontario, Canada; urban and rural; pregnant and postpartum women; exploring adequacy of stop } \\
\text { smoking support for pregnant and postpartum women }\end{array}$ \\
\hline Bowker 2016 & England, UK; pregnant women; understanding pregnant smokers' adherence to NRT \\
\hline Butterworth 2014 & $\begin{array}{l}\text { North Solihull, England, UK; urban; pregnant and postpartum women; perceptions of smoking ces } \\
\text { sation services }\end{array}$ \\
\hline England 2016 & $\begin{array}{l}\text { Memphis (Tennessee), Philadelphia, (Pennsylvania), Oklahoma City (Oklahoma), Billings, (Mon- } \\
\text { tana), USA; urban; pregnant and postpartum women; perceptions of NRT and emerging tobacco } \\
\text { products }\end{array}$ \\
\hline
\end{tabular}

Hotham 2002 Australia; urban; pregnant women; pregnant smokers' barriers to cessation, attitudes to NRT and perceptions of cessation counselling

Naughton $2013 \quad$ Cambridgeshire and Suffolk, England, UK; urban and rural; pregnant and postpartum women; dissonance and disengagement in pregnant smokers 
CERQual evidence profile: finding 3

Finding 3, NRT : women report concerns that using NRT during pregnancy is unsafe for the baby, due to perceived lack of information about nicotine safety for the fetus.

\section{Assessment for each CERQual component}

Methodological limitations

Minor concerns: 4 studies with moderate (unclear sampling procedure, insufficiently described data collection or analysis) and all 12 studies with minor

\begin{tabular}{ll}
\hline Coherence & No or very minor concerns \\
\hline Relevance & No or very minor concerns \\
\hline Adequacy & Minor concerns: 5 studies contributed very thin data, but overall rich data from 7 studies
\end{tabular}

\section{Overall CERQual assessment}

High confidence

\section{Contributing studies}

\begin{tabular}{|c|c|}
\hline Study & Context \\
\hline Ashwin 2010 & England, UK; urban and rural; pregnant women; views on using NRT in pregnancy \\
\hline Bauld 2017 & $\begin{array}{l}\text { England and Scotland, UK; urban and rural; pregnant and postpartum women; perspectives and } \\
\text { experiences of barriers to and facilitators of smoking cessation }\end{array}$ \\
\hline Borland 2013 & $\begin{array}{l}\text { Ontario, Canada; urban and rural; pregnant and postpartum women; exploring adequacy of stop } \\
\text { smoking support for pregnant and postpartum women }\end{array}$ \\
\hline Bovill 2018 & $\begin{array}{l}\text { Hunter and New England regions, Australia; pregnant and postpartum women; barriers to smoking } \\
\text { cessation support during pregnancy }\end{array}$ \\
\hline Bowker 2016 & England, UK; pregnant women; understanding pregnant smokers' adherence to NRT \\
\hline Butterworth 2014 & $\begin{array}{l}\text { North Solihull, England, UK; urban; pregnant and postpartum women; perceptions of smoking ces- } \\
\text { sation services }\end{array}$ \\
\hline England 2016 & $\begin{array}{l}\text { Memphis (TN), Philadelphia, (PA), Oklahoma City (OK), Billings, (MT), USA; urban; pregnant and } \\
\text { postpartum women; perceptions of NRT and emerging tobacco products }\end{array}$ \\
\hline Glover 2012 & $\begin{array}{l}\text { North Island, New Zealand; urban and rural; pregnant women; pregnant Maori smokers' perception } \\
\text { of smoking cessation support }\end{array}$ \\
\hline Hotham 2002 & $\begin{array}{l}\text { Australia; urban; pregnant women; pregnant smokers' barriers to cessation, attitudes to NRT and } \\
\text { perceptions of cessation counselling }\end{array}$ \\
\hline Naughton 2013 & $\begin{array}{l}\text { Cambridgeshire and Suffolk, England, UK; urban and rural; pregnant and postpartum women; dis- } \\
\text { sonance and disengagement in pregnant smokers }\end{array}$ \\
\hline Radley 2013 & $\begin{array}{l}\text { Tayside, Scotland, UK; pregnant women; outcomes and factors influencing uptake of an incentive } \\
\text { scheme for smoking cessation for pregnant smokers }\end{array}$ \\
\hline
\end{tabular}

Factors influencing the uptake and use of nicotine replacement therapy and e-cigarettes in pregnant women who smoke: a qualitative 
CERQual evidence profile: finding 4

Finding 4, e-cigarettes : women believe that e-cigarettes are safer than smoking in the general population; they believe e-cigarettes contain fewer harmful chemicals than traditional cigarettes.

\begin{tabular}{|c|c|}
\hline \multicolumn{2}{|c|}{ Assessment for each CERQual component } \\
\hline Methodological limitations & $\begin{array}{l}\text { Minor concerns: } 2 \text { studies with moderate (insufficient description of data analysis and/or data col- } \\
\text { lection), all } 5 \text { studies minor issues }\end{array}$ \\
\hline Coherence & Moderate concerns: views varied within studies \\
\hline Relevance & No or very minor concerns \\
\hline Adequacy & $\begin{array}{l}\text { Minor concerns: overall moderately rich data but some studies contributed very thin data; } 1 \text { study - } \\
\text { data from one participant only }\end{array}$ \\
\hline \multicolumn{2}{|l|}{ Overall CERQual assessment } \\
\hline Moderate confidence & $\begin{array}{l}\text { Moderate concerns about coherence and minor concerns about methodological issues and ade- } \\
\text { quacy }\end{array}$ \\
\hline \multicolumn{2}{|l|}{ Contributing studies } \\
\hline Study & Context \\
\hline Bauld 2017 & $\begin{array}{l}\text { England and Scotland, UK; urban and rural; pregnant and postpartum women; perceptions of new } \\
\text { stop smoking interventions }\end{array}$ \\
\hline Bowker 2018 & UK; pregnant and postpartum women; views on and experiences of e-cigarettes \\
\hline England 2016 & $\begin{array}{l}\text { Memphis (TN), Philadelphia, (PA), Oklahoma City (OK), Billings, (MT), USA; urban; pregnant and } \\
\text { postpartum women; perceptions of NRT and emerging tobacco products }\end{array}$ \\
\hline Fallin 2016b & $\begin{array}{l}\text { USA; pregnant and postpartum women; smoking in pregnant women in treatment for opioid de- } \\
\text { pendence }\end{array}$ \\
\hline Grant 2020 & South Wales, UK; pregnant women; stigma of smoking during pregnancy \\
\hline
\end{tabular}

CERQual evidence profile: finding 5

Finding 5, e-cigarettes : women report concerns that e-cigarettes can deliver unsafe amount of nicotine (higher than a traditional cigarette), for example due to the belief that unlike smoking, vaping has no discernable end point.

\section{Assessment for each CERQual component}


(Continued) $\begin{array}{ll}\text { Methodological limitations } & \text { Minor concerns: } 2 \text { studies with moderate (insufficient description of data analysis and/or collec- } \\ \text { tion) and all } 3 \text { with minor }\end{array}$

\begin{tabular}{ll}
\hline Coherence & Minor concerns due to opposing cases \\
\hline Relevance & $\begin{array}{l}\text { Moderate concerns: data from } 3 \text { studies, } 2 \text { from USA and } 1 \text { from the UK, setting unclear in all stud- } \\
\text { ies }\end{array}$ \\
\hline
\end{tabular}

\begin{tabular}{|c|c|}
\hline Adequacy & Moderate concerns: data from 3 studies only, thin data \\
\hline \multicolumn{2}{|c|}{ Overall CERQual assessment } \\
\hline Low confidence & $\begin{array}{l}\text { Moderate concerns about relevance and adequacy, and minor concerns about coherence and } \\
\text { methodological issues }\end{array}$ \\
\hline Study & Context \\
\hline Bowker 2018 & UK; pregnant and postpartum women; views on and experiences of e-cigarettes \\
\hline England 2016 & $\begin{array}{l}\text { Memphis (TN), Philadelphia, (PA), Oklahoma City (OK), Billings, (MT), USA; urban; pregnant and } \\
\text { postpartum women; perceptions of NRT and emerging tobacco products }\end{array}$ \\
\hline Fallin 2016b & $\begin{array}{l}\text { USA; pregnant and postpartum women; smoking in pregnant women in treatment for opioid de- } \\
\text { pendence }\end{array}$ \\
\hline
\end{tabular}

CERQual evidence profile: finding 6

Finding 6, e-cigarettes : women report concerns that using e-cigarettes during pregnancy is unsafe for the baby, due to perceived lack of information about nicotine safety for the fetus.

\section{Assessment for each CERQual component}

\begin{tabular}{ll}
\hline Methodological limitations & No or very minor concerns \\
\hline Coherence & No or very minor concerns \\
\hline Relevance & $\begin{array}{l}\text { Moderate concerns: data from 3 studies, 2 from USA and } 1 \text { from the UK, setting unclear in all stud- } \\
\text { ies }\end{array}$ \\
\hline Adequacy & Minor concerns: data from 3 studies, but overall moderately rich \\
\hline
\end{tabular}

\section{Overall CERQual assessment}

\begin{tabular}{ll}
\hline Moderate confidence & Moderate concerns about relevance and minor concerns about adequacy \\
\hline Contributing studies & Context \\
\hline Study & England and Scotland, UK; urban and rural; pregnant and postpartum women; perceptions of new \\
\hline Bauld 2017 & stop smoking interventions \\
\hline
\end{tabular}

Factors influencing the uptake and use of nicotine replacement therapy and e-cigarettes in pregnant women who smoke: a qualitative 
(Continued)

Bowker $2016 \quad$ England, UK; pregnant women; understanding pregnant smokers' adherence to NRT

\begin{tabular}{ll}
\hline Bowker 2018 & UK; pregnant and postpartum women; views on and experiences of e-cigarettes \\
\hline Fallin 2016b & $\begin{array}{l}\text { USA; pregnant and postpartum women; smoking in pregnant women in treatment for opioid de- } \\
\text { pendence }\end{array}$
\end{tabular}

CERQual evidence profile: finding 7

Finding 7 , NRT: women report concerns that NRT is as addictive as smoking.

\begin{tabular}{|c|c|}
\hline \multicolumn{2}{|c|}{ Assessment for each CERQual component } \\
\hline Methodological limitations & $\begin{array}{l}\text { Minor concerns: } 2 \text { studies with moderate (insufficient description of data analysis and/or collec- } \\
\text { tion) and all } 4 \text { with minor }\end{array}$ \\
\hline Coherence & No or very minor concerns \\
\hline Relevance & Moderate concerns: data from 4 studies, 3 from the UK, in similar setting, 1 from USA \\
\hline Adequacy & Moderate concerns: 4 studies contributed, overall thin data \\
\hline \multicolumn{2}{|l|}{ Overall CERQual assessment } \\
\hline Moderate confidence & Moderate concerns about relevance and adequacy, minor concerns about methodological issues \\
\hline \multicolumn{2}{|l|}{ Contributing studies } \\
\hline Study & Context \\
\hline Ashwin 2010 & England, UK; urban and rural; pregnant women; views on using NRT in pregnancy \\
\hline Bowker 2016 & England, UK; pregnant women; understanding pregnant smokers' adherence to NRT \\
\hline England 2016 & $\begin{array}{l}\text { Memphis (TN), Philadelphia, (PA), Oklahoma City (OK), Billings, (MT), USA; urban; pregnant and } \\
\text { postpartum women; perceptions of NRT and emerging tobacco products }\end{array}$ \\
\hline Taylor 2010 & UK; pregnant and postpartum women; beliefs about stop smoking services and NRT in pregnancy \\
\hline
\end{tabular}

CERQual evidence profile: finding 8

\section{Finding 8, NRT : women who had positive experience with NRT, or heard from others about positive experiences with NRT be- ing effective report greater readiness to use it in pregnancy}

\section{Assessment for each CERQual component}

Methodological limitations Minor concerns: 1 study with moderate issues (insufficiently reported data collection and or/analysis) and all 5 with minor issues. 
(Continued)

\begin{tabular}{ll} 
Coherence & No or very minor concerns \\
\hline Relevance & Moderate concerns: all from the UK \\
\hline Adequacy & Minor concerns: 5 studies contributing overall thin data
\end{tabular}

\section{Overall CERQual assessment}

$\begin{array}{ll}\text { Moderate confidence } & \text { Moderate concerns about relevance and minor concerns about adequacy and methodological is- } \\ \text { sues }\end{array}$

\section{Contributing studies}

\begin{tabular}{ll}
\hline Study & Context \\
\hline Bauld 2017 & $\begin{array}{l}\text { England and Scotland, UK; urban and rural; pregnant and postpartum women; perspectives and } \\
\text { experiences of barriers to and facilitators of smoking cessation }\end{array}$ \\
\hline Bowker 2016 & England, UK; pregnant women; understanding pregnant smokers' adherence to NRT \\
\hline Butterworth 2014 & $\begin{array}{l}\text { North Solihull, England, UK; urban; pregnant and postpartum women; perceptions of smoking ces- } \\
\text { sation services }\end{array}$ \\
\hline Pledger 2015 & $\begin{array}{l}\text { UK; pregnant and postpartum women; exploring pregnant smokers' experiences using an NHS stop } \\
\text { smoking service }\end{array}$ \\
\hline Taylor 2010 & UK; pregnant and postpartum women; beliefs about stop smoking services and NRT in pregnancy \\
\hline
\end{tabular}

CERQual evidence profile: finding 9

Finding 9, NRT : women who had past negative experiences with NRT, or heard from others who had negative experiences with NRT being ineffective, were reluctant to use NRT in pregnancy.

\begin{tabular}{ll}
\hline Assessment for each CERQual component \\
\hline Methodological limitations & $\begin{array}{l}\text { Moderate concerns: } 6 \text { studies with moderate (insufficiently rigorous description or conduct of data } \\
\text { collection and/or analysis) and all 9 with minor }\end{array}$ \\
\hline Coherence & No or very minor concerns \\
\hline Relevance & No or very minor concerns \\
\hline Adequacy & $\begin{array}{l}\text { Minor concerns: } 3 \text { studies contributed very thin data, but overall moderately rich data from all } \\
\text { studies }\end{array}$ \\
\hline Overall CERQual assessment & Moderate concerns about methodological issues and minor concerns about adequacy \\
\hline Moderate confidence & Context \\
\hline Contributing studies & \\
\hline Study &
\end{tabular}

Factors influencing the uptake and use of nicotine replacement therapy and e-cigarettes in pregnant women who smoke: a qualitative 
(Continued)

Ashwin $2010 \quad$ England, UK; urban and rural; pregnant women; views on using NRT in pregnancy

Bauld $2017 \quad$ England and Scotland, UK; urban and rural; pregnant and postpartum women; perspectives and
experiences of barriers to and facilitators of smoking cessation

Bowker $2016 \quad$ England, UK; pregnant women; understanding pregnant smokers' adherence to NRT

\begin{tabular}{ll}
\hline England 2016 & Memphis (TN), Philadelphia, (PA), Oklahoma City (OK), Billings, (MT), USA; urban; pregnant and \\
postpartum women; perceptions of NRT and emerging tobacco products
\end{tabular}
postpartum women; perceptions of NRT and emerging tobacco products

Fallin $2016 a$

$\begin{array}{ll}\text { Hotham } 2002 & \begin{array}{l}\text { Australia; urban; pregnant women; pr } \\ \text { perceptions of cessation counselling }\end{array}\end{array}$

Mantzari 2012

Pledger 2015

Taylor 2010

CERQual evidence profile: finding 10

Birmingham, England, UK; urban; pregnant and postpartum women; effectiveness of financial incentives for smoking cessation during pregnancy

UK; pregnant and postpartum women; exploring pregnant smokers' experiences using an NHS stop smoking service

UK; pregnant and postpartum women; beliefs about stop smoking services and NRT in pregnancy

\section{Finding 10, e-cigarette : women present mixed views on effectiveness of e-cigarettes.}

\begin{tabular}{|c|c|}
\hline \multicolumn{2}{|c|}{ Assessment for each CERQual component } \\
\hline Methodological limitations & No or very minor concerns \\
\hline Coherence & No or very minor concerns \\
\hline Relevance & Moderate concerns: 4 studies, all from the UK, from similar setting \\
\hline Adequacy & Serious concerns: overall very thin data from 2 studies and limited contributions from 2 studies \\
\hline \multicolumn{2}{|l|}{ Overall CERQual assessment } \\
\hline Low confidence & Serious concerns about adequacy and moderate concerns about relevance \\
\hline \multicolumn{2}{|l|}{ Contributing studies } \\
\hline Study & Context \\
\hline Bauld 2017 & $\begin{array}{l}\text { England and Scotland, UK; urban and rural; pregnant and postpartum women; perceptions of new } \\
\text { stop smoking interventions }\end{array}$ \\
\hline Bowker 2016 & England, UK; pregnant women; understanding pregnant smokers' adherence to NRT \\
\hline Bowker 2018 & UK; pregnant and postpartum women; views on and experiences of e-cigarettes \\
\hline Grant 2020 & South Wales, UK; pregnant women; stigma of smoking during pregnancy \\
\hline
\end{tabular}

Factors influencing the uptake and use of nicotine replacement therapy and e-cigarettes in pregnant women who smoke: a qualitative 
CERQual evidence profile: finding 11

Finding 11, NRT : women report that experiencing and feeling unable to deal with side effects of NRT is a barrier to using it in pregnancy.

\begin{tabular}{ll}
\hline Assessment for each CERQual component \\
\hline Methodological limitations & $\begin{array}{l}\text { Moderate concerns: } 5 \text { studies with moderate (relating to insufficiently rigorous description or con- } \\
\text { duct of data collection and/or analysis) and all } 9 \text { with minor issues }\end{array}$ \\
\hline Coherence & No or very minor concerns \\
\hline Relevance & No or very minor concerns \\
\hline Adequacy & No or very minor concerns
\end{tabular}

\section{Overall CERQual assessment}

High confidence

\section{Contributing studies}

\begin{tabular}{|c|c|}
\hline Study & Context \\
\hline Ashwin 2010 & England, UK; urban and rural; pregnant women; views on using NRT in pregnancy \\
\hline Bauld 2017 & $\begin{array}{l}\text { England and Scotland, UK; urban and rural; pregnant and postpartum women; perspectives and } \\
\text { experiences of barriers to and facilitators of smoking cessation }\end{array}$ \\
\hline Bovill 2018 & $\begin{array}{l}\text { Hunter and New England regions, Australia; pregnant and postpartum women; barriers to smoking } \\
\text { cessation support during pregnancy }\end{array}$ \\
\hline Bowker 2016 & England, UK; pregnant women; understanding pregnant smokers' adherence to NRT \\
\hline Butterworth 2014 & $\begin{array}{l}\text { North Solihull, England, UK; urban; pregnant and postpartum women; perceptions of smoking ces- } \\
\text { sation services }\end{array}$ \\
\hline England 2016 & $\begin{array}{l}\text { Memphis (TN), Philadelphia, (PA), Oklahoma City (OK), Billings, (MT), USA; urban; pregnant and } \\
\text { postpartum women; perceptions of NRT and emerging tobacco products }\end{array}$ \\
\hline Mantzari 2012 & $\begin{array}{l}\text { Birmingham, England, UK; urban; pregnant and postpartum women; effectiveness of financial in- } \\
\text { centives for smoking cessation during pregnancy }\end{array}$ \\
\hline Pledger 2015 & $\begin{array}{l}\text { UK; pregnant and postpartum women; exploring pregnant smokers' experiences using an NHS stop } \\
\text { smoking service }\end{array}$ \\
\hline Taylor 2010 & UK; pregnant and postpartum women; beliefs about stop smoking services and NRT in pregnancy \\
\hline
\end{tabular}

\section{CERQual evidence profile: finding 12}

\section{Finding 12, NRT : women report that receiving clear and consistent reassurance from health professionals about NRT safety in pregnancy can facilitate NRT use.}

Factors influencing the uptake and use of nicotine replacement therapy and e-cigarettes in pregnant women who smoke: a qualitative 
(Continued)

\section{Assessment for each CERQual component}

Methodological limitations

Minor concern: 2 studies with moderate (insufficient reporting and/or conduct of data collection or analysis) and all 6 with minor issues

\begin{tabular}{ll}
\hline Coherence & No or very minor concerns \\
\hline Relevance & Minor concerns: 4 studies from the UK, but varied settings, 2 studies from Australia \\
\hline Adequacy & Minor concerns: some studies contributed very thin data
\end{tabular}

\section{Overall CERQual assessment}

Moderate confidence Minor concerns about methodological issues, relevance and adequacy

\section{Contributing studies}

\begin{tabular}{ll}
\hline Study & Context \\
\hline Ashwin 2010 & England, UK; urban and rural; pregnant women; views on using NRT in pregnancy \\
\hline Bauld 2017 & $\begin{array}{l}\text { England and Scotland, UK; urban and rural; pregnant and postpartum women; perspectives and } \\
\text { experiences of barriers to and facilitators of smoking cessation }\end{array}$ \\
\hline Bowker 2016 & England, UK; pregnant women; understanding pregnant smokers' adherence to NRT \\
\hline Gamble 2015 & Australia; pregnant women; pregnant women's experiences of smoking cessation interventions \\
\hline Hotham 2002 & $\begin{array}{l}\text { Australia; urban; pregnant women; pregnant smokers' barriers to cessation, attitudes to NRT and } \\
\text { perceptions of cessation counselling }\end{array}$ \\
\hline Taylor 2010 & UK; pregnant and postpartum women; beliefs about stop smoking services and NRT in pregnancy \\
\hline
\end{tabular}

CERQual evidence profile: finding 13

\section{Finding 13, NRT : women report that experiencing lack of support towards NRT use in pregnancy from health professionals is a barrier to NRT use.}

\section{Assessment for each CERQual component}

Methodological limitations Moderate concerns: 7 studies with moderate (insufficient reporting and/or conduct of data collection or analysis; findings insufficiently substantiated by the data), all 11 studies with minor issues.

\begin{tabular}{ll}
\hline Coherence & No or very minor concerns \\
\hline Relevance & No or very minor concerns \\
\hline Adequacy & No or very minor concerns
\end{tabular}

\section{Overall CERQual assessment}

High confidence $\quad-$


(Continued)

\section{Contributing studies}

\begin{tabular}{|c|c|}
\hline Study & Context \\
\hline Borland 2013 & $\begin{array}{l}\text { Ontario, Canada; urban and rural; pregnant and postpartum women; exploring adequacy of stop } \\
\text { smoking support for pregnant and postpartum women }\end{array}$ \\
\hline Bovill 2018 & $\begin{array}{l}\text { Hunter and New England regions, Australia; pregnant and postpartum women; barriers to smoking } \\
\text { cessation support during pregnancy }\end{array}$ \\
\hline Bowker 2016 & England, UK; pregnant women; understanding pregnant smokers' adherence to NRT \\
\hline Gamble 2015 & Australia; pregnant women; pregnant women's experiences of smoking cessation interventions \\
\hline Glover 2012 & $\begin{array}{l}\text { North Island, New Zealand; urban and rural; pregnant women; pregnant Maori smokers' perception } \\
\text { of smoking cessation support }\end{array}$ \\
\hline Hauck 2013 & $\begin{array}{l}\text { Perth, Australia; urban; pregnant women; challenges and enablers to smoking cessation for preg- } \\
\text { nant smokers }\end{array}$ \\
\hline Herbec 2014 & $\begin{array}{l}\text { UK; pregnant women; needs and preferences of pregnant smokers regarding internet based smok- } \\
\text { ing cessations }\end{array}$ \\
\hline Hotham 2002 & $\begin{array}{l}\text { Australia; urban; pregnant women; pregnant smokers' barriers to cessation, attitudes to NRT and } \\
\text { perceptions of cessation counselling }\end{array}$ \\
\hline Mantzari 2012 & $\begin{array}{l}\text { Birmingham, England, UK; urban; pregnant and postpartum women; effectiveness of financial in- } \\
\text { centives for smoking cessation during pregnancy }\end{array}$ \\
\hline Pledger 2015 & $\begin{array}{l}\text { UK; pregnant and postpartum women; exploring pregnant smokers' experiences using an NHS stop } \\
\text { smoking service }\end{array}$ \\
\hline Taylor 2010 & UK; pregnant and postpartum women; beliefs about stop smoking services and NRT in pregnancy \\
\hline
\end{tabular}

CERQual evidence profile: finding 14

\section{Finding 14, NRT : women feel discouraged from NRT use in pregnancy by the perceived views and experiences of other people} (non-health-professionals).

\section{Assessment for each CERQual component}

\begin{tabular}{ll} 
Methodological limitations & $\begin{array}{l}\text { Minor concerns: } 2 \text { studies with moderate issues relating to data collection and or/analysis and all } 4 \\
\text { with minor methodological issues }\end{array}$ \\
\hline Coherence & No or very minor concerns \\
\hline Relevance & Minor concerns: data from 4 studies, but from three continents \\
\hline Adequacy & Moderate concerns: most data from 1 study, supported by the other 3 (fairly thin data) \\
\hline
\end{tabular}

\section{Overall CERQual assessment}


(Continued)

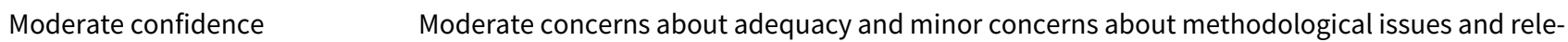
vance

\section{Contributing studies}

\begin{tabular}{ll}
\hline Study & Context \\
\hline Bovill 2018 & $\begin{array}{l}\text { Hunter and New England regions, Australia; pregnant and postpartum women; barriers to smoking } \\
\text { cessation support during pregnancy }\end{array}$ \\
\hline England 2016 & $\begin{array}{l}\text { Memphis (TN), Philadelphia, (PA), Oklahoma City (OK), Billings, (MT), USA; urban; pregnant and } \\
\text { postpartum women; perceptions of NRT and emerging tobacco products }\end{array}$ \\
\hline Hotham 2002 & $\begin{array}{l}\text { Australia; urban; pregnant women; pregnant smokers' barriers to cessation, attitudes to NRT and } \\
\text { perceptions of cessation counselling }\end{array}$ \\
\hline Taylor 2010 & UK; pregnant and postpartum women; beliefs about stop smoking services and NRT in pregnancy \\
\hline
\end{tabular}

CERQual evidence profile: finding 15

\section{Finding 15, e-cigarettes : women's readiness to use e-cigarettes in pregnancy is influenced by the advice they report receiving from health professionals.}

\begin{tabular}{ll}
\hline \multicolumn{2}{l}{ Assessment for each CERQual component } \\
\hline Methodological limitations & No or very minor concerns \\
\hline Coherence & Minor concerns: a few opposing cases \\
\hline Relevance & Minor concerns: 4 studies from the UK, 1 from USA, context unclear in some \\
\hline Adequacy & No or very minor concerns
\end{tabular}

\section{Overall CERQual assessment}

\begin{tabular}{ll}
\hline High confidence & - \\
\hline Contributing studies & Context \\
\hline Study & $\begin{array}{l}\text { England and Scotland, UK; urban and rural; pregnant and postpartum women; perceptions of new } \\
\text { stop smoking interventions }\end{array}$ \\
\hline Bauld 2017 & England, UK; pregnant women; understanding pregnant smokers' adherence to NRT \\
\hline Bowker 2016 & UK; pregnant and postpartum women; views on and experiences of e-cigarettes \\
\hline Bowker 2018 & $\begin{array}{l}\text { USA; pregnant and postpartum women; smoking in pregnant women in treatment for opioid de- } \\
\text { pendence }\end{array}$ \\
\hline Grant 2020 & South Wales, UK; pregnant women; stigma of smoking during pregnancy \\
\hline
\end{tabular}


CERQual evidence profile: finding 16

Finding 16, e-cigarettes : women's readiness to use e-cigarettes in pregnancy is influenced by other people (non-health professionals).

\begin{tabular}{ll}
\hline Assessment for each CERQual component \\
\hline Methodological limitations & No or very minor concerns \\
\hline Coherence & No or very minor concerns \\
\hline Relevance & Moderate concerns: 3 studies contributed data, all from UK \\
\hline Adequacy & Moderate concerns: very thin data from small number of studies \\
\hline Overall CERQual assessment & \\
\hline Moderate confidence & Moderate concerns about relevance and adequacy \\
\hline Contributing studies & Context \\
\hline Study & $\begin{array}{l}\text { England and Scotland, UK; urban and rural; pregnant and postpartum women; perceptions of new } \\
\text { stop smoking interventions }\end{array}$ \\
\hline Bauld 2017 & UK; pregnant and postpartum women; views on and experiences of e-cigarettes \\
\hline Bowker 2018 & South Wales, UK; pregnant women; stigma of smoking during pregnancy \\
\hline Grant 2020 & M
\end{tabular}

CERQual evidence profile: finding 17

Finding 17, NRT : perceived characteristics of the NRT product, such as cost, convenience, ability to mimic a cigarette can influence uptake and continuous use of NRT in pregnancy

\section{Assessment for each CERQual component}

\begin{tabular}{ll}
\hline Methodological limitations & $\begin{array}{l}\text { Moderate concerns: } 6 \text { studies with moderate issues relating to data collection and or/analysis and } \\
\text { all } 12 \text { with minor methodological issues }\end{array}$ \\
\hline Coherence & No or very minor concerns \\
\hline Relevance & No or very minor concerns \\
\hline Adequacy & No or very minor concerns \\
\hline
\end{tabular}

\section{Overall CERQual assessment}

High confidence

\section{Contributing studies}

Factors influencing the uptake and use of nicotine replacement therapy and e-cigarettes in pregnant women who smoke: a qualitative 
(Continued)

\section{Study}

Ashwin 2010

Bauld 2017

Bowker 2016

Bowker 2018

Butterworth 2014

\section{Context}

England, UK; urban and rural; pregnant women; views on using NRT in pregnancy

England and Scotland, UK; urban and rural; pregnant and postpartum women; perspectives and experiences of barriers to and facilitators of smoking cessation

England, UK; pregnant women; understanding pregnant smokers' adherence to NRT

UK; pregnant and postpartum women; views on and experiences of e-cigarettes

North Solihull, England, UK; urban; pregnant and postpartum women; perceptions of smoking cessation services

\section{England 2016}

Memphis (TN), Philadelphia, (PA), Oklahoma City (OK), Billings, (MT), USA; urban; pregnant and postpartum women; perceptions of NRT and emerging tobacco products

\begin{tabular}{ll}
\hline Fallin 2016a & Kentucky, USA; pregnant and postpartum women; perceptions of e-cigarettes \\
\hline Fallin 2016b & $\begin{array}{l}\text { USA; pregnant and postpartum women; smoking in pregnant women in treatment for opioid de- } \\
\text { pendence }\end{array}$ \\
\hline Hotham 2002 & $\begin{array}{l}\text { Australia; urban; pregnant women; pregnant smokers' barriers to cessation, attitudes to NRT and } \\
\text { perceptions of cessation counselling }\end{array}$ \\
\hline Pledger 2015 & $\begin{array}{l}\text { UK; pregnant and postpartum women; exploring pregnant smokers' experiences using an NHS stop } \\
\text { smoking service }\end{array}$ \\
\hline Radley 2013 & $\begin{array}{l}\text { Tayside, Scotland, UK; pregnant women; outcomes and factors influencing uptake of an incentive } \\
\text { scheme for smoking cessation for pregnant smokers }\end{array}$ \\
\hline Taylor 2010 & UK; pregnant and postpartum women; beliefs about stop smoking services and NRT in pregnancy \\
\hline
\end{tabular}

\section{CERQual evidence profile: finding 18}

Finding 18, e-cigarette : perceived characteristics of e-cigarettes, such as cost, convenience, ability to mimic a cigarette can influence uptake and continuous use of e-cigarettes in pregnancy

\section{Assessment for each CERQual component}

\begin{tabular}{ll}
\hline Methodological limitations & $\begin{array}{l}\text { Minor concerns: } 2 \text { studies with moderate (relating to reporting or conduct of data collection and/or } \\
\text { analysis) and all } 4 \text { studies with minor issues }\end{array}$ \\
\hline Coherence & No or very minor concerns \\
\hline Relevance & Minor concerns: 4 studies contributed data, from 2 continents, setting often unclear \\
\hline Adequacy & Minor concerns: overall moderately rich data, but from four studies only. \\
\hline
\end{tabular}

\section{Overall CERQual assessment}

Moderate confidence Minor concerns about methodological issues, relevance and adequacy

Factors influencing the uptake and use of nicotine replacement therapy and e-cigarettes in pregnant women who smoke: a qualitative 
(Continued)

\section{Contributing studies}

\begin{tabular}{ll}
\hline Study & Context \\
\hline Bauld 2017 & $\begin{array}{l}\text { England and Scotland, UK; urban and rural; pregnant and postpartum women; perceptions of new } \\
\text { stop smoking interventions }\end{array}$ \\
\hline Bowker 2018 & UK; pregnant and postpartum women; views on and experiences of e-cigarettes \\
\hline England 2016 & $\begin{array}{l}\text { Memphis (TN), Philadelphia, (PA), Oklahoma City (OK), Billings, (MT), USA; urban; pregnant and } \\
\text { postpartum women; perceptions of NRT and emerging tobacco products }\end{array}$ \\
\hline Fallin 2016b & $\begin{array}{l}\text { USA; pregnant and postpartum women; smoking in pregnant women in treatment for opioid de- } \\
\text { pendence }\end{array}$ \\
\hline
\end{tabular}

Appendix 6. Integration of the QES findings with descriptions of interventions described in effectiveness trials included in Cochrane review (Coleman 2015; updated Claire 2020)

\begin{tabular}{|c|c|}
\hline Key QES findings & Description of the intervention from clinical trials \\
\hline Study & Berlin 2014 \\
\hline $\begin{array}{l}\text { Was the advice on NRT delivered by a health professional trained in } \\
\text { smoking cessation? (Finding 12, finding 13) }\end{array}$ & $\begin{array}{l}\text { Yes - Doctor or nurse with a diploma in smoking cessa- } \\
\text { tion }\end{array}$ \\
\hline \multirow[t]{2}{*}{$\begin{array}{l}\text { Was the advice delivered consistently throughout pregnancy? (Finding } \\
\text { 12, finding 13) }\end{array}$} & $\begin{array}{l}\text { Intervention - up to } 7 \text { visits, } 1^{\text {st }} \text { - } 1 \text { h of behavioural sup- } \\
\text { port for smoking cessation, then at least } 10 \text { minutes; re- } \\
\text { minder to use NRT at each visit }\end{array}$ \\
\hline & $\begin{array}{l}\text { Impossible to determine what information women re- } \\
\text { ceived from other health professionals throughout the } \\
\text { routine antenatal pathway }\end{array}$ \\
\hline $\begin{array}{l}\text { Was the strength of NRT appropriate to the level of addiction to best } \\
\text { help manage cravings? (Finding } 8 \text {, finding 9) }\end{array}$ & $\begin{array}{l}\text { Yes - patch strength assigned based on salivary cotinine } \\
\text { level }\end{array}$ \\
\hline $\begin{array}{l}\text { Were women given a choice of NRT to best suit their needs? (Finding } \\
\text { 11, finding 17) }\end{array}$ & No - all women received patches \\
\hline $\begin{array}{l}\text { Was safety of NRT in pregnancy discussed, with reassurance that NRT } \\
\text { is safer for the developing baby than smoking? (Finding } 1 \text {, finding } 2 \text {, } \\
\text { finding } 3 \text {, finding } 7 \text { ) }\end{array}$ & Unclear if and/or in how much detail \\
\hline \multirow{2}{*}{$\begin{array}{l}\text { Were clear instructions and support given on how to use NRT effective- } \\
\text { ly? (Finding 8, finding 9) }\end{array}$} & Yes \\
\hline & $\begin{array}{l}\text { Women were also encouraged to stay on the patch dur- } \\
\text { ing lapses }\end{array}$ \\
\hline $\begin{array}{l}\text { Was preparation for/coping with side effects and practical issues with } \\
\text { NRT discussed? (Finding 11) }\end{array}$ & Unclear if and/or in how much detail \\
\hline Study & Coleman 2012 \\
\hline
\end{tabular}


(Continued)

Was the advice on NRT delivered by a health professional trained in smoking cessation? (Finding 12, finding 13)
Yes - trained research midwives, with use of smoking cessation manual
Was the advice delivered consistently throughout pregnancy? (Finding 12, finding 13)
Intervention - up to 4 behavioural support sessions, $1^{\text {st }}$ $-1 \mathrm{~h}$ face to face, then over the telephone

Women were encouraged to ask for further support from research midwives and to access NHS stop smoking services

Impossible to determine what information women received from other health professionals throughout the routine antenatal pathway

No - all women received the same strength at the onset
Was the strength of NRT appropriate to the level of addiction to best help manage cravings? (Finding 8, finding 9)

\section{Were women given a choice of NRT to best suit their needs? (Finding 11, finding 17) \\ No - all women received patches}

\author{
Was safety of NRT in pregnancy discussed, with reassurance that NRT \\ is safer for the developing baby than smoking? (Finding 1 , finding 2 , \\ finding 3, finding 7)
}

Unclear if and/or in how much detail
Were clear instructions and support given on how to use NRT effective- Unclear if and/or in how much detail ly? (Finding 8, finding 9)

\begin{abstract}
Was preparation for/coping with side effects and practical issues with Unclear if and/or in how much detail NRT discussed? (Finding 11)
\end{abstract}

\begin{tabular}{|c|c|}
\hline Study & El-Mohandes 2013 \\
\hline $\begin{array}{l}\text { Was the advice on NRT delivered by a health professional trained in } \\
\text { smoking cessation? (Finding 12, finding 13) }\end{array}$ & Trial staff, unclear who \\
\hline \multirow[t]{2}{*}{$\begin{array}{l}\text { Was the advice delivered consistently throughout pregnancy? (Finding } \\
\text { 12, finding 13) }\end{array}$} & $\begin{array}{l}5 \text { behavioural support sessions, } 5 \text { As Model based } \\
\text { counselling; }\end{array}$ \\
\hline & $\begin{array}{l}\text { Impossible to determine what information women re- } \\
\text { ceived from other health professionals throughout the } \\
\text { routine antenatal pathway }\end{array}$ \\
\hline $\begin{array}{l}\text { Was the strength of NRT appropriate to the level of addiction to best } \\
\text { help manage cravings? (Finding } 8 \text {, finding 9) }\end{array}$ & $\begin{array}{l}\text { Yes - patch strength assigned based on salivary cotinine } \\
\text { level }\end{array}$ \\
\hline $\begin{array}{l}\text { Were women given a choice of NRT to best suit their needs? (Finding } \\
\text { 11, finding 17) }\end{array}$ & No - all women received patches \\
\hline $\begin{array}{l}\text { Was safety of NRT in pregnancy discussed, with reassurance that NRT } \\
\text { is safer for the developing baby than smoking? (Finding1, finding2, } \\
\text { finding } 3 \text {, finding } 7 \text { ) }\end{array}$ & Unclear if and/or in how much detail \\
\hline $\begin{array}{l}\text { Were clear instructions and support given on how to use NRT effective- } \\
\text { ly? (Finding } 8 \text {, finding 9) }\end{array}$ & $\begin{array}{l}\text { Yes - participants were given clear verbal and written } \\
\text { instructions on patch use. They were advised never } \\
\text { to smoke while using the patch, to remove the patch } \\
\text { before going to sleep and never to use other NRT } \\
\text { method(s). }\end{array}$ \\
\hline
\end{tabular}


(Continued)
Was preparation for/coping with side effects and practical issues with
Unclear if and/or in how much detail NRT discussed? (Finding 11)

Study
Was the advice on NRT delivered by a health professional trained in
smoking cessation? (Finding 12, finding 13)

Hotham 2006

Researcher or by one of the part-time researcher officers, midwives who had undergone specialised cessation training

Was the advice delivered consistently throughout pregnancy? (Finding 12, finding 13)

5 minutes counselling at $1^{\text {st }}$ visit, plus $<2$ min counselling at subsequent visits

Impossible to determine what information women received from other health professionals throughout the routine antenatal pathway

Was the strength of NRT appropriate to the level of addiction to best help manage cravings? (Finding 8, finding 9)
No - all women received the same strength NRT at onset

Were women given a choice of NRT to best suit their needs? (Finding

No - all women received patches

11, finding 17)

Was safety of NRT in pregnancy discussed, with reassurance that NRT

Unclear if and/or in how much detail is safer for the developing baby than smoking? (Finding1, finding2, finding 3 , finding 7 )

Were clear instructions and support given on how to use NRT effective- Women received the patch with "use instructions" ly? (Finding 8, finding 9)
Was preparation for/coping with side effects and practical issues with
Unclear if and/or in how much detail NRT discussed? (Finding 11)

Study
Was the advice on NRT delivered by a health professional trained in
smoking cessation? (Finding 12, finding 13)

Was the advice on NRT delivered by a health
smoking cessation? (Finding 12, finding 13)

\section{Kapur 2001}

$1^{\text {st }}$ session - a non-personalised video message plus 3 counselling sessions, unclear with whom

Impossible to determine what information women received from other health professionals throughout the routine antenatal pathway

4 sessions, unclear with whom, weekly telephone contact

No - all women received the same strength at the onset No - all women received patches

Were women given a choice of NRT to best suit their needs? (Finding 11, finding 17)

Was safety of NRT in pregnancy discussed, with reassurance that NRT Unclear if and/or in how much detail is safer for the developing baby than smoking? (Finding1, finding2, finding 3, finding 7) 12, finding 13)

Was the strength of NRT appropriate to the level of addiction to best help manage cravings? (Finding 8, finding 9)

\section{Were clear instructions and support given on how to use NRT effective- Unclear if and/or in how much detail} ly? (Finding 8, finding 9) 
(Continued)
Was preparation for/coping with side effects and practical issues with
Unclear if and/or in how much detail NRT discussed? (Finding 11)

Study
Was the advice on NRT delivered by a health professional trained in
smoking cessation? (Finding 12, finding 13)

Oncken 2008

Yes - research assistant trained to deliver smoking cessation counselling. In addition to the counselling sessions, subjects received printed educational materials that were tailored for use in pregnancy and twicemonthly telephone calls to monitor progress until delivery

\section{Was the advice delivered consistently throughout pregnancy? (Finding} 12, finding 13)
Up to 9 sessions of behavioural support of up to 35 minutes per session

\title{
Was the strength of NRT appropriate to the level of addiction to best help manage cravings? (Finding 8 , finding 9 ) \\ No - all women received the same strength at the onset
}
Were women given a choice of NRT to best suit their needs? (Finding
No - all women received gum

11, finding 17)

\begin{abstract}
Was safety of NRT in pregnancy discussed, with reassurance that NRT is safer for the developing baby than smoking? (Finding1, finding2, finding 3 , finding 7 )
\end{abstract}

Unclear if and/or in how much detail

\section{Were clear instructions and support given on how to use NRT effective- Unclear if and/or in how much detail ly? (Finding 8, finding 9)}

\section{Was preparation for/coping with side effects and practical issues with Unclear if and/or in how much detail NRT discussed? (Finding 11)}

$\begin{array}{ll}\text { Study } & \text { Oncken } 2019\end{array}$

Was the advice on NRT delivered by a health professional trained in smoking cessation? (Finding 12, finding 13)
Yes - study nurse who was trained to deliver the counselling using a motivational interviewing approach, written educational materials on smoking cessation during pregnancy and the package insert for the nicotine inhalator

\section{Was the advice delivered consistently throughout pregnancy? (Finding 3 counselling sessions, up to 35 minutes,} 12, finding 13)
Impossible to determine what information women received from other health professionals throughout the routine antenatal pathway

Inhalator strength assigned based on nicotine dependence level (CPD)

\section{Were women given a choice of NRT to best suit their needs? (Finding No - all women received an inhalator} 11, finding 17)

\author{
Was safety of NRT in pregnancy discussed, with reassurance that NRT \\ is safer for the developing baby than smoking? (Finding 1 , finding 2 , \\ finding 3, finding 7)
}

\section{Unclear if and/or in how much detail}

Women received the package insert for the nicotine inhalator
Were clear instructions and support given on how to use NRT effectively? (Finding 8, finding 9) 
(Continued)
Was preparation for/coping with side effects and practical issues with
Unclear if and/or in how much detail NRT discussed? (Finding 11)

Study
Was the advice on NRT delivered by a health professional trained in
smoking cessation? (Finding 12, finding 13)
Was the advice delivered consistently throughout pregnancy? (Finding
12, finding 13)

Pollak 2007

Yes - support specialists, but unclear who

6 counselling sessions, 5 face to face, 1 telephone, plus a "quit kit" including various cessation aids

Impossible to determine what information women received from other health professionals throughout the routine antenatal pathway

Was the strength of NRT appropriate to the level of addiction to best help manage cravings? (Finding 8 , finding 9)
Yes - patch strength assigned depending on nicotine dependence (CPD)

\section{Were women given a choice of NRT to best suit their needs? (Finding 11, finding 17)}

Gum, patch or lozenge with support to make an informed choice at the onset of the study Unclear if able to change if not happy with their choice

\author{
Was safety of NRT in pregnancy discussed, with reassurance that NRT \\ is safer for the developing baby than smoking? (Finding $\mathbf{1}$, finding 2 , \\ finding 3 , finding 7 )
}

Unclear if and/or in how much detail

\section{Were clear instructions and support given on how to use NRT effective- ly? (Finding 8, finding 9) \\ At one session, advantages and disadvantages of these 3 NRT modes were discussed and women were sup- ported in making a choice}

\title{
Was preparation for/coping with side effects and practical issues with Unclear if and/or in how much detail NRT discussed? (Finding 11)
}

\begin{tabular}{ll} 
Study $\quad$ Wisborg 2000 \\
\hline
\end{tabular}

\begin{abstract}
Was the advice on NRT delivered by a health professional trained in smoking cessation? (Finding 12, finding 13)

Yes - midwife independent of antenatal care
\end{abstract}

Was the advice delivered consistently throughout pregnancy? (Finding 4 behavioural support sessions plus a pamphlet 12, finding 13)

Impossible to determine what information women received from other health professionals throughout the routine antenatal pathway

Was the strength of NRT appropriate to the level of addiction to best help manage cravings? (Finding 8, finding 9)
No - all women received the same strength NRT at onset

No

Were women given a choice of NRT to best suit their needs? (Finding 11, finding 17)

\author{
Was safety of NRT in pregnancy discussed, with reassurance that NRT \\ is safer for the developing baby than smoking? (Finding 1, finding 2 , \\ finding 3 , finding 7 )
}

\section{Unclear if and/or in how much detail}

\footnotetext{
Were clear instructions and support given on how to use NRT effective- Unclear if and/or in how much detail ly? (Finding 8, finding 9)
} 


\section{Was preparation for/coping with side effects and practical issues with Unclear if and/or in how much detail NRT discussed? (Finding 11)}

\section{HISTORY}

Review first published: Issue 5, 2020

\section{CONTRIBUTIONS OFAUTHORS}

Study conception: TC; data collection/screening/extraction: $\mathrm{KC}, \mathrm{TCH}, \mathrm{KB}, \mathrm{SLC}$ and SC; appraisal of study quality: KC and SLC; data analysis: KC, KB and TC; GRADE CERQual: KC and TCH. All authors contributed to writing and revising the manuscript.

\section{DECLARATIONS OF INTEREST}

Katarzyna Campbell: I have received salary from the University of Nottingham, working on projects funded by Collaboration for Leadership in Applied Health Research and Care East Midlands (CLAHRC EM), NIHR and NICE. I am the second author on one of the studies included in this review. I did not lead on the data extraction or risk assessment for this study.

Thomas Coleman-Haynes: none known.

Katharine Bowker: I am lead author on two studies which have been included in this review. I did not lead on data extraction and assessment of my own studies.

Sue E Cooper: I am a co-applicant and employed by funding for an NIHR Programme Grant for Applied Research that includes conducting this review. I am co-author on two of the studies included in this review, but was not involved in the data extraction or assessment of these studies.

Sarah Connelly: none known.

Tim Coleman: My institution received a grant to pay for a fraction of the researcher time required to produce this review and also receives funding for other smoking and e-cigarettes related studies which I either lead or am involved in. Two studies which I co-authored are included in the review; for these I had no role in either data extraction or quality assessment.

\section{SOURCES OF SUPPORT}

\section{Internal sources}

- UK Centre for Tobacco Control Studies: a Public Health Centre of Research Excellence, UK

\section{External sources}

- National Institute for Health Research (NIHR) Programme for Applied Research (Programme number RP-PG-0615-20003), UK

- National Institute for Health and Care Excellence, UK 